\title{
HEALTH MAINTENANCE ORGANIZATIONS AND THE MARKET FOR HEALTH SERVICES
}

\author{
Clark C. Havighurst*
}

In its health care proposals pending in the Ninety-second Congress, the Nixon administration has specified the so-called "health maintenance organization," or "HMO," as one cornerstone of its solution to the widely noted health care crisis in the United States. First, the pending Medicare amendments, which were included in H.R. I along with the President's "Family Assistance Plan" of welfare reform, ${ }^{1}$ would incorporate HMOs into the Medicare program as potential providers of care for those program beneficiaries who elect to enroll in them at the federal government's expense. Second, the President's package of health care proposals that was originally announced on February $18, I 97{ }^{2},{ }^{2}$ places heavy emphasis on the restructuring of the health care delivery system by stimulating the organization and growth of HMOs through a series of affirmative measures. The administration hopes that by 1980 HMO enrollment will be available to ninety per cent of the population as an alternative means of procuring health care. ${ }^{3}$

In addition to the administration's proposals, a number of other proposals for meeting the health care crisis are also pending in Congress. Many of these plans incorporate models of health care delivery organizations that are at least subspecies of HMO, indicating the breadth of the consensus that has embraced this mode of rendering health services. Thus, the Kennedy-Griffiths proposal" ${ }^{4}$ for "national health insurance," widely thought to be the leading contender against the administration's

- Professor of Law, Duke University; Director, Committee on Legal Issues in Health Care.

This article was written in conjunction with work performed under contract No. HSM 110-69-214 with the Public Health Service, Department of Health, Education, and Welfare. The research and other assistance of Mrs. Martha D. Ballenger is gratefully acknowledged, as are the comments, on an carly draft, of David Mechanic, Guido Calabresi, and Reuben Kessel, members of the Committee on Legal Issues in Health Care.

${ }^{1}$ H.R. I, 92d Cong., Ist Sess. $\$ 239$ (I97I). H.R. I, as reported by the Ways and Means Committce, was passed by the House on June 22. II7 CoNG. Rec. H57I7 (daily ed. June 22, r97r).

2 Message from the President of the United States Rejattve to Bullding a National Health Strategy, H.R. Doc. No. 92-49, 92d Cong., ist Sess. (r97I) [hereinafter cited as President's Healthi MEssage]. The final bill embodying the President's proposals was finally submitted to the Congress on April 22, I97I, after this article was substantially completed. S. I623, 92d Cong., Ist Sess. (r97I) (the "National Health Insurance Partnership Act of x971") [hereinafter cited as S. r623]. See also H.R. 774I, 92d Cong., Ist Sess. (I97I), which is the administration's bill with changes made by Representative Byrnes before introduction. See N.Y. Times, Apr. 28, 197r, at 3r, col. r. Other bills constituting part of the President's program are H.R. 56I4 and H.R. 5615, 92d Cong., Ist Sess. (I97I). No cffort was made to analyze the administration's bills completely in this article, although important points are noted.

${ }^{3}$ Letter to the author from John G. Veneman, Under Secretary of HEW, May 21, x97x.

'S. 3, H.R. 22, H.R. 23, 92d Cong., Ist Sess. (I97I) (all substantially identical) [hereinafter cited as Kennedy-Griffiths bill]. 
plan, ${ }^{5}$ incorporates the "comprehensive health service organization" as an important feature.

This paper is addressed to the policies needed to obtain the best possible implementation of the HMO concept. The ultimate thrust is toward detailing the policy choices necessary to create a market-oriented system of health care delivery, with HMOs as an essential element. My thesis is that a congeries of legislatively and professionally conceived and executed trade restraints have heretofore prevented the market from functioning with close to its potential effectiveness and that restoration of a market regime offers the best hope for solving the nation's health care problem in all of its numerous dimensions.

Although the paper discusses the role of HMOs in several of the various legislative proposals now before Congress, it does not attempt to give a complete and current picture of any of them. It focuses to the greatest extent on the administration's proposals because I find them to embody an interesting and useful device for effectively implementing the HMO concept in the context of a federally funded insurance scheme covering the poor and the aged. This device, operating against the background of a functioning health care marketplace, would provide simple, nonbureaucratic, but effective protections against excessive costs to government on the one hand and, on the other hand, against turning HMOs into purveyors of "second class" medical care to disadvantaged citizens.

Presupposing adoption of this device and an adequate health insurance plan for the poor, I then proceed to describe the benefits which I think the market, supervised and supplemented by selective regulation, would be able to deliver. This hopeful model is then evaluated in the light of concerns about emphasizing the profit motive in health care and about monopoly tendencies in the health care marketplace. Ultimately I advocate vigorous antitrust enforcement, explicit federal preemption of restrictive state laws, and a number of other policies designed to assist in recreating an unrestrained competitive market for health services. The result is, surprisingly enough to those who think the market is currently being relied upon and has been found wanting, a fairly radical proposal. Although Congress may lack the decisiveness expressly to embrace the notion of a competitive health care marketplace, something approaching it might still be realized if the legislation adopted does not exclude the possibility and if the Antitrust Division of the Department of Justice could be persuaded to take up the cause.

The article is being written in the midst of intense Congressional activity, and the conditions it discusses are subject to sudden change. Nevertheless, some kind of HMO is certain to emerge, with government support, as a permanent feature of the health care scene, ${ }^{b}$ and extended discussion of its role and the means available for implementing it must begin before all minds are made up. At the very least, my

"Altogether eight different plans have been introduced in Congress. N.Y. Times, Apr. 28, I97I, at $3 x$, col. $x$.

'See, e.g., Am. Med. News, Apr. 5, I97r, at r. 
emphasis on what the market, if given a chance, could be expected to achieve should improve many observers' perspective on the health care "crisis." At best, it might provoke some reconsideration of the desirability of continuing to adopt ever more intrusive governmental policies designed to ameliorate the symptoms of monopoly without considering whether the disease itself might be subject to cure by using traditional remedies.

The Nature, Pros, and Cons of HMOs

\section{A. Terminology}

The exigencies of legislative drafting are such that some term will have to be chosen to identify those entities which the government is willing to support in the provision of health care by means of per capita payments rather than on a costreimbursement or fee-for-service basis. The most common form of health care delivery featuring such capitation payments is "prepaid group practice," in which this mode of payment by consumers is coupled with the organization of physicians in groups. ${ }^{7}$ Because capitation payments may also be accepted by organizations of independent practitioners and by middlemen of various kinds, the term "prepaid group practice" or "group practice prepayment" was too narrow for statutory purposes. The Nixon administration therefore chose "health maintenance organization," and Senator Kennedy and Congresswoman Griffiths selected "comprehensive health service organization," to describe what they had in mind. ${ }^{8}$ The distinctive characteristic of the entities encompassed is that the provider of care is also a risk bearer, being paid an actuarially determined premium in return for its largely openended contractual undertaking to provide specified care to the extent of the subscribers' needs. ${ }^{9}$ Although the terms selected signify similar concepts, their proposed definitions in the administration and Kennedy-Griffiths bills differ in important respects both from each other and from the traditional model of prepaid group practice.

The term "health maintenance organization" (HMO), which was either coined

\footnotetext{
${ }^{7}$ For an excellent, up-to-date, and exceedingly well-documented discussion of such plans, see Note, The Role of Prepaid Group Practice in Relieving the Medical Care Crisis, 84 Harv. L. Rnv. 887-roor (I97I). In view of the comprehensive documentation provided by this source, I have occasionally felt justified in limiting my own.

${ }^{8}$ Senator Javits' proposals use the designation "comprehensive health service system." S. $836,92 \mathrm{~d}$ Cong., Ist Sess. $\$ 407$ (I97I); S. 837, 92d Cong., Ist Sess. $\$ 2$ (a) (I97I).

- An analogy to provider prepayment can be found in service contracts sold by some retailers, such as Sears Roebuck, with major appliances. Warranties providing for free repair are also similar, but when, as with auto warranties, they run from the manufacturer and provide for reimbursement of independent dealers or repairmen, they are more analogous to third-party insurance. The problems that have arisen with respect to auto warranties therefore do not reflect adversely on provider prepayment. They do, however, call attention to the need for uniform disclosure of covcrage and the problems of controlling utilization under an insurance scheme, which the auto manufacturers have tried to control, with uneven results, by zeducing the profitability of warranty work to dealers.
} 
or popularized by Dr. Paul M. Ellwood, Jr., ${ }^{10}$ and subsequently adopted by the Nixon administration, is something of an overstatement, but it serves a useful descriptive purpose. Thus, under a system where the provider is paid a predetermined premium, it has a direct financial interest in keeping the patient well or in restoring him quickly to health. Fee-for-service medicine, on the other hand, provides no such incentive to practice "preventive medicine."11 Nevertheless, the expression "health maintenance organization" probably promises too much. Medical care is primarily a remedial service, and, while there are some preventive measures (such as prenatal care and some immunizations) that are worthwhile, ${ }^{12}$ preventive medicine practiced by providers cannot achieve health benefits even remotely approaching those obtainable from public health measures, over which HMOs will have no direct influence. ${ }^{13}$ As a consequence, the "health maintenance" idea, while a sound one, runs the risk of being oversold.

Despite this reservation about the reference to "health maintenance" and despite the gracelessness of the abbreviation, I have still employed the term "HMO" in this paper. "HMO" has not yet been given a statutory meaning, and the definition proposed in the administration's pending Medicare amendments is quite unrestrictive in comparison with the Kennedy-Griffiths bill's definition of "comprehensive health service organization." Moreover, unlike "prepaid group practice," the term is not closely identified with existing plans, and therefore its use will facilitate discussion of those delivery mechanisms that feature prepayment of the provider but differ in some ways from these traditional forms.

For reasons that will appear later on, I wish to exclude the so-called "medical care foundations" from the HMO category. The concept as embodied in the administration's bills would encompass these entities, which are prepayment plans sponsored by medical societies and featuring fee-for-service compensation of the participating doctors. However, being creatures of the medical societies, they are unique in purpose, organization, and function from the independent entities otherwise referred to under the HMO rubric, and any generalizing about HMOs is greatly complicated if the exceptional status of the society-dominated foundations must be constantly noted. It is my view, developed later, ${ }^{14}$ that, in a market-oriented system, the foun-

\footnotetext{
${ }^{10}$ See P. Ellwood, The Health Maintenance Strategy (Institute for Interdisciplinary Studies, 1970). Dr. Ellwood is widely credited with being the architect of the administration's proposals.

${ }^{11}$ On the nature of the incentives provided by the fee-for-service system of payment, see generally W. Glaser, Paying the Doctor 138-203 (1970).

${ }^{12}$ Many preventive measures, such as periodic physical exams, are of debatable value. See Note, supra note 7 , at 897-99. Particularly in a time of shortage, the opportunity costs of devoting health resources to preventive medicine-that is, the value of other benefits that might be obtained from their use-must be counted and might be substantial.

${ }^{13}$ However, the reversal of incentives would substantially increase the interest of HMO physicians in promoting preventive measures such as pollution control, sanitation, immunization, and better food and drug regulation. Enlistment of the direct interest of a growing segment of the medical profession in these matters might prove the more important contribution of the HMO concept to "health maintenance."
} 
dations are distinctly anti-HMO and that, if the Sherman Act were applied to them, they would be held to violate it.

After excluding the foundation plans, the HMO I am left with differs in outline from familiar group practice prepayment in such matters as its size, the auspices under which it may be formed, and its capacity for rendering care in kind as opposed to providing it through purchase from hospitals or fee-for-service doctors.

\section{B. The Advantages of HMOs}

Even more remarkable than the spate of health policy proposals in recent months is the widespread agreement-the medical societies excepted-on the need to steer away from preponderant reliance on fee-for-service medicine toward a system in which consumers, if they wish, may obtain care by prepaying (or having the government prepay) the provider. The enthusiasm for this approach has been prompted in large part by the apparent success over a period of time of the prepaid group practice plans, which, though existing in only some parts of the nation, now serve around eight million people and have generated some impressive statistics on the per capita cost of providing care of a generally high quality. ${ }^{15}$

In addition to the track record of existing prepaid group practice plans, there are important technical arguments, many of them seemingly borne out by the statistics, for supporting the concept of care rendered under a system of provider prepayment. ${ }^{16}$ These arguments, stated without documentation or evaluation, ${ }^{17}$ are to the effect that HMO-type care does the following things:

(I) reverses the incentives inherent in fee-for-service medicine (especially where health insurance removes the doctor's direct fiduciary obligation to his patient) for physicians and hospitals to provide unnecessary services in order to increase their income;

(2) introduces incentives, particularly absent where third-party insurance is available, for physicians to consider cost effectiveness and to avoid overusing expensive facilities and resources for such purposes as (a) obtaining an incommensurate medical benefit for the patient, $(b)$ adhering uncritically to "routine" practice, $(c)$ minimizing perceived malpractice risks, ${ }^{18}(d)$ rendering a certain

${ }^{14}$ See text accompanying notes $157-80$ infra.

${ }^{25}$ See Note, supra note 7 , at $921-24$, and references there cited.

${ }^{10}$ In Group Health Cooperative v. King County Medical Soc'y, 39 Wash. 2d 586, 604, 237 P.2d 737,

747 ( $195 \mathrm{r}$ ), the court summarized the advantages of a prepaid group practice plan as follows:

"increased opportunities for, and convenience in, effectuating referral of patients to other doctors to take advantage of various specialties; access to more and better equipment and laboratory facilities; improved quality of service because of constant surveillance by other members of the staff; opportunities for consultation, staff conferences, refresher courses, and post-graduate studies; better organization of time as, for example, the rotation of emergency night-call service; greater incentive to give patients proper treatment; security of professional income regardless of daily patient load; and disassociation of the business aspects of the service, so that the doctors may devote themselves entirely to professional matters."

${ }^{17}$ For a fuller statement, documentation, and tentative evaluation, see Note, stipra note 7, at 921-33.

18 This motivation is often alleged to cause excessive $x$-ray and other diagnostic tests by physicians 
service in such a way (for example, on an inpatient basis) as to bring it within the terms of the patient's insurance coverage, or $(e)$ catering to the nonpaying patient's perceived preference that "everything possible" be done whatever the expense; ${ }^{19}$

(3) creates a decision maker with both the knowledge and the incentive to discriminate on the basis of price and value in the purchase of needed goods and services-particularly drugs, ${ }^{20}$ hospital services, and specialists' care-, thus strengthening competition and economic performance in markets adjacent to the market for primary care;

(4) strengthens incentives for realizing available efficiencies in the use of manpower and other resources, incentives that are weak where providers are not subject to substantial price competition due to the structure and customs of the marketplace or where cost-reimbursement is more or less assured by government or private health insurance;

(5) creates an organizational structure in which available efficiencies and improvements in performance can be more readily realized in such areas as (a) maintenance of complete, up-to-date, and nonduplicative medical records; $(b)$ manpower and equipment utilization; (c) utilization of specialists' services; (d) continuing education for personnel at all levels; and (e) administration generally, particularly in billing and in freeing physicians of business details;

(6) creates an incentive for providers to keep patients well by such preventive measures as are economic, to detect disease at an early stage, to treat causes rather than symptoms, and generally to effect an early cure; ${ }^{21}$

(7) improves incentives affecting referrals and outside consultations, whereby fee-for-service physicians may only lose income from a patient but prepaid pro-

practicing "defensive medicine." This allegation is currently being evaluated in a study being conducted by the Duke Law Journal.

${ }^{10}$ This last item differs from (a) only in suggesting how physicians tacitly combine with their patients to form coalitions to take advantage of insurance coverage. These coalitions operate to make health insurance extremely expensive by exploiting the absence of the usual cost constraint on consumers' decisions concerning whether a particular expenditure is worthwhile. Detailed coverage provisions to some extent limit the "luxuries" that may be enjoyed without cost, but since no effort is likely to be made to limit the number of diagnostic x-rays, for example, many $x$-rays will be done under circumstances where their "value" is less than the sum of the cost plus the discounted hazard from irradiation. It is reasonable to regard the added procedures thus done, or the unwarranted hospitalization expenses incurred in the absence of a cost constraint, as an inefficiency of third-party insurance. In an HMO, on the other hand, the consumer might be denied on purely medical grounds an $x$-ray or day of hospitalization that he would have elected to purchase if he had been free to do so. The frequent use of outside fee-for-service physicians by prepaid group practice subscribers may be explained in part as the indulgence of such preferences by consumers. It is entirely appropriate for consumers to have and to exercise the right to purchase such additional reassurance, and, without more, their election to do so should not reflect adversely on the HMO concept; indeed, such luxuries should be purchased separately with one's own funds.

${ }^{20}$ Advantages connected with drug prescribing are potentially of great importance but are seldom cited in support of HMOs because existing plans do not often cover prescription drugs. The subject is developed at length in another connection in the text accompanying notes 189-99 infra.

${ }^{21}$ But see note ${ }_{04}$ infra. 
viders may gain protection against the financial costs of a subscriber's worsened condition;

(8) offers the opportunity for organizing care more conveniently for consumers by providing an accessible and continuously available "entry point" into the health care system and responsible guidance for the patient through the system so that he may obtain promptly and centrally such services as he requires;

(9) provides, by encouraging larger organizations of physicians in the place of solo practitioners, a better vehicle for maintaining the quality of care rendered outside the hospital; and

(Io) provides stronger incentives for maintaining effective peer review and other quality controls in hospitals than exist in the present system of hospital practice.

The foregoing are persuasive reasons for wishing to see wider use of HMOs. They are especially appealing arguments when the nation is faced with both an existing imbalance between the supply of medical resources and the demand for them and a strong desire for a further stimulation of demand by expanding government's role in health care financing. In this climate, HMOs hold out a politically appealing hope that, by eliminating overutilization and introducing substantial efficiencies, existing resources can be spread further, giving care to more people without sacrifice of essential quality.

\section{Some Negative Considerations}

A few negative considerations need to be noted here without any attempt at analysis. Several of these matters will be discussed at a later point.

First, despite the governmental boosting that would be put behind HMOs under the various pending proposals, there are still severe impediments to their rapid growth. While several of the proposals would provide financial assistance for HMO formation, the sufficiency of the incentive to private parties to create them and to doctors to accept employment with them remains far from clear. The funds and organizational efforts called for, the difficulty of educating and attracting sufficient enrollees from a public accustomed to fee-for-service medicine, and the problems of attracting physicians into such plans $\mathrm{s}^{22}$ are all likely to be underestimated. It is argued below that these barriers are so substantial that they can be overcome in a reasonable time only by allowing plans to generate profits for the benefit of nonphysician investors of capital and talent in the enterprise.

A more fundamental objection to group practice prepayment centers on the incentive created to deny needed care in some circumstances. Of course, the plan has

\footnotetext{
${ }^{22}$ FMO employment appeals to some physicians as professionally rewarding, and it allows physicians to have greater leisure through better organization of the workload. Greater leisure for individual physicians implies a possible loss in total manhours of physicians' services which might not be offset by improvements in their efficiency, but it is not clear why HMO physicians, like lawyers in large firms, would not take on more paying clients than they could serve in a 40 -hour week.
} 
an appropriate stake in quickly restoring health so as to avoid the costs of a worsened condition, but occasionally there would be a temptation to omit an expensive form of treatment solely because of cost considerations. The clearest example would be in the temptation to let a patient die of a cardiac arrest rather than place him in the intensive care unit at a cost of $\$ 300$ per day. This possibility, while important to consider, is not quite so hair-raising as it sounds, and it is discussed later in connection with the question whether a for-profit HMO is open to particular criticism on this score.

Another area of concern is the fear that HMOs will become a vehicle for delivering care exclusively to low-income or elderly elements in the population and thus, either in appearance or in reality, a "second-class" type of medicine. Again, the possibilities for avoiding this outcome are discussed later on.

Finally, it should be noted that the evidence on prepaid group practice is subject to some dispute, if not as to the existence at least as to the extent of the cost savings realizable from this method of organizing health care delivery. For one thing, plan enrollees are known to purchase substantial amounts of care outside the plan, ${ }^{23}$ resulting both in understatement of the costs of serving plan members and in an increase of the services rendered in the fee-for-service sector and counted against that mode of delivery in statistical analyses. Further, the enrolled population of a prepaid group practice plan is probably not comparable to the clientele of the fee-for-service physicians in the community, making statistical comparisons difficult and very possibly misleading. ${ }^{24}$ There is also evidence that, while existing plans have been generally well received, they have not been conspicuously successful in delivering care in a personalized and convenient way. Expectations concerning HMO success must take into account the possibility that the advantages of HMOs may have been overstated ${ }^{25}$ or that gains in efficiency may be offset by losses in other relevant departments.

Against this background, it can be said that, although enthusiasm for the HMO concept should not be unquestioning, the arguments provide a warrant for affirmative governmental efforts to stimulate HMO formation to the end that consumers and

\footnotetext{
${ }^{33}$ See Note, supra note 7, at 921-22 n.I; The Kaiser Foundation Medical Care Program, in 2 REPORT of the National Aovisorx Comm'n on Health Manpower 197, 207 (1967).

34 M. Pauly, Medical Care at Public Expense 95-96 (1971), suggests that HMOs, because of their tendency to provide less care, may attract only those Medicare beneficiaries with below-average demands for care. This would make HMO's performance seem better in comparison with the fee-for-service sector than it in fact was. Pauly does not indicate whether the apparently lower costs of prepaid group practice plans might be explained by this thesis, but it would seem that they could be in some part.

${ }^{20}$ See, e.g., Klarman, Approaches to Moderating the Increases in Medical Costs, 7 MED. CARE 175 , I83 (1969); Densen, et al., Prepaid Medical Care and Hospital Utilization, Hospirals, Nov. I6, 1962, at 62. On the other hand, many existing plans have been quite conservative in their use of paramedical personnel and in other respects. See, e.g., The Kaiser Foundation Medical Care Program, supra note 23, at 206. The purposes behind this hesitancy have probably been to avoid accusations and malpractice suits and to reassure their subscribers. Nevertheless, the many potential economies that have not yet been tapped are one basis for the hope that the HMO concept may indeed revolutionize health care. Competitive pressures will be needed, however, to stimulate the search for and implementation of available economies.
} 
providers shall have this mode of transacting for health services available as an option; going any further, such as by forcing any group in the society to accept HMO care, seems unwarranted either by the pro-HMO evidence or by the total performance of the fee-for-service sector. Competition between HMOs and fee-for-service medicine would maximize consumer choice and would determine most democraticallyby consumer votes-the role of each system in the delivery of care. Creating the basis for a restructuring of incentives to curtail overuse and to spread resources more widely would seem to be a justifiable goal of public policy at the present time. Moreover, clearing away obstacles to the introduction of larger-scale primary care providers, with greater potentiality for achieving available efficiencies and providing internal quality controls, may also be regarded as a proper function of government.

\section{II}

\section{The Role of HMOs in Recent Policy Proposals}

It is beyond the scope of this paper to do full justice to the various pending health policy proposals. The discussion here is primarily for the purpose of highlighting the role contemplated for HMOs in different approaches to health care delivery. The greater portion of the discussion focuses on the administration's proposals, and my main interest here and throughout this discussion is to discover the extent of reliance, if any, on the market and how the various mechanisms proposed would relate to or affect the functioning of market forces.

\section{A. The Administration's Health Care Program}

\section{The 197 Proposals}

On February I8, I971, the President announced his program to provide almost universal health insurance coverage for the American people. ${ }^{26}$ The program's main thrust was toward financing health care and expanding, extending, and prescribing the scope of health insurance coverage. To these ends, (I) employers would be required to provide specified basic health insurance coverage for their employees on a cost-sharing basis; (2) less extensive insurance coverage would be provided by the federal government for poor families headed by self-employed, intermittently employed, or unemployed persons by means of a "Family Health Insurance Plan" (FHIP) in which the very poor would participate without charge but others would pay increasing premiums, deductibles, and coinsurance payments in accordance with their income; (3) Medicaid would be continued for the aged poor, the blind, and the disabled; (4) Medicare would be continued for persons over sixty-five but without the special monthly charge for part B coverage; and (5) special insurance pools would be established for the self-employed and for high-risk individuals denied other coverage.

\footnotetext{
${ }^{20}$ See Prestdent's Heatth Message r4-17. See also note 2 supra.
} 
The President's message expressed the administration's enthusiasm for the HMO concept, reciting the importance of altering incentives in health care delivery to induce efficiencies and reduce overutilization. He indicated his hopes for rapid development of HMOs throughout the country and set forth some strategies for bringing it about. In the way of financial support, ${ }^{27}$ he proposed to allocate $\$ 23$ million for planning grants and to provide $\$ 300$ million in guarantees of private loans to HMO sponsors. In addition, he proposed $\$ 22$ million in subsidies for HMOs that would locate in areas where medical resources were in particularly short supply, primarily rural areas and urban ghettoes.

The administration's health insurance bill would require each employer to offer an HMO option to his employees, ${ }^{28}$ a step that would open up HMO opportunities to a significant degree since an individual would no longer be locked into the fee-forservice sector by the terms of insurance protection dictated by his employer. Unfortunately, however, the notion of free choice stops here, because the employee is not to be given a choice among available HMOs in the community but would instead be bound by the employer's election of an HMO to which his participation is transferable. It would have been simple enough to allow the employee such a choice and to have the employer pay an appropriate amount to whatever HMO he selected. ${ }^{29}$ If this were done, employees would have, in effect, a voucher entitling them to enter the marketplace in search of the kind of HMO care that appealed to them most. ${ }^{30}$ Such a strategy would vastly expand the opportunities for competitive HMO development. The administration's bill appears first to assume, and then to guarantee, that the business of rendering HMO-type care will be monopolized.

Under the President's proposal, those poor persons covered by FHIP would have the option of joining an HMO at government expense, and indeed they would have a free choice among those available. The proposed arrangement for exercising this option is similar in many ways to the arrangements for such elections by Medicare beneficiaries that is contained in the administration's pending Medicare proposals.

\section{The HMO Defined (The Medicare Proposals)}

The administration's proposed Medicare amendments set forth a definition of a "health maintenance organization" for the purpose of confirming in the Secretary of HEW the power to contract with such an agency to provide prepaid health care on a capitation basis to persons whose care has become a federal responsibility

\footnotetext{
${ }^{27}$ President's Health Message 6-7. See also H.R. 56I5, $92 \mathrm{~d}$ Cong., ist Sess. (I97I) (the administration's "Health Maintenance Organization Assistance Act of I97I") [hereinafter cited as H.R. 5615].

${ }^{28}$ S. 1623 , § Ior, proposed $\S 603(\mathrm{~h})$.

${ }^{20}$ The President referred to the "actuarial value" of the employee's insurance coverage as being transferable, President's Health Message 6, but this seems wrong. If "community rating" for persons under $6_{5}$ is required of HMOs, then the employee should be able to transfer his pro rata share of the employer's total premium. Otherwise only older persons will transfer to HMOs, since only they would not have to make a supplementary payment.

${ }^{30}$ In order to induce cost and value comparisons, an employee transferring his membership to an HMO should be entitled to a cash refund if the HMO membership is cheaper than the insurance coverage, or else he might be given additional benefits by the HMO in lieu of a refund.
} 
under Medicare. ${ }^{31}$ Thus, persons covered by the program who would elect to be enrolled in an HMO would become the subject of such a contract, and their federal benefits would then take the form of a periodic fixed-sum payment to the HMO rather than, as formerly, of payments to hospitals or fee-for-service physicians for services actually rendered. Under the FHIP proposal, similar contractual arrangements would be authorized to permit HMO coverage of that program's beneficiaries. ${ }^{32}$

On its face, the administration's Medicare bill (H.R. I) ${ }^{33}$ promised to generate, to the extent HMOs were in fact utilized, an immediate and politically appealing saving in cost over the present method of providing Medicare benefits. Thus, the bill provided that the rate of payment to the HMO "shall be designed to provide payment at a level not to exceed 95 per centum of the amount that the Secretary estimates (with appropriate adjustments to assure actuarial equivalence) would be payable" for Medicare services for the same population if the services were to be furnished by fee-for-service providers. ${ }^{34}$ From this it appeared that the draftsman expected that bringing the HMO into the picture would save at least five per cent on the cost of caring for the HMO-enrolled population.

H.R. I defined the term "health maintenance organization" at some length. It appeared in most respects to have modeled the HMO on the most familiar type of prepaid group practice plan. As set forth in the version of the bill recently passed by the House of Representatives, an HMO would be a public or private organization which

(I) provides, either directly or through arrangements with others, health services to ... [enrollees] on a per capita prepayment basis;

(2) provides, either directly or through arrangements with others, ... (through institutions, entities, and persons meeting the applicable requirements of section I86r), all of the services and benefits covered under parts $A$ and $B$ of this title;

(3) provides physicians' services (A) directly through physicians who are either

\footnotetext{
${ }^{81}$ The immediate occasion for the amendments was the problem that Medicare, providing only for cost reimbursement, did not adequately reward the efficiencies achieved by prepaid group practice plans. The problem has been described by the Senate Finance Committee as follows:

"Under present law, organizations providing comprehensive health services on a per capita prepayment basis cannot be reimbursed by medicare through a single prospective capitation payment such as the organizations normally charge for services covered under both . . . parts of the medicare program. Instead, medicare reimbursement to group practice prepayment plans, whether it is made on a cost or charge basis, must be related, retrospectively, to the costs to the organization of providing specific services to beneficiaries, so that some of the financial incentives which such organizations may have in their regular non-medicare business to keep costs low and to control utilization of services are not fully incorporated directly in their relationship with medicare."

S. REP. No. 9I-I43I, 9rst Cong., 2d Sess. I3I-32 (I970) [hereinafter cited as S. REP. No. 9I-143I]. See also Phelan, Erickson \& Fleming, Group Practice Prepayment: An Approach to Delivering Organized Health Services, in this symposium, p. 796, 811-12; Note, stupra note 7, at 988-90.

${ }^{22}$ S. $1623, \$ 201$, proposed $\$ 628(j)$.

${ }^{33}$ H.R. I, 92d Cong., Ist Sess. (I97I) [hereinafter cited as H.R. I]. The House-passed version (see note I supra) is hereinafter cited as "H.R. I as amended."

${ }^{34}$ H.R. I $\$ 239(\mathrm{a})$, proposed $\$ 1876(\mathrm{a})(2)$.
} 
employees or partners of such organization, or (B) under arrangements with one or more groups of physicians (organized on a group practice or individual practice basis) under which each such group is reimbursed for its services primarily on the basis of an aggregate fixed sum or on a per capita basis, regardless of whether the individual physician members of any such group are paid on a fee-for-service or other basis;

(4) demonstrates to the satisfaction of the Secretary proof of financial responsibility and proof of capability to provide comprehensive health care services, including institutional services, efficiently, effectively, and economically;

(5) except as provided ... [elsewhere], has at least half of its enrolled members consisting of individuals under age 65 ;

(6) assures that the health services required by its members are received promptly and appropriately and that the services that are received measure up to quality standards which it establishes in accordance with regulations; and

(7) has an open enrollment period at least every year under which it accepts up to the limits of its capacity and without restrictions, except as may be authorized in regulations, individuals who are eligible to enroll .... in the order in which they apply for enrollment (unless to do so would result in failure to meet the requirements of paragraph $(5)) \cdot^{\mathbf{3 5}}$

There is of course no uniform mold from which existing prepaid group practice plans have been cast, but certain features associated with the largest plans may have come to be regarded as typical. As defined in H.R. I, the HMO seems to be distinct from the typical prepaid group practice plan in at least four important respects. First, it appears that the HMO might be permitted to serve some patients on a feefor-service basis. ${ }^{36}$ Thus, any clinic or hospital might form an HMO to serve some of its clientele while continuing to provide traditional care to others. This would greatly facilitate HMO formation by existing providers since an abrupt change in methods of doing business would not be necessary. Moreover, individual physicians could become associated with an HMO without abandoning their former patients, thus simplifying physician recruitment by the HMO. While there is no reason for existing prepaid group practice clinics not to provide fee-for-service care to the general public, this has not been common. ${ }^{37}$ The medical care foundations, which fall within the definition of HMO by virtue of a recent clarification of paragraph (3), ${ }^{38}$ render all their services through fee-for-service physicians who are paid on a piecework basis for services rendered to foundation enrollees.

Under the H.R. I definition, HMOs would be free to be substantially smaller

\footnotetext{
${ }^{35}$ H.R. I as amended, $\S 226(\mathrm{a})$, proposed $\$ I 876(\mathrm{~b})$. A similar definition originally appeared in H.R. I7550, 91st Cong., 2d Sess. $\$ 239$ (a) (I970), and H.R. I, $\$ 239$ (a). The administration has since changed its basic definition somewhat. E.g., S. I623, $\S$ ror, proposed $\S 604(\mathrm{a}) ;$ id. $\$ 201$, proposed $\S 628$ (b); H.R. 5615, 2 (c), proposed $\S$ I IOI (r).

so The Kennedy-Griffiths bill, $\S 47(b)$, would also permit this.

${ }^{37}$ One example is the Palo Alto (California) Clinic, which has $15 \%$ prepaid subscribers. Note, supra note 7 , at $903^{-04}$ n.9. It is not clear that all consumers are offered a choice of prepayment or fee-for-service care. See also id. at 938 .

${ }^{38}$ Compare H.R. I, $\S 239(\mathrm{a})$, proposed $\$ 1876(\mathrm{~b})(3)$, with H.R. I as amended, $\S 226(\mathrm{a})$, proposed $\S \mathrm{I} 876(\mathrm{~b})(3)$.
} 
than are the familiar prepaid group practice plans, and this could contribute to the existence of a greater number of HMOs, featuring different prices and varieties of service and contributing to a competitive environment. Other pending definitions of HMO offered by the administration have included a requirement that they have at least ro,000 enrollees. ${ }^{39}$ Why so arbitrary an exclusion of would-be providers might be deemed desirable is not clear. Such a requirement would greatly reduce both actual and potential competition and would discourage innovation and free choice. It is notable that H.R. I as recently passed by the House, quoted above, does not contain the requirement of 10,000 enrollees.

The third way in which an HMO, as defined in H.R. I, appears to differ from the familiar type of prepaid group practice plan is in the apparent opportunity for organizing and operating an HMO for the express purpose of earning a profit for someone other than the physicians involved. Most prepaid group practice plans have been organized either by the doctors themselves or by consumer groups, unions, or employers for the benefit for their membership or employees. In the case of consumer-sponsored or employer-sponsored groups, the founding organization normally contracts with a group of doctors to provide the care in return for a per capita payment by or on behalf of the individual participants. The organization itself acts only as a sponsor and takes no profit off the top for its entrepreneurial initiative. The proposed bill would not limit HMO organization to enterprises of the voluntary, nonprofit kind, leaving open the possibility that profit-seeking middlemen might become engaged in HMO formation. The suggestions developed below, which look to potential profits as an important stimulus for HMO formation, depend heavily on the accuracy of this appraisal of the expectations underlying the drafting of H.R. I. It is notable that the Senate Finance Committee found this a major point of difference with the administration in $1970^{40}$ and that the Kennedy-Griffiths bill contemplates only nonprofit "comprehensive health service organizations." 11

A final area of difference between HMOs, as defined, and the most familiar variety of prepaid group practice plan lies in the provision of hospital and specialists' services. Many of the major plans of provider prepayment furnish hospital services in hospitals owned either by the plan itself or by the medical group with which the plan contracts. ${ }^{42}$ Similarly, physician services are rendered almost exclusively in-house, except where emergency care must be obtained by subscribers away from the plan's facility. No requirement concerning the form in which hospital or physician services are provided would be imposed on the HMO by H.R. I, leaving it free to provide them by purchase from independent public or private hospitals where its

\footnotetext{
${ }^{80}$ S. I623, $\S$ Ior, proposed $\$ 604(\mathrm{a})(5)$; id. $\S 201$, proposed $\$ 628(\mathrm{~b})(5)$.

${ }^{20}$ See S. REP. No. 9I-I 43I, at I3I-32, and text accompanying note 90 infra.

¿1 Kennedy-Griffiths bill $\S 47$ (a)(2).

62 The differences between hospital-based plans and others are discussed in Note, supra note 7, at 9ro-18. Some existing plans do not cover hospital benefits at all, requiring the member to purchase hospitalization coverage elsewhere.
} 
doctors have staff privileges ${ }^{43}$ and from fee-for-service specialists by referral of its patients. ${ }^{44}$ This freedom would go far towards permitting HMOs to be formed on a relatively small scale compared to the best known prepaid group practice plans and to be constituted without large capital inputs. It would also assure subscribers that specialized hospital and physician care of the highest quality could be obtained when it was needed. Even more important perhaps, HMO purchasing of hospital and physician services could introduce desirable influences into the market for each.

\section{A Device for Avoiding "Second-class" Status and Protecting the Public Purse}

Because the President's program would provide optional HMO-based care for Medicare beneficiaries and for beneficiaries of the proposed FHIP, there is a risk that it will provide for these disadvantaged persons, the aged and the poor, only a type of "second-class" medicine. Of course, such consumers would be free not to select HMO-type care and to remain in the fee-for-service sector, obtaining care as needed from physicians whom they locate by their own efforts. But the alternatives available to many health care consumers in these groups are so few and so unattractive that this opportunity to reject HMO membership provides only slight protection against forcing the elderly and poor into accepting care from institutions that they might regard as somehow second-class. Some means of guaranteeing that HMOs will not become a vehicle for second-class medicine would be desirable not only as a protection for the poor but also to protect the "image" of HMO-provided care so that the middle-class will not associate it with ghetto dwellers and be induced to reject the HMO for their own purposes.

Another problem is the difficulty of determining the price that government should

\footnotetext{
"s The Kennedy-Griffiths bill, $\$ \$ 47(\mathrm{a})(2)-(3), 87(\mathrm{c})$, also contemplates the possibility that hospital services may be provided on other than an in-house basis. For the view that hospital services must be at least contracted for rather than purchased randomly, see Division of MEDiCaI PRACTICE, AMERICAN Medical Ass'n, HMO's as SeEn by the AMA-An Analysis 7-8 (197r). The AMA's argument turned on H.R. I, $\S 239(\mathrm{a})$, proposed $\$ 1876(\mathrm{~b})(6)$, which was altered slightly but significantly in H.R. I as amended, $\$ 226(\mathrm{a})$.

"H.R. I as amended, $\S 226(\mathrm{a})$, proposed $\$ 1876(\mathrm{~b})(3)$, quoted in text at note 35 supra, indicates that physicians' services shall be provided "directly through physicians who are either employees or partners" of the HMO or members of a group that has contracted with the HMO to provide the services on a fixed-fee basis. One reading of this language would preclude the possibility of an HMO's purchasing some of the services that it provides from fec-for-service physicians to whom it refers its enrollees from time to time, perhaps for more specialized care than it can render. There is no reason that, having contracted with the patient to provide all the care he needs, the HMO should be precluded from doing so on occasion by employing outside physicians for the purpose, and indeed it would be prejudicial to HMO subscribers to cut off the possibility that specialists' services could be obtained in this manner. Thus, one hopes that the bill will be read as being nonexclusive in its requirement, so that it would be sufficient if the HMO provided only some physicians' services, perhaps all primary care, through the specified mechanism. Similarly, although the requirement in id., proposed $\$ 1876$ (b) (4), of "proof of capability to provide comprehensive health care services" might be read to require either in-house capability or the financial capability to purchase needed additional services in the open market, the regulations should recognize either kind of capability as sufficient. The Comprehensive Health Service Organization of the Kennedy-Griffiths proposal would be permitted to purchase the services of outside physicians. See Kennedy-Griffths bill $\$ 47$ (2)(2). A proposal in New York would allow only emergency services to be purchased. See Note, supra note 7, at 979.
} 
pay for the coverage of Medicare and FHIP beneficiaries. The price must be fair to the government and to the HMO and ideally should not involve the government too deeply in supervising the costs and practices of the HMOs with which it deals. The maximum price that the government would pay is, as noted above, ninety-five per cent of the cost of serving the same patient population under a fee-for-service system. Since this is a maximum figure, lower rates might be appropriate, but H.R. I provided only an indefinite guide as to how such rates would be fixed, stating that, subject to the ninety-five per cent ceiling, federal payments to HMOs would be determined by "taking into account the health maintenance organization's premiums with respect to its other enrollees (with appropriate actuarial adjustments to reflect the difference in utilization... ) and such other pertinent factors as the Secretary shall prescribe in regulations ...." .5 $^{4}$ It was thus contemplated that the primary guide for pricing services received by Medicare and FHIP beneficiaries would be the prices charged by the HMO to private subscribers purchasing HMO services with their own funds.

Tying the government's payments to the prices paid by private subscribers is an attractive idea. It makes each potential private subscriber a sort of proxy who would "shop" for health services not only for himself but also for one or more Medicare, FHIP, or Medicaid clients. For this "proxy-shopping" approach to be effective, however, there would have to be some requirement that each HMO have some minimum proportion of private subscribers. The administration's FHIP bill would require that at least half of the HMO's enrollees not be FHIP or Medicaid beneficiaries, ${ }^{46}$ and H.R. I would similarly limit HMO enrollment of Medicare beneficiaries to fifty per cent. ${ }^{47}$ If the two bills could be coordinated so as to preclude development of plans with half Medicare and half FHIP or Medicaid enrollees and to require specifically that self-supported subscribers constitute at least fifty per cent of the membership, the government should be able safely to rely on such subscribers' willingness to pay for the service as a guide in setting the price it would pay for persons under its sponsorship.

The proxy-shopping device would guarantee that the price the government paid for its clients was one determined, in effect, by a competitive market. It would control costs to the government not by introducing a cumbersome system of quality and cost audits but by relying on the private consumer, who is still the most sensitive indicator of relative values yet discovered. It would maximize free choice and would make the passing of the ultimate market test-the attraction of a relatively sophisticated paying customer-a prerequisite for the HMO's enrollment of each governmentsponsored individual. This test would have to be met again and again and would in fact increase the HMO's incentive to attract paying customers since each "sale"

\footnotetext{
${ }^{55}$ H.R. I, $\$ 239$ (a), proposed $\S 1870$ (a) (2).

${ }^{60} \mathrm{~S}$. I $623, \S 20 \mathrm{I}$, proposed $\S 628(\mathrm{~b})(5)$. Exceptions are made for the early years of operation and for special problems precluding compliance. Id., proposed $\$ \$ 628(\mathrm{~h})-(\mathrm{i})$.

${ }^{47}$ H.R. I as amended, $\S 226(\mathrm{a})$, proposed $\S \mathrm{i} 876(\mathrm{~b})(5)$.
} 
would carry with it, as a bonus, the right to sign up a person who, not being price-conscious, must be persuaded only to want the service. The HMO's interest in attracting paying customers would serve to keep the price down, while its interest in attracting customers of both classes would serve to sustain the quality of care (at least as apprehended by the subscribers) and the conditions under which it was rendered. The problem of second-class medicine would be substantially avoided. ${ }^{48}$

The flaw in the proxy-shopping device in the original H.R. I lay in the lack of incentive to Medicare and FHIP beneficiaries to accept HMO enrollment rather than more expensive fee-for-service care. If their coverage was the same in either event and the advantage of the HMO's lower cost accrued not to them but to the government, they would be unlikely to surrender the free choice and possibility of greater attention at no extra cost that accompany government-financed fee-for-service care. The administration has evolved an answer to this problem that appears not to sacrifice the advantage of the proxy-shopping device. In the FHIP bill, ${ }^{49}$ the cost problem is dealt with by first requiring the HMO to account separately for the costs of serving FHIP beneficiaries and other subscribers. Then there is a requirement that the "retention" rate-that is, profit as a percentage of income-on the FHIP group must not exceed that for the other group, and any such "excessive retentions" are required to be returned to the government unless they are applied either to providing increased benefits or to reducing premiums, coinsurance payments, or deductibles. Thus, as long as such "excessive retentions" are used to make HMO coverage more attractive than coverage under FHIP itself, the government will not require the HMO to refund any of its payments made at the full rate of ninetyfive per cent of the anticipated cost of fee-for-service coverage. ${ }^{50}$ Although first appearing in the FHIP bill, this approach was recently incorporated by the House Ways and Means Committee in its version of the Medicare amendments, which subsequently passed the House ${ }^{51}$ and are now awaiting action by the Senate.

The FHIP bill thus represents a useful modification of the proxy-shopping device, providing in effect a Ioo per cent subsidy to the HMO to provide attractive extra benefits to beneficiaries of the government program. The source of the funds for providing this subsidy is the efficiency of the HMO itself, which accounts for the existence and extent of the spread between the HMO's regular charges to private subscribers and the maximum amount the government is willing to commit. The most efficient HMOs will therefore be able to provide the most attractive benefit package to induce enrollment by FHIP beneficiaries.

\footnotetext{
${ }^{2}$ The private-subscriber requirement should of course be imposed with respect to each facility the HMO might operate in order that it could not be met by establishing one branch in the ghetto and one in the suburbs. In addition to avoiding the "separate-but-equal" stigma, this would encourage HMOs to locate themselves so as to be convenient to subscribers of both classes.

${ }^{20} S$. $x 623, \S 20 \mathrm{x}$, proposed $\$ 628(\mathrm{a})(2)(\mathrm{B})$.

${ }^{50} I d$., proposed $\$ 628(\mathrm{a})(2)(A)$.

E1 H.R. I as amended, $\$ 226(\mathrm{a})$, proposed $\S 1876(\mathrm{a})$.
} 
Appropriately, the modified proxy-shopping device also allows the HMO to earn a profit in serving its FHIP enrollees that is proportionate to the profit which it is able to earn in caring for its private subscribers. The profit incentive is thus left intact, and only minimal government supervision is necessitated. The most difficult regulatory problems would probably be accounting ones, particularly in allocating joint costs between the government-sponsored enrollees and others.

Subsequent discussion relies heavily on the modified proxy-shopping technique of accomplishing the dual goals of controlling costs and providing attractive care for the elderly and the poor. Indeed, it forms an important cornerstone of the market-oriented delivery system that I advocate. Of course, a competitive market is essential to the functioning of the modified proxy-shopping device, and most of the rest of the paper explores the prospects in this regard.

\section{B. Some Other Proposals}

\section{The Proposed Health Security Act (The Kennedy-Griffiths bill)}

This bill, sponsored by Senator Edward M. Kennedy and Representative Martha W. Griffiths, would provide federally financed comprehensive health services for virtually all U.S. residents. ${ }^{52}$ Financing of the program would be effected through a tax on employers, on employee income, and on self-employment income, with the federal government contributing up to an equal amount of funds, as required, from general revenues. The Health Security Trust Fund established with these contributions would pay for a wide range of services if rendered by a "participating provider," the qualifications for which are specified at length. Independent practitioners could qualify as "participating providers" and could elect to be paid on a fee-for-service basis, although a fee schedule would be imposed for each region, state, or area.

The bill indicates particular support for the delivery of services on a prepaid basis. The independent practitioner would have the option of electing to be compensated by the capitation method, receiving a fixed sum for each person on his list-that is, those to whom he is obligated to render, or arrange for, comprehensive care; a practitioner so compensated would fall just outside my definition of HMO since the capitation payment he receives covers only primary and not comprehensive care. The large-scale HMO is presented as a feasible, and perhaps favored, alternative, though under a different name-Comprehensive Health Service Organization (CHSO). Organizations satisfying specified criteria may be "participating providers" under the proposed scheme and will be eligible to receive the prescribed capitation payment for each person enrolled. An analysis of the bill provided by Congresswoman Griffiths describes the CHSO provisions as follows: ${ }^{53}$

\footnotetext{
${ }^{82}$ See note 4 supra.

${ }^{68}$ M. Griffiths, Section-By-Section Analysis [of the Proposed Health Security Act] 6, r97I.
} 
The section [47] is designed to accommodate forms of organization typical of existing prepaid group practice plans, but also to be flexible enough to permit experimentation with somewhat different forms. In some urban or rural areas, for example, it may be impracticable to bring all of the various services together in one place, and the section has been designed to encompass what has been described as "comprehensive group practice without walls"; the basic essential is the assumption of responsibility for a reasonably comprehensive range of services (including health maintenance) on a continuing and coordinated basis, to a group of persons who have been chosen to receive all or nearly all their health care from the organization.

Other requirements are spelled out in this section: The organization must furnish services through the prepaid group practice of medicine, or as near an approximation to prepaid group practice as is feasible. It must be a nonprofit organization, or if several providers share in the furnishing of services the prime contractor with the Board must be nonprofit. All persons living in or near a specified service area will be eligible to enroll, subject to the capacity of the organization to furnish care and subject to minimal underwriting protections. Services must be reasonably accessible to persons living within the specified service area. Periodic consultation with representatives of enrollees is required. Professional policies and their effectuation, including monitoring the quality of services and their utilization, is to be the responsibility of a committee or committees of physicians. Health education and the use of preventive services must be stressed, and lay persons are to be employed so far as is consistent with good medical practice. Charges for any services not covered by Health Security must be reasonable. Finally, the organization must agree to pay for services furnished by other providers in emergencies, either within the service area of the organization or elsewhere, but may meet this requirement to the extent feasible through reciprocal service arrangements with other organizations of like kind.

This formulation differs from the administration's HMO (I) in requiring the CHSO (a) to be a nonprofit entity, (b) to consult on policies and practices with its enrollees, and $(c)$ to replicate the prepaid group practice model to the extent feasible, and (2) in providing greater specificity about numerous elements that are consistent with the HMO concept in the administration's bill but would not be legally embodied in it, such as utilization of paramedical manpower, maintenance of reasonable charges on services not insured, and maintenance of health education and peer review. The bill seems to contemplate greater supervision of internal affairs than the administration's proposal would impose.

Incentives for the formation and efficient functioning of $\mathrm{CHSO}$ sould be afforded by allowing a bonus payment, in addition to the capitation payment, if the organization can establish that, during a fiscal year, (I) the average utilization of hospital and skilled nursing home services was less than the average utilization of such services by comparable population groups not enrolled in such organizations, and (2) the services of such organization have been of high quality and adequate to the needs of its enrollees. The bonus would be equal to seventy-five per cent of the savings achieved and could be used by the organization for "any of its purposes," 
including the elimination of deductibles and copayments and the provision of additional services not covered under the bill. ${ }^{54}$

In assessing the probable performance of $\mathrm{CHSO}$, it can be seen that the utilization bonus, if applied to giving additional benefits or to beautifying the clinic's surroundings or to membership recruitment, could lead to increased enrollments. To the extent increased enrollments would permit realization of further efficiencies and hence higher salaries, the physicians involved in formulating CHSO policies might be inclined to invest in such growth, and over-all (though perhaps gradual) growth of the CHSO sector could reasonably be anticipated. The bonus and the benefits of other efficiencies of course represent a "profit" which, in view of the requirement of nonprofit status, may not be distributed to investors but may be reflected in physician and administrator salaries. It does not appear that these would be controlled, although distribution of the utilization bonus directly to the medical staff might be prevented under the vague requirements noted above.

2. "Ameriplan"

This is the designation of a plan approved by the American Hospital Association (AHA) as its proposed solution to the nation's health care needs. ${ }^{65}$ The plan would be similar to the administration's in providing for the aged through the Social Security mechanism and for the poor and near-poor through a federal program. Other persons would purchase basic protection-the "standard benefits package"from prepayment plans or private insurance companies. As a distinctive feature, a two-part package covering "health maintenance and catastrophic illness benefits" would be provided for all persons through a federal program covering the poor and near-poor from general federal revenues and all others through a tax collected though the Social Security system.

Entitlement to the "health maintenance and catastrophic illness benefits package" would be conditioned on a consumer's previous purchase of the "standard benefits package" and registration with a "Health Care Corporation" (HCC). The HCC is the cornerstone of the plan and its nearest counterpart to an HMO. It will be paid on a capitation basis to provide the federally financed "health maintenance" benefits but will be paid for all other services at rates regulated prospectively by state health commissions. Forswearing capitation for these remaining services because of "technical difficulties" and the HCC's undue exposure to financial risk, it nevertheless looks ahead to "the development of total capitation payment."

\footnotetext{
5t Kennedy-Griffiths bill $\$ \S 87$ (d)-(e).

er American Hospital Ass'n, Amertplan-A Proposal for the Delivery and Financino of Healtith Services in the United States (Report of a Special Committee on the Provision of Health Services, 1970) [hereinafter cited as AMceriplan]. The plan is said to have been modeled on Health, Inc., of Boston, which is described as a "primary responsibility" organization. Note, supra note 7, at 919.

${ }^{50}$ AmerIplan, supra note 55, at 45. It has been said of Health, Inc. (See note 55 stpra), that "[W]hile it offers fee-for-service on the theory that most people are unfamiliar with anything else, it will encourage consumers to contract with the plan for prepaid comprehensive care." Note, stupra note 7, at 919.
} 
could make any arrangement it wished with actual providers, employing physicians on a salary, capitation, or fee-for-service basis. The state health commission would license HCCs and establish their primary service areas. Such service areas would be exclusive unless more than one such corporation could establish its capacity to "coordinate needed services effectively" within the area. ${ }^{57}$ The HCC would have to demonstrate its ability to care for all persons in its service area who might voluntarily register during regular periods of open registration and would be expected to attempt to recruit an assigned list of potential registrants. It could, however, also accept registrants from outside its primary area to fill its quota.

Each HCC would be directly responsible for the delivery of health care to its registrants, either through its own facility or through contracts with other providers. It would be required to render emergency care to nonregistrants and could provide other services to nonregistrants to the extent that the quality and adequacy of services to registrants would not be jeopardized. The HCC would also be responsible for monitoring the quality of care and for securing the participation of physicians in management and of consumers in policy making. Incentives for rendering preventive care and efficient utilization would be supplied by means of bonuses of the kind described in connection with the Kennedy-Griffiths bill. The HCC would be responsible for the competence of its personnel, and the proposal recommends that the present manpower licensure system be phased out.

By withholding important federal benefits from persons not registered with an HCC, Ameriplan would effectively compel such registration. This requirement would make the Health Care Corporation not merely an available alternative but practically the sole vehicle through which health care could be obtained. Consumers would have no opportunity, or at least no encouragement, to purchase HMOtype care, and individual HCCs would effectively monopolize most markets, with exclusionary regulation apparently contemplated through the system of primary service areas. Each HCC would probably be dominated by physicians dedicated to the preservation of lucrative fee-for-service medicine and would therefore be operated merely as a fiscal agent with that purpose in view. Unless this orientation was reasonably guaranteed, physicians would not accept the plan, since a monopsonistic purchasing agent not under their control might be capable of greatly depressing their incomes.

\section{3. "Medicredit"}

The proposed Health Care Insurance Act of I97I, introduced in the Ninetysecond Congress as H.R. r460 and S. 987, is the so-called "Medicredit" proposal of the American Medical Association (AMA). The plan is designed to encourage and facilitate the voluntary purchase of basic and catastrophic health insurance coverage. For persons with no income or income so low as to produce no income tax liability for the base year, the federal government would issue vouchers for full payment for

\footnotetext{
${ }^{67}$ AMeriplan, supra note 55, at 20.
} 
the coverage specified by the act. Persons with income tax liability would likewise have the portion of the premium attributable to catastrophic coverage paid in full by the government. Tax credits scaled to the amount of tax liability and in some cases part-payment vouchers from the government would be available for application toward the premium for basic coverage.

The principal thrust of the proposal is thus concerned with the financing of insurance protection, although necessary components of the benefit packages are specified and carriers would have to meet qualifications established by state insurance departments pursuant to minimum federal standards. The crucial problem of the system whereby care is actually rendered is not addressed other than by a proscription against federal supervision or control over the practice of medicine, and apparently no federal encouragement of change in delivery methods is contemplated. The AMA's preference for maintaining the many existing barriers against HMO formation is manifest.

\section{III}

\section{A Market-Ortented Heatth Care System}

The administration's proposals stand out among the competing plans in allowing the market a more substantial role in allocating resources, stimulating efficiencies, and controlling utilization of the system. Other proposals, particularly KennedyGriffiths, would introduce financial incentives here and there to induce physicians and administrators to do what the proponents think they should do, but otherwise would abjure the market and substitute comprehensive economic regulation in its place. The AMA plan would perpetuate the status quo with respect to the organization of the health care system and, while ostensibly relying on the market, would in fact continue in effect the restraints that have so far precluded a fair test of the HMO's attractiveness to consumers. The AHA Ameriplan, by forcing everyone into large Health Care Corporations, would create monopolistic tendencies in the marketplace so that market forces would have little opportunity to perform their customary functions, necessitating comprehensive regulation.

It is my thesis that a market-oriented system-by which I certainly do not mean laissez-faire or contemplate such drastic measures as termination of physician licensure-would be preferable to the alternatives so far presented. But the market cannot function until existing legislative and professional restraints in health care are lifted, until regulatory efforts are redirected to stimulate and guide, rather than to displace or repress, market forces, and until all the American people are provided with the means of entering the health care marketplace. The administration's proposals, while requiring some substantial modifications and clarifications, have the potential for creating conditions under which market forces could adequately perform their usual allocative and incentive functions and vastly improve the performance of the health care industry. 
A. The Possibility of Price Controls to Minimize the Impact of Increased Health Insurance

Prompt government action to make health care available to all Americans is, of course, desirable as a long overdue recognition of a basic civil right and public responsibility. But a sudden influx of previously deprived users into the system would necessarily stimulate the market to ration the limited available resources by attaching still higher prices to them. This result would appeal only to the sellers of these services, and Congress could understandably refuse to appropriate funds to provide care for the poor if, as has happened with Medicare, a large part of the public's investment would be lost in higher prices. ${ }^{58}$ Price controls may therefore appear practically imperative if government is not to see providers enriched largely at its expense and care still denied to those whose circumstances, even with a government supplement for health care, would not permit them to bid effectively in the market against the more affluent.

The problem with price controls is that, if prices are not allowed to perform their usual rationing function, some other means of rationing must be found. The system has long used queuing-waiting time-to limit consumption in public clinics, and this could be expected to increase throughout the system. Physicians would be overburdened and would probably, in keeping with either a sense of professional obligation or much stricter utilization controls, tend to ration their time in accordance with direness of need, turning away the insignificant, self-limiting complaints. Quality of care might be more seriously jeopardized as less ethical physicians, of the kind who profited so handsomely from Medicaid, ${ }^{59}$ shortened the time given to treating substantial complaints, without reducing their bills. Whether a black market in health services could get established on a broad scale is perhaps doubtful, but the temptation to resort to bribery would certainly be present.

These possibilities are far from palatable, but the alternatives are perhaps no more attractive. The shortage of resources and the consequent need for a nonprice rationing system would be equally great under the Kennedy-Griffiths national health insurance proposal, which would, however, not provide adequate incentives for attracting private talents and capital into the service of the nation's health, thereby prolonging the shortage and the need for rationing services. The hope, of course, is that rapid HMO growth would introduce new resources, efficiencies, and checks on utilization that would render short-lived any shortage created by new federal programs of health care financing. One cannot of course make reliable predictions in this regard, but the expectation seems not unrealistic.

My preference for a "market-oriented system" of health care delivery does not

\footnotetext{
${ }^{88}$ One estimate is that approximately half of the additional funds poured into medical care between Ig66 and 1969 was swallowed up in price increases. Cooper, Medical Care Outlays for Aged and Nonaged Persons, 1966-1969, Soc. SEc. BuLL., July 1970, at 3, Ir.

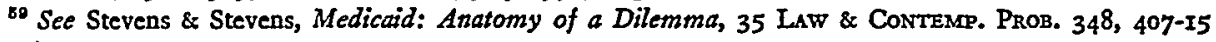
(1970).
} 
necessarily exclude price controls designed to minimize the impact of universal health insurance. The question reduces to which rationing system is more appealing, all things considered, and this is ultimately a political decision. One can appreciate Congress's reluctance to repeat the Medicare-Medicaid experience with the unpredictable magnitude of price increases attributable to bidding for scarce resources. ${ }^{00}$ Moreover, I have a sense that the disadvantaged would come out worse, at a higher price to taxpayers, if prices are not controlled and that a system of queuing and utilization controls would steer medical resources to their best uses more reliably than an auction system would. Furthermore, Congress may find it politically easier to impose an added burden in finding health care on middle-class voters than to vote the appropriations and the taxes necessary to finance new health services under conditions of shortage. In any event, without venturing a final opinion on the ultimate issue of the need for or desirability of price controls, I can advance several conditions that, under my preference for primary reliance on market forces, should be met by any controls that might be introduced.

First, they should be temporary. There is as yet no reason for making health care the first industry brought by Congress under comprehensive economic regulation since the Depression era. Indeed, the experience with existing schemes of such regulation is anything but reassuring about the ability of regulation to cope with even relatively easy problems, let alone the incredibly complex job of costing individual medical procedures, eliminating price discrimination, valuing the services of individual practitioners, and maintaining the quality of service under a system of "public utility" medicine. ${ }^{.1}$ The basis for my confidence concerning the market's ability to take over the bulk of the regulatory job once the supply-demand imbalance is roughly restored is set forth at length later on.

Second, price controls should be ceilings only-with lower competitive charges encouraged-and should be in the nature merely of a freeze on all but cost-related increases. In addition to being the simplest and, in the short run, the fairest regulatory mechanism, a price freeze contemplates and lends itself to eventual lifting of the controls and restoration of a market regime. The pending Medicare amendments would use existing prices as a basis for establishing price ceilings, ${ }^{62}$ and a temporary freeze might be easily modeled on those provisions.

Third, no direct price controls should be imposed on HMOs except for an across-the-board limit of the kind proposed for government payments to HMOs in the Medicare amendments, namely a premium ceiling of ninety-five per cent of the actuarially determined cost of caring for the HMO's patient population in the fee-forservice sector. ${ }^{63}$ Since prices in the latter would be temporarily controlled, the

\footnotetext{
${ }^{60}$ See note 58 supra. On the estimation problems, see Stevens \& Stevens, stupra note 59, at 378-90. Conceivably the bad experience provided data that would facilitate better estimates in the future.

o1 Some of the problems of introducing comprehensive regulation of hospital charges are indicated in the text accompanying notes 128-39 infra. The same arguments would apply a fortiori to physicians' fees and HMO charges.

${ }^{62}$ H.R. I, $\$ 224$. See H.R. Rep. No. 9I-I096, 9Ist Cong., 2d Sess. 35-38 (1970).

${ }^{63}$ See text accompanying note 34 supra.
} 
danger of HMO profiteering would be substantially eliminated, and indeed the public would be assured of at least a five per cent saving over the controlled price to the extent it elected HMO-provided care. A particularly attractive by-product of leaving $\mathrm{HMOs}$ free to earn profits within this liberal constraint might be substantially increased attractiveness to physicians of HMO employment as providing both a relative haven from government control and a better opportunity for increasing earnings. Such increased incentives for HMO organization under a system of frozen fee-for-service prices would speed the realization of efficiencies and the needed reallocation of resources.

\section{B. Has the Market Already Failed?}

My advocacy of a market-oriented system will seem strange to those who believe that the present health care crisis itself reflects a colossal market failure. ${ }^{64} \mathrm{~A}$ word to clarify this point may therefore be in order.

The medical profession's remarkable success in repressing market forces has been amply demonstrated elsewhere. ${ }^{65}$ The American Medical Association's domination of the licensure system and particularly of the medical schools since the Flexner Report $^{60}$ has limited the number of physicians and raised physician incomes. ${ }^{67}$ Emulating the physicians' example, other health professions have likewise obtained exclusionary licensing legislation, which has further raised costs by restricting the supply and mobility of health manpower and the opportunities for achieving efficiencies in the rendering of care. ${ }^{68}$ In the name of medical "ethics," prepaid group practice was successfully limited in its impact, often by restrictive state legislation, and generally prevented from competing on an equal footing with fee-for-service providers. $^{69}$ A combination of "ethics," customs of the trade, and pressures of varying degrees of subtlety have repressed even the vestiges of price competition in

'L This belief is widely shared and indeed is a dominant assumption in the debate. See, e.g., Letter to the Editor from William J. Taylor, N.Y. Times, Apr. I6, I971, at 36, col. 3; Falk, National Health Insurance: A Review of Policies and Proposals, in this symposium, p. 669, 693.

${ }^{\circ 5}$ See generally E. Rayack, Professional. Power and American Medicine (I967); Kessel, The A.M.A. and the Supply of Physicians, 35 LAw \& Contemp. ProB. 267 (1970); Rayack, Restrictive Practices of Organized Medicine, I3 Antmtrust Bul.. 659 (1968); Kessel, Price Discrimination in Medicine, I J. Law \& Econ. 20 (1958). Note, supra note 7, at 954-60; Comment, The American Medical Association: Power, Purpose, and Politics in Organized Medicine, 63 YALE L.J. 937 (r954).

${ }^{\circ}$ A. Flexner, Medical Edocation in the United States and Canada (igro).

${ }^{67}$ See Kessel, The A.M.A. and the Supply of Physicans, 35 LAw \& Contemp. Prob. 267 (1970); Carnegie Commission on Higher Education, Report on Medical Education (r970).

There has been much debate as to whether there is truly a physician shortage, some arguing that resources are simply badly distributed. Compare R. Fein, The Doctor Shortage: An Economic Diagsosis (1967), with E. Ginzberg \& M. Osrow, MEN, Money, AND MEdrcine (1969), and McNerney, Why Does Medical Care Cost So Much?, 282 N. ENG. J. MED. I458 (1970). Of course, since there is no easy means of redistributing physicians, the debate seems academic. Improvement of money-making opportunities in areas of shortage would seem to be only one step in luring physicians to those places; educational subsidies to area residents also seem promising.

${ }^{68}$ See Forgotson, Bradley \& Ballenger, Health Services for the Poor-The Manpower Problems, I970 Wisc. L. REv. 756. On licensure generally, see M. Friedman, Capitalism and Freedom ch. 9 (1962); L. Friedman, Freedom of Contract and Occupational Licensing r890-19ro: A Legal and Social Study, 53 Calif. L. Rev. 487 (1965).

${ }^{69}$ See Note, supra note 7 , at 954-75; Comment, supra note 65, at 976-96. 
the delivery of physicians' services. ${ }^{70}$ Under these conditions, the market has never had a chance.

It is ironic that ethics and the quality of care have been so successfully advanced as justifications for restrictive legislation and professionally authorized restraints of trade. Whether this was always wholly a pretext on the part of the proponents of restrictive policies is of course doubtful, but the total effect was a raising of the cost of care and the incomes of health professionals. It was apparently not recognized that the allegedly high ethical and quality standards resulting from these exclusionary practices would be heavily paid for, not only in cash by paying patients but also in the suffering and lives of those who were effectively denied care. One regrettable but still recurring theme in medicine is the continuing willingness of many people, most of them prompted only by professional conscientiousness and a real concern for patient welfare, in effect to deny care to large groups in the society on the ground that such care, if provided, might not be good enough by the standards of middle-class medicine. For example, this tendency to ignore the need for expanding quantity, even at the risk of some sacrifice in average quality, is manifested in the frequently encountered hesitation about permitting physicians freely to delegate functions, ${ }^{71}$ about scrapping most licensure requirements, and-particularly relevant here-about allowing HMOs and other health care providers to return a profit to their nonphysician organizers. The point is also generally relevant to the objections to reliance on market forces to see that health care gets delivered: the objections are basically quibbles about whether quality might be slightly impaired, while the cost in undelivered care has been and can continue to be high.

The general obeisance to the medical profession's professions of ethical concerns where their economic interests were at least equally affected ${ }^{72}$ is matched by this language from the Supreme Court's 1952 decision in United States v. Oregon State Medical Society, ${ }^{73}$ an antitrust action brought unsuccessfully by the government to vindicate the position of health care prepayment plans in Oregon against certain alleged activities of the medical society:

We might observe in passing, however, that there are ethical considerations where the historic direct relationship between patient and physician is involved which are quite different than the usual considerations prevailing in ordinary commercial matters. This Court has recognized that forms of competition usual in the business world may be demoralizing to the ethical standards of a profession. ${ }^{74}$

\footnotetext{
${ }^{70}$ Kessel, Price Discrimination in Medicine, I J. LAw \& EcoN. 20, 42-5I (1958).

${ }^{71}$ See Havighurst, Licenstre and Its Alternatives, in Procendings of the 30 ANnund Duke CoNperence on Physician's Assistants 121, 125-26 (1970).

${ }^{2}$ One citizen who has not been taken in by the profession's ethical pretensions is the typesetter responsible for the following in a recent galley proof: "The American Medical Association's Principles of Medical Ethics are ... 'not laws but standards by which a physician may determine the proprietary [sic] of his conduct ...." Cf. Note, supra note 7 , at 955, quoting AMA, Principles of Medical Etrmes. ${ }^{73} 343$ U.S. 326 (1952). See also text accompanying notes $160-63$ infra.

${ }^{74} 343$ U.S. at 336 . It was noted that the trial judge, in deciding against the government, had engaged in "irrelevant soliloquies on socialized medicine, socialized law, and the like ...." Id. at 331; see
} 
Since this view has had many adherents in the state legislatures and in attorneygeneral offices as well as in the courts, the medical profession has been largely selfregulated by the medical societies and by the doctor-run state boards of medical examiners, who are legally charged with policing the profession's ethics. Any student of antitrust knows that a self-regulatory regime organized for the prevention of "unethical business practices" is likely to be a device to suppress competition. In most other areas the courts have rejected pleas that a particular industry is a "special case" and have enforced the antitrust laws to restore a competitive regime. ${ }^{75}$ With respect to medicine, however, neither courts nor legislatures were so perspicacious, and the market was denied its accustomed role.

The greatest failure of the health care system has of course been in delivering care to the poor. Some of the responsibility here is government's, for failing to recognize the need and to employ its powers of wealth redistribution to make decent health care financially available to all citizens. Government largely surrendered its responsibility to the medical profession, which undertook to provide charity services in return for noninterference. It was thus the profession's failure properly to honor its commitment that produced the crisis, for if the profession had been meeting the needs, there would have been either no need for Medicare and Medicaid or no supply-demand imbalance when they were enacted. Nevertheless, government's abdication of its wealth redistribution function in favor of the medical profession and private charity seems the ultimate cause of the system's failure. The market was implicated only to the extent that it distributes the rewards of the society unequally, a circumstance that is to some extent within the power of government to change. Fortunately, Congress seems about to act to bring about a long overdue rectification of wealth discrepancies with respect to health care. ${ }^{76}$

95 F. Supp. r03, 109-ro (D. Ore. I950). This juxtaposition of the two professions' interests should indicate that lawyers, who have reasonably effective trade associations of their own, are not conspicuously well qualified to pass, either as legislators or as judges, on the proper role of the market in the delivery of professional services. The judiciary's somewhat more enlightened treatment of the legal profession's analogous activities deserves mention, however. Cf. Brotherhood of R.R. Trainmen v. Virginia ex rel. Virginia State Bar, 377 U.S. I (1964).

${ }_{76}$ E.g., United States v. National Ass'n of Real Estate Boards, 339 U.S. 485 (1950); Fashion Originators' Guild of America, Inc. v. FTC, 3 I2 U.S. 457 (I94I); Sugar Institute, Inc. v. United States, 297 U.S. 553 (1936); Northern Calif. Pharmaceutical Ass'n v. United States, 306 F.2d 379 ( 9 th Cir.), cert. denied, $37 x$ U.S. 862 (Ig62); United States v. Utah Phamaceutical Ass'n, 201 F. Supp. 29 (D. Utah), aff'd per curiam, 37 I U.S. 24 (I962).

${ }^{70}$ The basis for treating health care as a specific subject for wealth redistribution-a "merit good"is complex. See generally R. Musgrave, Theory of Public Finance (x959). To some extent there has always been a societal commitment to render care to persons unable to pay, and the question is in large part merely one of how to finance this service and how better to deliver on a moral commitment long since made but not conspicuously well honored. Further, better health care for the poor may generate externalities benefiting the public generally, primarily by helping to break the poverty cycle and produce more self-supporting citizens. But see Lave \& Lave, Medical Care and Its Delivery: An Economic Appraisal, 35 LAw \& Contemp. Pros. 252, 255 (I970). The harder questions relate to the limits of the commitment and particularly to their implementation. For example, who tells the indigent patient that his benefits are exhausted and that he is asked to leave the hospital? At this point, the burden, which the state escapes by impersonally declaring a dollar limit on the benefits it will pay, falls on the providers of care as a moral matter. While some providers are the beneficiaries of direct public sub- 
In the light of the foregoing it cannot be argued that the market's failure accounts for the present state of affairs. In attaching blame, if that is important, it seems unfair to expect the organized medical profession to have acted against its self-interest. Rather, the fault lies with well-meaning policy makers who failed to make the profession's trade-restraining activities unlawful and indeed enacted many trade restraints into positive law. The mystique surrounding medical care and the "physician-patient relation" served to validate the profession's assertions of high ethical and quality standards and led many well-meaning persons into becoming, in Kessel's phrase borrowed from the I930s, "dupes of the interests."77 It is thus ironic in a purportedly free-enterprise system that, where radical reforms of the health care delivery system are being proposed on every side, the most radical reform possible might be restoration of a free market. This, coupled with supplementary regulation and a carefully designed system of universal health insurance, could be expected to produce swift and dramatic but orderly change. ${ }^{78}$

\section{Some Shortcomings of the Market for Health Services ${ }^{70}$}

Even under the best of circumstances, the market for medical care could never function as smoothly as might an unrestrained market for services like those of, say, a barber. For one thing, consumers are not always capable of accurately evaluating the doctor's skill. Moreover, they are not in a position to know what services are and are not needed, and they are consequently forced to delegate numerous economically important decisions to the physician. Finally, these decisions of the physician as well as the consumer's own may often be influenced by the presence of health insurance, which largely removes the cost constraint on the consumption of health services.

We have already seen how HMOs can help to overcome the problem of the consumer's ignorance as to when he is receiving excessive care as well as some of the distorting effects of third-party payment, but, again because of consumer ignorance, HMOs may feature tendencies of the opposite kind, toward denial of needed care as a result of excessive cost-consciousness on the provider's part. The further problem of consumer inability to judge the quality of services received would also still exist to some extent in an HMO-dominated marketplace, and some fee-for-service providers would continue to operate with their bills paid in large part by health insurance carriers, thus perpetuating for consumers choosing that mode of care

sidies which enable them to absorb some such costs, the system is anything but rational. Moreover, it seems to defy rationalization that would satisfy both economic and ethical concerns. Clearly there remains a large role for charity even in a health care system dominated by government.

${ }^{77}$ Kessel, supra note 67 , at 268 .

${ }^{78}$ See T. LOWn, ThE END OF LIBERALISM 59 (1969), which, in ranking public and private policies according to their relative likelihood to produce change, includes "Social Security programs based on graduated income tax," "real antitrust," and "competitive business" near the top of the list.

${ }^{70}$ See generally H. Krarman, The Economics of HenLth (1965); Arrow, Uncertainty and the Welfare Economics of Medical Care, 53 AM. Ecos. Rev. 94I (1963); Fuchs, The Contribution of Health Services to the American Economy, 44 Mrlank Memorial Fund Q., pt. 2, no. 4, at 65 (rg66); Lave \& Lave, supra note 76 , at 252. 
some of the market irregularities that have contributed to the present problem. Nevertheless, significant as these departures from the competitive model are, consumers of medical care are probably not much worse off than consumers of many other technical services. For example, I feel about as competent to deal with doctors as I do to instruct an auto mechanic. And in either case my opportunity for repeated dealings and for obtaining confirming opinions from other consumers permits me more secure judgments than I can exercise in choosing a one-time supplier or serviceman from the "yellow pages."

Although many goods and services are bought and sold under substantially less than ideal competitive circumstances, the government has not always intervened. More important, it has often limited its intervention to a strengthening of market forces or to the introduction of some requirement thought to be inadequately enforced either by the market or by apprehensions about potential tort liability or other legal consequences. ${ }^{80}$ Therefore, the first question with respect to health care is whether acceptable performance could be expected of the market mechanism if policies were tailored in a conscious attempt to achieve it. If doubt persists, then a regulatory alternative must be considered, but, because regulatory schemes, like economic analysis, are also based on faulty assumptions-about regulators' motivations, resources, and competence and about the tractability of problems-, they should be evaluated with as much skepticism as is the market's behavior. Unfortunately, a comparative inquiry into the relative imperfections of a market-oriented solution to the health care crisis on the one hand and a comprehensive regulatory solution on the other is beyond the scope of this paper. But, while I have confined myself to showing how the market could be expected to function under policies designed to improve its performance, I must say that I have greater confidence in both our ability to predict these matters and the attractiveness of the outcome (even with some deviation from expectations) than I have in our ability to design an appealing regulatory and administrative scheme. I am also impressed by the difficulty of reversing our direction once we are committed to the latter course.

\section{How a Market-Oriented System Might Work}

Taking the administration's proposals as a starting point, it is possible to speculate about the total performance of a health care market which has been freed of pernicious restraints and which is instead regulated in accordance with wiser policies. It will be appropriate after offering this hopeful description to deal with some specific issues that may be raised and to indicate the policies necessary to realize the hopes expressed and to minimize any fears.

\footnotetext{
${ }^{80}$ For example, the automobile industry is widely thought to be less than highly competitive, due in large part to there being only four domestic manufacturers. Nevertheless, when safety issues were raised, it was thought sufficient to regulate only the industry's safety equipment, since the market and the legal system appeared not to supply sufficient incentives to cause either consumers or producers to value safety highly. See National Traffic and Motor Vehicle Safety Act of 1966, Pub. L. No. 89-563, 80 Stat. 7I8, I5 U.S.C. $\$ \S 1381-1425$ (Supp. III, I968).
} 
In these prognostications I have assumed that HMOs will prove capable of offering significantly lower prices for coverage than do health insurers. The assumption is reasonable, since, whether due to inherent advantages or not, HMOs do appear to feature greater organizational efficiency and effective discouragement of overutilization. Of course, the HMO may gain further advantages by skimping on needed care or by attracting less intensive users of the system-persons less put off by the difficulty of getting the HMO to give attention to minor, self-limiting complaints; ${ }^{81}$ if these are real possibilities, the HMO's competitive effectiveness may be somewhat greater than is warranted by the quality of its product, placing fee-for-service medicine at a slightly unfair competitive disadvantage. The corner-cutting issue is discussed at length shortly and is not deemed an insurmountable problem. The further possibility that consumers with low use propensities will be attracted seems not to be a valid basis for criticism since there is room for a system that is less responsive to insignificant complaints; moreover, lower use propensities should entitle subscribers to pay less for coverage than they do under health insurance, where they cannot select themselves out and are consequently exploited by those who overuse the system. In any event, whatever the source of HMOs' advantages, their presence in the marketplace seems likely to enforce efficiency and less discriminatory pricing in the fee-for-service sector with an effectiveness that no other system of social control could easily match.

HMOs could reasonably be expected to spring up in large numbers in a market freed of physician-sponsored restraints. Availability of federal funding would be a factor, though a small one, in such growth. More significant would be the attractiveness to private investors of the potential profits, which could be earned even with rates significantly below health insurance premiums for the same coverage. A requirement that employers make a choice among HMO alternatives available to all employees could open up tremendous competitive opportunities, and consumers, offered a lower-cost alternative and educated by advertising for the first time, could be expected to respond to that inducement as long as other factors did not reduce the attractiveness of HMO-type care. The market opportunities opened up would not be merely short-run phenomena since the federal financing commitment would promise permanent stability. Moreover, the health industry is one in which high rates of return are likely to prevail generally due to consumer willingness to pay for psychic satisfactions and not to make price the main consideration. In economic terms, the possibilities for differentiating "products" and exploiting consumer loyalties would seem to be great, and these factors, coupled with the likely prevalence in health care of large amounts of "consumer surplus"- the excess of each consumer's valuation of his benefits and satisfactions over the price he pays for them-, would allow each seller some pricing freedom. The resulting high profit potential could be counted on quickly to lure resources into the health care industry.

\footnotetext{
${ }^{81}$ See note 24 supra.
} 
Offsetting the high profit potential would be a high degree of risk. Consumers of health services are apt to be volatile, transferring their patronage whenever their confidence in the provider wavers. ${ }^{82}$ The marketplace envisioned would offer a sufficient number of both HMO and fee-for-service alternatives and sufficient information concerning each that providers would be faced with fluctuating profits. Once the supply catches up with the demand, high profits would be assured only so long as the provider succeeded in delivering a combination of cost, quality, convenience, and reassurance that a sufficient number of consumers desires.

One possible deterrent to the entry of profit-seeking enterprises would be the presence of nonprofit providers with whom it would be necessary to compete. These enterprises would be accorded certain tax advantages, would enjoy a preference among many consumers, and would have no need to show net earnings at the end of the year, making them formidable competitors. Therefore, rather than competing head-to-head for the customers of an existing nonprofit provider, profit-seeking enterprises would usually prefer to enter those markets, such as the inner city, where consumers were newly supplied with the means for purchasing care and where existing resources were inadequate to meet the new demand. ${ }^{83}$ Nevertheless, nonprofit providers may often be so inefficient or may have priced their services so discriminatorily ${ }^{84}$ as to invite entry. The competition thus offered by profit-seeking new entrants should be deemed healthy because it would compel efficiency and the elimination of the practice of pricing in accordance with ability to pay.

Greater problems may lie in the lack of managerial talents necessary to create $\mathrm{HMOs}^{85}$ and in the lack of physicians' interest in accepting employment with them. ${ }^{86}$ Nevertheless, no greater stimulus to the creation of the needed expertise could be imagined than the profit potential offered by the market, and businesses interested in diversifying into HMO operation would invest heavily in the necessary training.

${ }^{82}$ There is no inconsistency with the earlier reference to consumer loyalty. Volatility would occur at the margin and only when confidence was lost. Otherwise consumers would be disinclined to accept services elsewhere even at lower cost. The incentive to maintain consumer confidence would be very great.

${ }^{\mathbf{8 3}}$ See Steinwald \& Neuhauser, The Role of the Proprietary Hospital, in this symposium, p. 817.

${ }^{84}$ Discriminatory pricing takes several forms. One is pricing some services below cost and making up the difference through higher prices on other services. See id. at 832-34, discussing "cream-skimming," the name given to the proprietary hospital's alleged tendency to provide only the profitable services and to leave the unremunerative services to be provided by voluntary hospitals. Because benefit packages will be prescribed, HMOs will not be able to pick and choose the services they will cover, but in deciding what services to provide in-house they will have an opportunity to practice "cream-skimming" of this kind. The tendency will be to cause hospitals to price their various services more in line with costs.

Another kind of diseriminatory pricing is the tendency to price in accordance with willingness and ability to pay. See notes I5I \& I59 infra. To the extent HMOs offer a flat rate to all subscribers this discrimination would be eliminated. The only troublesome possibility might be a tendency of HMOs to neglect to recruit poor persons, even those supported under a federal insurance system, because of the expectation of unpaid bills for deductibles and coinsurance and for benefits in excess of those contracted for. See text accompanying notes $235-36$ infra. The burden of caring for these persons would then fall on the voluntary sector, perhaps placing it at a competitive disadvantage.

${ }^{85}$ Note, supra note 7 , at 953-54.

${ }^{80} \mathrm{Id}$. at $946-48$. 
Physicians, too, would respond to a substantial profit potential held out by the market. Particularly if fees in the fee-for-service sector were controlled to prevent the bidding up of prices for health services, doctors might find the HMO sector more attractive from an earnings standpoint. The potential efficiency gains in HMO operation could be made to redound very largely to the physicians' personal benefit, and they could be expected to move in significant numbers toward those areas where potential gains were greatest.

If a ceiling were imposed on fee-for-service charges, HMOs might soon be established in sufficient numbers to compete effectively with each other and with fee-forservice medicine, perhaps rather quickly driving charges in some areas well below the ceiling. Because competition would develop at different rates in different areas, the greater profit potentials remaining in areas not yet penetrated by HMOs would quickly lead to nationwide HMO establishment. The market would eventually establish the appropriate spread between the HMO's charge and the higher cost of health insurance applicable to the purchase of fee-for-service care; this spread-which could be denominated a "premium" if the word were not already being used in its insurance sense-would probably be substantially greater than the five per cent discount from fee-for-service cost contemplated in the administration's proposed Medicare amendments. Thus, if HMO charges should stabilize in the neighborhood of, say, eighty-five per cent of the current fee-for-service cost of caring for the same population, fee-for-service charges in the market area served by HMOs might fall to, say, ninety-four per cent of their present level if consumers found fee-for-service care only that much more attractive than HMO enrollment. In these circumstances, health insurers, faced with the shrinkage and possible disappearance of the fee-forservice sector, would tend to be stricter about utilization and the level of charges, ultimately driving costs down to levels where fee-for-service care would coexist in some measure with HMOs.

Smaller HMOs, lacking in-house capacity to render hospital and some specialized physician services, would purchase these in the fee-for-service sector, introducing a knowledgeable purchaser who could control utilization and shop with regard to price. Conscientious smaller HMOs, in serving their customers in this important middleman capacity, would hire the best specialists or highest-cost hospitals only for the most difficult cases; in more routine matters they would use less expensive providers, thereby helping the market to perform its important function of allocating scarce health resources to their best uses. (If such informed purchasing became widespread, the incomes of the best specialists might increase while the incomes of mediocre practitioners fell, improving currently weak incentives for achieving and preserving competence.) Patrons of such smaller HMOs, having access to the best specialists in time of greatest need, would possess an advantage denied subscribers to the larger, "closed-panel" plans. In a competitive market, less conscientious HMOs of this smaller variety which skimped too much in search of 
economies in the purchase of specialist and hospital care would lose subscribers, and serious cases of such overeconomizing would be subject to regulatory control.

The prices charged by different HMOs would vary, of course, even in the same market area. Because HMOs would be of different sizes and would have different reputations for quality and convenience and other things that consumers value, they would be able to price their service differently. Smaller HMOs, for example, would probably be less efficient but might provide more personalized and responsive care, enabling them to survive even at a substantially higher price than was charged by competing HMOs modeled on the Kaiser plans. By the same token, consumers would have a range of choices even in the HMO sector of the marketplace and would be able to shop for the combination of cost, quality, convenience, and amenities that best suited their particular need and pocketbook. As a further example of what the market, responding to consumer wants, might produce, one can visualize a twoor three-man pediatric HMO, providing well-baby and routine sick care in kind and purchasing orthopedic and other specialized attention in the open market; parents subscribing to such a plan might elect either membership in another HMO or insured-fee-for-service care for themselves.

In such a system, the poor and elderly would directly benefit from the efforts of HMOs to attract paying customers from among the self-supporting classes. As described earlier, this result might flow from use of the modified "proxy-shopping" device whereby a certain proportion of private subscribers would have to be attracted and satisfied before the government would pay the HMO to care for its clients. The HMO's efforts to attract such subscribers could be expected to drive down costs and keep up the quality and convenience of the services offered. In such a system, there could never be an accusation that "second-class" care was being provided to those groups who were sponsored by the government so long as the government was willing to pay the higher premiums-up to the ninety-five per cent ceiling-for Medicare, Medicaid, and FHIP beneficiaries who wished to enroll in smaller, higher-priced HMOs. ${ }^{87}$ In addition to assuring the poor and elderly access to care of high quality, such a policy would increase the number of smaller HMOs that might exist in the marketplace, thereby preserving not only price competition but also competition in the quality and convenience of the care rendered.

\section{E. The Issues Presented}

In trying to picture the results of a properly organized marketplace, I have made some assumptions about market behavior and ignored certain possibilities that must

\footnotetext{
${ }^{87}$ H.R. I and the FHIIP bill would permit payments up to the $95 \%$ amount, thus supporting the higher-priced HMOs. See text accompanying notes 49-5I, supra. The latter would not be able to offer the inducements of greater coverage to the same extent as the larger HMOs but could compete on other grounds. Because the government would presumptively derive a $5 \%$ cost saving on every federal program beneficiary who could be induced to switch from the fee-for-service sector to HMO-type care, it should cultivate HMOs having different characteristics. Concern about relegating the poor and the elderly to the mammoth, superefficient, and impersonal HMOs should argue for the same policy.
} 
now be examined. In the next section, I will take up the possible risks of introducing the profit motive into HMOs and particularly the fear that overeconomizing at the expense of patients' health might be encouraged.

Another controversial question is whether competition and the market can be relied upon to produce acceptable results or whether monopolistic and other anticompetitive forces might subvert the market's functioning. In this connection, the natural monopoly characteristics of the health care market will be considered, together with the risks of medical society exclusionary tactics that might foreclose meaningful HMO development. This discussion leads to a consideration of the antitrust laws as the appropriate means of policing the marketplace against anticompetitive activities. Next, the legislation necessary to overcome the effects of restrictive state laws is suggested, and, finally, a number of supplementary measures to improve market performance are discussed.

If the picture I have drawn of the market's potential performance seems overly hopeful, it is not beyond the range of realistic possibility. To the extent HMO development falls short of my optimistic estimate for reasons unconnected with continued market restraints, nothing would have been lost, and much might have been gained in widening the range of consumer choice and compelling greater efficiencies and utilization controls in the fee-for-service sector. The important thing is to provide the field for a fair market test.

\section{IV}

\section{For-Profit HMOs}

A truly vexing issue raised by a market-oriented system of health care delivery is whether an HMO should be permitted to earn a "profit"-that is, whether it may distribute to investors other than the participating physicians all or a portion of whatever is left of the premiums after the care contracted for has been rendered. The Nixon administration's proposal makes no distinction between nonprofit and for-profit HMOs, whereas the Kennedy-Griffiths bill would not allow a for-profit CHSO to participate as a provider of primary care. ${ }^{88}$ The issue has already provided an occasion for substantial controversy.

In the Ninety-first Congress, the House of Representatives accepted that portion of the administration's proposed Medicare amendments which would bave placed no limit on the profitability of HMOs and would have excluded no HMO from

\footnotetext{
${ }^{88}$ In introducing 5.836 , stspra note 8 , Senator Javits termed it

"an effort to use the whole private enterprise system for the purpose [of providing access to health care], rather than to establish a new system, to use existing carriers, profit and nonprofit, and to encourage, by financing and other means, the development of group practice and other health maintenance organizations."

II7 Cong. REc. SI472 (daily ed. Feb. I8, I97I). Governor Rockefeller's plan for restructuring medical practice in New York State is reportedly similar to the administration's proposals, but it appears that the plan's equivalent of the HMO will be restricted to nonprofit status. See Severo, Rockefeller Asks a Nonprofit Setup for Health Care, N.Y. Times, Apr. I6, I97I, at 1 , col. x.
} 
participation in Medicare solely on the ground that it was organized for profit.89 The Senate Finance Committee, however, took issue with this tolerance of for-profit enterprises in the business of rendering government-financed health care. After noting the administration's strong advocacy of the HMO as a stimulus to cost reduction and quality improvements, the Committee said that it was

concerned that, to the contrary, the health maintenance organization provision could turn out to be an additional area of potential abuse which might have the effect of increasing health care costs-paying a larger profit than is now or should be, paid to these organizations-and decreasing the quality of service available or rendered. ${ }^{90}$

The Committee proposed some rather complex revisions of the House bill to curb profitability ${ }_{3}{ }^{21}$ and its version passed the Senate ${ }^{92}$ only to die at adjournment before the differences between the two bills could be resolved. The debate on this issue is likely to be joined again in the Ninety-second Congress.

\section{A. The Consequences of Excluding For-Profit HMOs}

Before discussing the validity of the objections that may be raised to for-profit HMOs, it is useful to consider what may be at stake in excluding them since it seems to be more than a matter of principle. HMO formation is a costly and risky business, often involving major construction, extensive delays in reaching break-even operations, difficulty in employing medical staff and experienced managers, and problems in attracting sufficient numbers of consumers. Thus, although the potential for profitably delivering low-cost health care of acceptable quality would seem to be considerable, the risk attending any particular initiative in the formation of an HMO would also be substantial. In these circumstances, it is not clear that the voluntary-nonprofit sector or the governmental sector will be capable of generating either the funds or the entrepreneurial talents necessary to make rapid HMO growth a reality.

Without a profit stimulus, most of the HMOs likely to be formed will be sponsored by labor unions, employers, and substantial consumer groups. These plans will have primarily a middle-class base and may lack interest in caring for the persons now deprived of adequate care. ${ }^{93}$ HMOs developed by university medical centers will be community-oriented and dedicated to meeting social needs, but the financial resources of these medical centers are already depleted and are badly needed

\footnotetext{
${ }^{80}$ H.R. I7550, 9rst Cong., 2d Sess. $\$ 239$ (1970).

${ }^{\circ 0}$ S. REP. No. 91-I431, at 132 .

${ }^{01} I d$. at $133-35$.

${ }^{22}$ II6 CoNG. REc. S213I4-46 (daily ed. Dec. 29, 1970).

${ }^{08} \mathrm{~A}$ requirement that the plan accept persons on a first-come, first-served basis will not prevent a plan from locating in areas far from the poor and from emphasizing middle-class persons in its recruitment efforts. The first-come, first-served requirement should not be viewed as in itself a substantial protection for the poor. This can come only by giving HMOs an incentive to seek them out and enroll them because it pays to do so.
} 
to expand the capacity of their medical schools. It is therefore unlikely that many broad-based HMO ventures will be commenced except where massive federal support is supplied. President Nixon has proposed a substantial program of such support. ${ }^{24}$

Of course, physicians themselves may be counted upon to start a number of HMOs using their own capital or capital that they borrow on their own account. Their incentive for doing this is, of course, the hope of improving their own level of earnings by providing a service for which consumers will pay. There is no difference in principle between such investments by physicians and investments by private investors not possessing a license to practice medicine, except that the latter would have to retain or employ physicians on some basis to provide care that they or their HMO service corporation had contracted to provide. Thus, an HMO may be organized as a not-for-profit enterprise without its being so in fact, and to this extent it is misleading to attach great importance to the ownership of the sponsoring corporation without reviewing as well the terms of the contract with the physician group and the salaries or other compensation paid by it to its members. ${ }^{95}$ No one but the AMA could find a reason for wanting to exclude all but physicians from participating in the profits of this potentially lucrative industry. ${ }^{00}$ In any event, physicians, though affluent as a group, cannot be relied upon to supply sufficient funds.

To expect all HMO initiatives to originate with physicians seems clearly unwise. While many doctors are dedicated to social service, there is a limit to what they can do even with lavish federal grants. They are not trained as administrators, and, although the medical schools with which many of them are affiliated could provide administrative skills, the number and location of medical schools impose limits on what can be realistically expected. Doctors have certain preferences about where they want to live and about the kinds of patients they wish to treat. Only exceptional ones are likely to have both the taste and the entrepreneurial skills to initiate an enterprise that would take them into those areas where needs are most acute. Profitseekers are less fastidious or particular, on the other hand, and could be expected to create opportunities for those physicians who might be attracted into deprived-area practice by the right offer but who otherwise would take the path of least resistance to the suburbs. Finally, physicians are also subject to pressures from their colleagues and, for this reason or because of more subtle influences traceable to their education and professional acculturation, might be more inclined to honor the organized profession's preferences as to the nature, scope, and aggressiveness of any HMO they might organize; nonphysician organizers, less inhibited by the "ethical" im-

\footnotetext{
${ }^{04}$ See text accompanying note 27 supra. The Health Policy Advisory Center (Health-PAC) estimates that the President's proposed $\$ 23$ million in grants would pay for setting up HMOs serving $x, 400,000$ people. Health-PAC Bull., Apr. 197r, at 3. In H.R. 56r4, 92d Cong., rst Sess. (r97r), the administration proposes aid for medical-school-based HMOs.

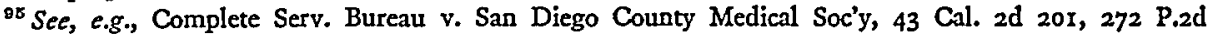
497 (I954). The shakiness of the profit-nonprofit distinction is observed in Note, supra note 7 , at 962.

o See Comantree on Medical Facilities, AMA Council on Medical Service, Report on Physician-Hospital Rezations 4 ( 1964 ) (recording opposition to plans in which "a third party ... derive[s] a profit from payment received for medical services"), quoted in Note, stipra note 7, at 956 .
} 
plications of competition, would be freer to start HMOs and to realize their true potential. The medical profession's inertia seems too great to be counted on alone for the needed initiatives.

There would therefore seem to be some reason to fear that elimination of the profit potential for nonphysician HMO organizers would significantly retard the growth of the HMO sector. ${ }^{97}$ This would mean, quite simply, that needed care would not be rendered and that available efficiencies would not be realized. Even if some arguments against for-profit HMOs seem to have validity, they must be weighed against forfeiture of this potentiality for increased efficiency and for delivering care to people who are now seriously deprived. What may be at stake is whether the HMO will be an occasional experimental curiosity or a serious contender for the role of family doctor for millions of persons at all levels of society in all parts of the country.

Even at best, nonprofit HMOs would probably distribute themselves in such a way that few consumers would have access to more than one, producing a monopolistic situation not conducive to efficiency or to vigorous efforts to please consumers. Moreover, many nonprofit HMOs would be dominated, directly or indirectly, by persons beholden to the organized medical profession and consequently operated responsively to its interests rather than the interests of potential customers. Similarly, university medical centers are often alleged to operate with primary emphasis on their educational and research missions and to fail to hold the interests of their patients foremost. By this token, the performance of university-sponsored HMOs may fall short in important nonscientific respects.

In addition to being slow to develop, nonprofit HMOs are not likely to recruit aggressively both in the middle classes and among the poor. Even under statutory compulsion to engage in such recruitment, there may be a tendency to sign up blue collar employment groups exclusively. The result might be a kind of "public utility" medicine to which, even though the quality of care might be extremely high, the "second-class" image might attach because the conditions under which care was rendered were neglected. Waiting rooms would be crowded, and one could predict an increase in the agitation for consumer control of the delivery of medical care. On the other hand, under the market-oriented system outlined earlier, poor and elderly persons would generally be admitted only to plans that had proved their ability to attract paying patrons in a competitive environment. Health care consumers would indeed have a voice in the care they received, since they would have reasonable alternatives rather than the Hobson's choice of the public utility customer.

Another important dimension of the health care crisis has been the misallocation of capital resources, reflecting excessive or unwise investments undertaken by the

\footnotetext{
${ }^{07}$ The experience of proprietary hospitals, recounted with care by Steinwald \& Neuhauser, supra note 83 , at $818-30$, demonstrates the importance of the profit motive in stimulating prompt response to new demand for health services. They show that proprietaries appear primarily in those places where the voluntary sector has failed to generate needed investment.
} 
voluntary-nonprofit and governmental sectors. ${ }^{98}$ One consequence of the predominantly nonprofit orientation of the industry has been to free decision makers to maximize just about any value they choose, including in too many cases the gratification of administrators' empire-building impulses or physicians' convenience and income derivable from utilization of plant purchased with government or charitable funds. ${ }^{98}$ Thus, a few influential surgeons may be enriched through occasional use of an expensive heart surgery unit which was purchased with charitable funds and is maintained out of monopolistic charges to the hospital's paying patients. ${ }^{100}$ The movement toward "comprehensive health planning" can be seen as an attempt to structure decision making in the nonprofit sectors so as to minimize these tendencies and eliminate the impact of conflicts of interests on the part of decision makers.

Of course no one contends any longer that the pursuit of profits inevitably benefits the public or that profitability equates directly with service of the public interest. Nevertheless, decision makers in profit-making enterprises are more closely disciplined-by the market, a constant if not perfect taskmaster-than are decision makers in the nonprofit sector, and their decisions are more likely to accord with public needs than the decisions we have gotten in the past from managers with the other primary goals. Indeed, the competition of profit-making HMOs, by eliminating discriminatory pricing, will deprive many decision makers in the nonprofit sector of substantial amounts of discretionary funds. This should increase accountability by requiring them to appeal more often to legislatures, bureaucrats, and private benefactors, who, with the help of comprehensive health planning, should be able to impose the cost-benefit discipline so lacking in the past. Although comprehensive health planning does promise some improvement in the handling of discretionary funds earned by monopolistic hospitals, curtailment of the opportunity to earn such funds through pricing of services without regard to cost should also be a goal of public policy. Even assuming that discriminatory pricing may once have served a useful function in making care more widely available, the tax system is a better means of redistributing the society's wealth. Indeed, the need for direct public subsidies for capital construction or other purposes may be largely obviated by a truly adequate system of universal health insurance and federal financing for the poor. Once all consumers have or have been given the ability to pay for health care,

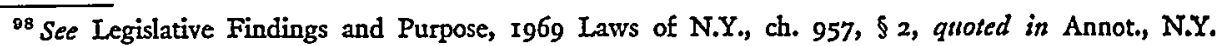
Pub. Health Law $\$ 2803$ (McKinney Supp. I970) ("Continued pressure for unneccssary duplication of facilities and heavy standby commitments for under-utilized services in one area contrast with long waiting lists for admission to facilities in other areas."); Randal, Wasteful Duplication in Our Hospitals, THE REPORTER, Dec. 15, 1966, at 35; Note, Unplanned and Uncoordinated Development of Hospital Facilities-A Need for Legislation, 52 IowA L. REv. Ir87 (1967).

${ }^{\circ 0}$ See Cherkasky, Resources Needed to Meet Effectively Expected Demands for Service, 42 Bun.. N.Y. ACAD. OF MED. 2D SER. I089, IOgI (I966) (reference to "the haphazard manner by which programs and institutions have grown up in response to a local need, a trustee's pride, an administrator's ambition, a doctor's self-interest"').

${ }^{100}$ See id.; H. KLARAsan, supra note 79, at I37. 
the market should be able to attract and allocate resources satisfactorily, and perhaps only remote rural areas would then require special public investment.

The medical profession could be relied upon vigorously to oppose for-profit HMOs on ethical grounds, ${ }^{101}$ and many legislators and policy makers will lend an attentive ear, for an ethical concern is indeed presented. ${ }^{102}$ Nevertheless, physicians' preference for reserving the profits of the industry for themselves alone should not be taken too seriously. Denial of profit participation to outsiders in the past has deprived the industry of the benefit of entrepreneurial input and thus of one important ingredient of creative change. With innovational and managerial talents devalued and excluded by the holders of the industry's purse strings, the system failed to develop organizationally, and, partly as a consequence, the current crisis is one of disorganization and misallocation of human and material resources. The ethical importance of the system's breakdown and failure to deliver needed care would seem to outweigh whatever it is that the profession would have in mind in opposing proprietary influences in HMO formation.

Of course many nonphysician observers doubt the wisdom of market-inspired investment and incentives in a field where consumers are thought to be ignorant about true values and consequently prone to select their provider on irrational grounds. There is, however, no obvious reason to fear that mass merchandising will have anything like the effects in the health care field that Galbraith attributes to it in other areas. ${ }^{103}$ On the other hand, consumer preferences for such things as convenience, personalized care, and certain amenities are entitled to expression, and indeed irrational factors have an important place in medical care, suggesting that

\footnotetext{
${ }^{201}$ See note 96 supra. The medical profession might attempt to bring its concerted opposition to for-profit plans under the recent case of Marjorie Webster Junior College, Inc. v. Middle States Ass'n of Colleges and Secondary Schools, Inc., 432 F.2d 650 (D.C. Cir. I970). In that case, the association refused to accredit the plaintiff college on the sole ground that it was a proprietary institution, without regard to whether it measured up in quality terms. The court of appeals held that the Sherman Act did not apply to activities having "noncommercial" objectives, citing Apex Hosiery Co. v. Leader, 3Io U.S. 469 (1940), and further that judicial interference with private groups would be limited by deference to professional judgment where the apprehended harm was not great. The court added, "we do not think it has been shown to be unreasonable for appellant to conclude that the desire for personal profit might influence educational goals in subtle ways difficult to detect but destructive, in the long run, of [an] atmosphere of academic inquiry ..." 432 F.2d at 657 .

The Marjorie Webster case turns primarily on assumptions about the association's motives and objectivity, which the plaintiff had failed adequately to impugn. In the medical care field, where the profession's economic interests are so near the surface, there would be a much firmer basis for skepticism about any effort to exclude for-profit HMOs, and the result should be different. Neither the profession nor any "blue-ribbon" group within it should be given a chance to justify any flat exclusionary rule, with or without the benefit of judicial deference. The judgment on this question should be made finally by Congress, which alone can appraise the total situation and decide whether the health care system needs the shake-up that for-profit HMOs could provide.

${ }^{102}$ The yielding of a profit to one other than a physician could be considered a fee-splitting arrangement. See AMA, Principles of Medical Etzics \$7 (1957). The existence of a third-party profitmaker may also be thought to impose a risk of interference with "the free and complete exercise of [the physician's] medical judgment and skill." Id. \$6. More broadly, the risks of corner-cutting in patient care are fundamentally an ethical problem.
}

${ }^{108}$ See J. Galbratth, The New Industrial State i99-210 (I967). 
consumers' wishes ought not to be too regularly second-guessed. Moreover, the consumer's highly valued right to take his business elsewhere should not be curtailed without good reason, particularly in a field, unlike telephone service, where personal rapport with and confidence in the provider of the service are so important. Certainly abuses are possible that would require control, but the needed controls can be achieved through regulation of advertising content and through supervision by accrediting agencies and other groups-the HMO offering free tonsillectomies to the children of new subscribers could not long remain in business! In view of the benefits derivable, selective controls on the excesses of the profit seekers should seem sufficient to obviate uneasiness about them.

Whether my high hopes would all be realized is, of course, uncertain. What is clear is that there is a realistic expectation that more health care could be rendered more efficiently and more cheaply to more people sooner if Congress is not too reluctant to allow market forces to function. A high profit potential has traditionally signaled the public's need for new resources, and the question is whether there is sufficient reason to depart from controlled use of the market's allocative function here.

\section{B. The Risks}

Recognizing that there is much to gain, we may now consider what risks would be run if for-profit HMOs were tolerated. In the course of this discussion it will be appropriate to consider the ways in which these risks can be minimized, if not eliminated, in order that the substantial benefits anticipated can be achieved without more than minimal danger. What must be avoided here, as elsewhere in the health care system, is the temptation to indulge fastidiousness about quality and other matters to the extent that some members of the public are denied their right to basic health care altogether.

\section{Overeconomizing}

The most arresting argument against for-profit HMOs is that they will on occasion be tempted to economize at the expense of patients' safety. Generally, of course, it is to the HMO's advantage to cure a patient as quickly as possible in order that his condition not worsen, thereby requiring greater expense to effect a cure. In the vast majority of cases this incentive will work to the combined benefit of the patient and the HMO proprietors, and their interests can be seen as coinciding. The troubling cases are those in which it would be clearly cheaper to let a patient die-death being the ultimate "economy" in these circumstances-rather than undertake expensive efforts to prolong his life, and there would probably also be instances in which the HMO would face the choice of providing a superior treatment that was extremely expensive or a less effective one that was cheaper. The problem in each case is that even with an HMO the incentives are not yet perfectly ordered, and therefore we still cannot rely totally upon the HMO's balancing of costs and benefits 
to produce optimal results; indeed, we would get closer to the desired incentive system if HMOs also provided life insurance coverage and if employers paid bonuses to the HMO for restoring their employees to good health-both extremely attractive possibilities that should be encouraged and perhaps even required by policy makers. Finally, there may be some reason to fear false economies which HMOs, taking too short-run a view, may occasionally practice. ${ }^{104}$

I think there are many reasons to doubt that HMOs will allow their economizing instincts to jeopardize life unduly or to dictate the choice of treatment. Moreover, I find a variety of substantial controls that already exist or could be introduced to prevent this from occurring.

Whether overeconomizing is a risk associated exclusively with for-profit HMOs is doubtful. If physicians are to respond to the incentives that HMO-type care is supposed to introduce, they must be given a financial stake in the outcomes of particular cases. This is typically done through profit-sharing arrangements and other incentives, and it would seem that the incentive to overeconomize would accompany the implementation of these incentive arrangements whether or not the HMO itself was organized on a for-profit basis. In either case the primary decision maker would be faced with a conflict of interests that could conceivably influence his judgment adversely to a patient in a particular case. There is no evidence that I know of, however, that prepaid group practice plans have been guilty of overeconomizing.

The lay management of a for-profit HMO might exercise limited control over some of the conditions under which care is rendered, influencing, for example, the ratio of staff to patient population or the decision on purchasing life-saving equipment. Those quality matters that are within the control of the HMO management would seem to be rather easily regulated from the outside by quality control teams assigned to visit the installation. Interference by lay management in the actual rendering of care is likely to be strictly prohibited.

Overeconomizing would be subjected to a number of significant sanctions. The first is, of course, the threat of malpractice suits against the HMO. ${ }^{105}$ While many

\footnotetext{
106 The representation that the HMO has an incentive to practice preventive medicine, to detect disease early, and to treat causes rather than symptoms assumes a long-range perspective. Presumably there will sometimes be uncertainties about payoffs and a tendency to short-run conservatism, yielding false economies of the sort referred to.

${ }^{106}$ See generally Aspen Systeiss Corp. (Health Law Center), Group Practice and the Law: A Digest of State Laws Affecting the Group Practice of Medicine 9-I I (1969). Note that malpractice law would fulfill a different quality control function with respect to HMOs than it has performed with respect to fee-for-service medicine, where undertreatment would seem to be a potential problem only when the patient lacks the ability to pay. Cf. Cantor, The Law and Poor People's Access to Health Care, in this symposium, p. 90I, 909-r3. (I know offhand of no malpractice case where skimping in the care of a nonpaying patient was charged.) Because of the limited cost-benefit awareness of fee-for-service doctors, courts should avoid being too much influenced by prevailing custom and practice in defining a standard of minimum treatment for HMOs. It is unlikely, however, that HMOs would be allowed by the courts to depart very far from standards in the fee-for-service sector, and therefore they may be compelled to adopt conservative policies in omitting $x$-rays and other tests and procedures of doubtful medical value. See notes $I 8$ and 25, supra, and accompanying text. Nevertheless, since
} 
instances of overeconomizing that might occur would escape the notice of potential malpractice plaintiffs, standards in the HMO would probably reflect a healthy respect for the possibility of such litigation, thus drastically cutting down the instances of corner-cutting. Regulatory oversight of quality could be expected to take into particular account those areas where overeconomizing would be likely to occur, ${ }^{100}$ and it is certain that any federal legislative move into the health field will provide for substantial increases in external supervision of quality. While there are probably many things related to quality that such medical audits and other investigatory techniques cannot uncover, I would think that most kinds of overeconomizing on any substantial scale could be easily detected. In view of the small return from overeconomizing on any but the largest scale, coupled with the likelihood of detection and the high stakes involved-loss of accreditation, malpractice judgments, and, above all, the loss of consumer confidence-, the HMO's incentive to skimp on patient care would be small indeed.

The HMO's professional staff could be expected to maintain standards, to resist lay interference, and to insist on honoring their Hippocratic Oath. Consumers would be quick to react to any evidence of overeconomizing at their expense, either in the form of malpractice suits, formalized complaints, or word of mouth charges conveyed to other consumers. Anticipating consumer reactions, the HMOs would be extremely concerned about their image and any possible criticism on this score; indeed, I would expect the management to take no chances about matters of this importance. In very few cases will competition ever become so intense as to force HMOs into corner-cutting in search of short-run survival. Occasional cases of this kind might occur, but again there is little reason to think they would be more frequent in for-profit enterprises.

Finally, if one still fears overeconomizing by HMOs, it would be possible to require reinsurance against those risks that seem most likely to produce the temptation. Thus, an HMO might insure its enrollees against the need for such things as treatment in a cardiac care unit or hemodialysis. In any event, reinsurance is likely to be widely used by those HMOs which, because of the smaller patient population enrolled, could not safely rely on actuarial estimates to predict their costs. Reinsurance promises to play an important role in making smaller HMOs feasible and in improving their financial stability. It should also minimize fears about overeconomizing in those HMOs most likely to practice it.

FIMOs may find it possible to have malpractice claims arbitrated rather than litigated, Doyle v. Giuliucci, 62 Cal. 2d 606, 40I P.2d I, 43 Cal. Rptr. 697 (1965), a standard might be evolved in that forum which (x) would allow some freedom to cut back on the numerous minor items having a benefit-cost ratio of less than unity, but (2) would enforce a duty to care for the extremely sick patient without regard to cost, up to the limits of his coverage. Query, however, the HMO's obligation to preserve, at extraordinary cost to itself, the life of a comatose patient whose brain function is permanently impaired.

100 The administration's proposals include a procedure that would enable consumers to bring their complaints about denial of desired services before an administrator. H.R. $1, \S 239(\mathrm{a})$, proposed $\$ 1876(f)$; S. 1623 , $\S 101$, proposed $\S 604(c)$; id. $\S 201$, proposed $\S 628(f)$. Query whether these provisions would create a new forum in which to bring a certain class of malpractice cases. Query further whether the forum would be or should be the exclusive one for prosecuting such complaints. 


\section{Exploitation and Commercialism}

A respectable body of judicial authority and tradition stands opposed to forprofit enterprises in the health care field. Much of the sentiment is expressed in the common-law rule against the corporate practice of medicine, which has been applied almost exclusively to for-profit enterprises. ${ }^{107}$ The history of medicine discloses many examples of commercialism and exploitation of an unwary public by quacks and profiteering physicians, ${ }^{108}$ and most recently distress has been voiced about the advertising, hard-sell tactics, and high prices of the abortion clinics in New York City. ${ }^{109}$ Furthermore, proprietary hospitals and proprietary nursing homes have a bad name in some circles and have been the subject of some controversy. ${ }^{110}$ All of these factors have contributed to producing a firm conviction on the part of many that the nonprofit tradition must be maintained. But, while these convictions do credit to their harborers, they cannot be honored without regard to cost. Thus, the countervailing considerations noted earlier-the need for incentives to stimulate HMO growth, the potential contribution of proprietary institutions to stimulating economic efficiency, and the need to enlist entrepreneurial talents in the reorganization of health care delivery-must be weighed against the substance of these concerns.

A popular shibboleth is that no one should profit from the illnesses of others. In a free economy, however, reasonable profits signify, at least prima facie, that a needed good or service is being adequately and efficiently supplied, and "excessive" returns betoken a shortage and serve the useful purpose of inducing new efforts to supply the still unsatisfied wants. ${ }^{111}$ Of course, some may be tempted to turn the shibboleth around and to insist that health services are so important in the greater scheme of things that the rewards attached to delivering them should be very great. But this is equally wrong, for the price of services must ultimately relate to their cost, including what is needed to induce sufficient numbers of competent people to enter the business of rendering them. In any event, the whole argument has no substance, for physicians and other health personnel-and lawyers, too, for that matter-already "profit" from the misfortunes of others, and there is no way of arranging things otherwise.

Still, "excessive" profits earned in the rendering of health care remain ethically and socially troubling. I have already expressed my willingness to accept a temporary freeze on price increases in health services so that the shortages that would be

\footnotetext{
${ }^{107}$ See Note, supra note 7 , at 960-62 and references there cited.

${ }^{208}$ See, e.g., J. Young, The Medical Messtahs (I967); Note, Quackery in California, II Stan. L. REv. 265 (1959).

${ }^{100}$ E.g., Disciplinary Action for Abortion Solicitors Backed, Am. Med. News, Dec. 14, I970, at 9.

110 See generally Steinwald \& Neuhauser, supra note 83 , at $830-37$.

111 While distasteful in the extreme to many, the abortion clinics are providing a service intensely desired by some persons and in seriously short supply. The business is therefore profitable, and advertising makes it more profitable by stimulating demand. If health services of a less controversial kind were involved, their profitability and the effort to make them more widely available might strike us more positively. A New York trial court has recently held abortion referral agencies illegal in large part because of their "commercial" nature. N.Y. Times, May I4, I97I, at I, col. 6.
} 
created by improved accessibility would not overwhelm government's financing efforts and merely enrich providers. High profits earned temporarily by HMOs under such ceilings would not seem so objectionable since they would flow from achieved cost savings rather than from exploitative price increases.

As to the relevance of some of the experience of the past, some distinguishing elements can be observed. Government's legal powers and administrative capabilities are now somewhat better developed and suited to the job of policing the unethical and dangerous provider. Thus, reasonably effective controls can be exerted over existing operations, and primary reliance need not be placed on exclusion of would-be providers from the marketplace, a costly form of over-kill in an era of shortage. Perhaps more important, the market-oriented system would leave very little room for exploitation of the poor and the elderly, the groups most likely to be imposed upon by unethical providers. This results from the adoption of the modified "proxyshopping" mechanism, which requires the HMO to demonstrate an ability to attract younger, self-sufficient, and relatively sophisticated consumers before the government would allow it to care for those citizens who are its special responsibility.

The poor reputation enjoyed by proprietary hospitals and proprietary nursing homes-on the justification for which I express no opinion-might suggest to some that tolerance of proprietary HMOs would be an invitation to abuse. But this loses sight of the fact that, whereas HMOs will generally have a direct stake in restoring their patients to health as quickly as possible, proprietary hospitals and nursing homes may not have been adequately penalized by the market for poor performance. The reason for their escape is that, due either to a shortage of facilities or to ignorance, infirmity, or the necessity of the moment, their customers may often not have been able to exercise free and informed choice. Thus, the accusations directed toward proprietary hospitals have been largely confined to their alleged use by their physician-proprietors as a means of facilitating overutilization, which their patients have not the opportunity, the knowledge, or perhaps the interest ${ }^{112}$ to detect, and of avoiding the kind of peer supervision that is customary in voluntary hospitals. ${ }^{118}$ Similarly, nursing homes may have had insufficient incentive to make their inmates' lives cheerful, since many patients, due to infirmity, disinterested families, and shortage of facilities, effectively lack the opportunity to take their business elsewhere. ${ }^{114}$ It would seem that the proprietary HMO could be rather fundamentally distinguished from either of these institutions and that what may be regarded as their poor record ought not to be held as evidence against the proprietary HMO's potential for rendering quality care.

\footnotetext{
${ }^{112}$ See note 19 supra.

${ }^{213}$ Some think that proprietary hospitals have been to some extent the refuge of poor doctors. See Steinwald \& Neuhauser, supra note 83 , at 829 . Whether or not this is so, HMOs would certainly not be such a refuge and could be expected to exercise more vigilant peer supervision than do other types of providers.

122 See generally Hearings Before the Subcomm. on Long Term Care of the Sentate Special Comm. on Aging, grst Cong., Ist Sess., pt. I (Ig6g).
} 
The decision on for-profit HMOs is not likely to be made by a careful weighing of the merits of the issue but will instead reflect special interests and some emotions. Not only will the health care "establishment" oppose the challenge to their power that rapid HMO promotion by outsiders could produce, but most liberal reformers in the health field will also react negatively. Many of the latter will object viscerally to the proposed comingling of the profit motive with the humanitarian impulses which they wish reform both to reflect and to restore in medical practice. The notion of a market-oriented system also flies in the face of the emerging consensus among reformers in favor of "planning" in health care, and inducing a reconsideration of this preference by these persons, many of whom personally anticipate power and prestige in the new order, is probably impossible. Congress nevertheless has the opportunity to resolve the question as part of the larger decision it must reach on the direction which health care will take. This decision will not necessarily be dictated by health care insiders.

Finally, whatever one's a priori preferences may be on profits from care of the sick, current emoluments-including not only net cash income but also power, prestige, and perquisites-belie most of the health industry's nonprofit pretensions. ${ }^{115}$ An explicit recognition of the existing profit orientation thus has the merit of avoiding much hypocrisy. More important, however, it would cause policy makers to focus on the market as the appropriate form of social control and to concentrate on improving and supplementing its functioning. Heretofore their assumption has too often been that the industry is fundamentally humanitarian, ethical, and nonprofit and that more admirable instincts uniformly prevail over crass self-interest. Under the new assumptions, the question becomes the market's ability, with supplemental regulatory assistance, to provide adequate policing of profits and practices. The risk presented by monopolistic and monopolizing tendencies in the marketplace is therefore the next subject for attention.

\section{V}

\section{Shaping Policies to Improve the Market's Performance}

\section{A. Natural Monopoly}

An argument can be made that in some circumstances HMOs will monopolize the market for health services, rendering it unwise to rely on competition and the market to control prices and to maintain the quality of care. If this is a substantial danger, then it may be that more direct regulation than I contemplate would be called for.

A "natural monopoly" is possessed by an enterprise that occupies an entire market by virtue of economies of scale that make it inefficient for more than one competitor to survive. If two competitors were to exist in a natural monopoly market,

\footnotetext{
${ }^{115}$ See generally Health Policy Advisory Center (Health-PAC), The American Health Empire: Power, Profits and Politics (I97r).
} 
one of them would drive the other out, barring collusion preventing this outcome. One competitor or the other would eventually get a size advantage, and, because its unit costs would then be lower by reason of scale economies, it would be able to set a price with which the other competitor could no longer contend. That hospitals may sometimes enjoy a natural monopoly seems clear. Scale economies are thought to be substantial up to $25^{\circ}$ beds, ${ }^{116}$ and a hospital of this size is roughly adequate to serve a population of $65,000 .^{117}$ Thus, in many population centers a single hospital may exist without significant actual or potential competition due to technological and other efficiencies which are available to only one seller, the incumbent. The implications of this market structure for policy toward HMOs are several.

HMOs themselves are not likely to be the beneficiaries of a natural monopoly except as it derives from that belonging to hospitals with which they are affiliated. Aside from the provision of hospital services, HMOs would probably enjoy some scale economies in the provision of physicians', laboratory, and $x$-ray services, but these are not likely to be substantial enough to be decisive.118 HMOs associated with nonmonopolistic hospitals will have additional economies available, but competing hospitals could also be expected to offer HMO care, providing adequate competition. Perhaps most important, consumers are interested in more things than price in purchasing physician services or HMO membership, and some consumers will prefer to patronize a solo fee-for-service practitioner or a small-scale (two- or three-man) $H M O$, even at a higher cost, because of personalized attention and convenience that a somewhat more efficient HMO could not match; the competitive position of such plans would be further improved by the government's willingness to pay the higher rates (up to the ninety-five per cent ceiling) for Medicare, Medicaid, or FHIP clients electing care though such a plan. Thus, it seems most doubtful that an HMO not affiliated with a monopolistic hospital could ever have a monopoly "thrust upon it."119 Nevertheless, the number of hospitals with substantial monopoly power is large, and therefore the danger of HMO monopoly derived from a hospital's natural monopoly must be considered in some detail.

An HMO sponsored by a monopolistic hospital will have a potentially decisive competitive advantage over competing, non-hospital-based HMOs and fee-for-service physicians in the community. Depending upon the distance to and competitive environment of the nearby alternative hospitals, independent HMOs would be more or less, but always in some degree, compelled to pay the monopolist's price for hospital services needed by its enrollees; patrons of fee-for-service physicians would likewise

\footnotetext{
${ }^{116}$ Steinwald \& Neuhauser, supra note 83 , at 836 . But see Lave \& Lave, Hospital Cost Functions, 60 AM. EcoN. REv. 379, 394 (1970) ("if economies of scale exist in the hospital industry, they are not very strong").

117 Based on the national ratio of 3.9 beds per $x 000$ of population.

${ }^{118}$ Group practice by physicians (without prepayment) has shown a tendency to grow but not at 2 rate suggestive of overwhelming scale economies. See, e.g., Note, supra note 7, at 903-04 n.9.

${ }^{110}$ United States v. Aluminum Co. of America, x48 F.2d 4r6, 429 (2d Cir. 1945).
} 
face these charges, which would in turn influence their health insurance premiums. Under these circumstances the hospital-sponsored HMO would be able to offer comparatively attractive rates by, in effect, subsidizing its HMO operation with the monopoly profits from its hospital services. ${ }^{120}$ This subsidization process can also be visualized as the product of discriminatory pricing, whereby the captive HMO is charged lower hospital rates than its competitors and thereby derives a critical cost advantage. 121

The situation thus presented is not an uncommon one in other contexts involving vertically integrated enterprises. ${ }^{122}$ For example, it resembles closely the "price squeeze" described in the famous aluminum monopoly case. ${ }^{123}$ In that case, Alcoa, the monopolist of aluminum ingot and one of several sellers of rolled aluminum sheets, was said to have

consistently sold ingot at so high a price that the "sheet rollers," who were forced to buy from it, could not pay the expenses of "rolling" the "sheet" and make a living profit out of the price at which "Alcoa" itself sold "sheet."124

Judge Learned Hand's opinion also indicated the applicable legal rule:

That it was unlawful to set the price of "sheet" so low and hold the price of ingot so high, seems to us unquestionable, provided, as we have held, that on this record the price of ingot must be regarded as higher than a "fair price."125

By making an assumption (to be examined later) that interstate commerce is adequately affected, the Alcoa price squeeze principle can be translated to the hospital-

\footnotetext{
${ }^{120}$ It is far from clear that a monopolist would want to spend its money, hard-earned or not, in subsidizing an FMO's competitive ventures. Such an investment would not pay unless the profits from eventual monopolization would more than recoup it, and there are reasons to doubt that the monopoly would be so valuable. Cf. Leeman, The Limitations of Local Price-Cutting as a Barrier to Entry, $6_{4}$ J. Poz. Econ. 329 (1956). Still, in view of the hospital's control of the supply of a service essential to survival or entry of competitors, the possibility of monopolization, at least of the business of giving HMO-type care, cannot be ignored.

${ }^{121}$ Cf. Comment, Application of the Robinson-Patman Act to Price Discrimination in Intra-Enterprise Transactions, 53 Nw. U.L. REv. 253 (I958), which discusses the general problems; however, the Robinson-Patman Act, ch. 592, 49 Stat. I526 (I936), I5 U.S.C. §I3 (I964), would not apply to the pricing of hospital services.

${ }^{132}$ See generally C. EDwards, MaIntaining COMPETItion 97-99, I7I-75 (1949); C. Kaysen \& D. Turner, ANtitrust Policy 122, 125-27 (1959).

${ }^{228}$ United States v. Aluminum Co. of America, I48 F.2d 4 I6 (2d Cir. I945). For other examples of the "price squeeze," see United States v. Corn Products Ref. Co., 234 Fed. 964 (S.D.N.Y. I9I6); United States v. New York Great Atl. \& Pac. Tea Co., I73 F.2d 79 (7th Cir. 1949), affirming 67 F. Supp. 626 (E.D. Ill. 1946).

124 I48 F.2d at 437. See also Baush Machine Tool Co. v. Aluminum Co. of America, 72 F.2d 236 (2d Cir. I934), 79 F.2d 217 (2d Cir. I935). The best explanation of the "squeeze" is that Alcoa was seeking to compete with sheet steel by lowering prices to auto makers, thus practicing price discrimination in favor of that class of users. See Adelman, Integration and Antitrust Policy, 63 HArv. L. Rev. 27, 45 ( 1949 ). Vertical integration facilitates the segregation of markets necessary to permit such price discrimination, and a price squeeze may often be an incidental effect of this practice rather than a predatory tactic. See note 126 infra.

${ }^{120}{ }_{148} \mathrm{~F} .2 \mathrm{~d}$ at 438 . The squeeze potential is itself objectionable even if unexercised, because it discourages entry by those who recognize the risk and because it can be used to discipline aggressive competitors. For these reasons mergers creating a squeeze potential may be held unlawful. See U.S. Dep't of Justice, Merger Guidelines para. 13 (Ig68).
} 
sponsored HMO context. The antitrust rule thus derived would be that, although a lawful (natural) hospital monopolist does not violate the law by charging monopoly prices, if it elects to compete with its HMO customers and with fee-for-service physicians by forming an HMO, it may not disadvantage them-that is, "squeeze" them, in the case of competing HMOs-by its pricing policies. ${ }^{126}$ The most likely antitrust penalty for so doing would be a treble-damage award to all injured competitors, including fee-for-service doctors. Divestiture and break-up of the HMO would be likely also, and criminal sanctions could be imposed in flagrant cases. Rigorous enforcement of such a rule against unfair competition would be one hope for controlling the problem, but its administration would be difficult because a price advantage of the hospital-based HMO could be as easily attributed to efficiencies from integration of functions as to predatory behavior. .27 $^{127}$

Direct regulation of hospital rates might appear to be another possibility for coping with this problem. This expedient has been adopted in New York, to deal with hospital costs generally, ${ }^{128}$ and it is recommended by the apparent congruence of the theory supporting it and the argument for public utility regulation, which is also founded on the natural monopoly characteristics of the market. ${ }^{120}$ The public utility analogy is deceptive, however, primarily because it is based on a premise that utility regulation has proved a distinct social success, a pervasive assumption that has nevertheless been effectively disputed. ${ }^{130}$ Among other things, utility regulation has proved quite incapable of governing the quality of service and indeed has often foundered on the fact of life that if rates are kept too low, or merely if management prefers short-run profitability, the utility always has available the option of reducing its office staff or plant maintenance or otherwise curtailing the present, or borrowing

\footnotetext{
${ }^{120}$ Classic discussions of vertical integration argue that use of a monopoly position to bring about equivalent domination at a lower level of the market can seldom increase market power, but an exception is noted where domination of a complementary product or service is achieved. See, e.g., Bork, Vertical Integration and the Sherman Act: The Legal History of an Economic Misconception, $22 \mathrm{U}$. CHI. L. REv. I57, I71-72, 196-99 (I954). The instant case of an HMO that might use its hospital monopoly to drive out competing HMOs and fee-for-service physicians falls within this (or a related) exception. Although not all services rendered by independent physicians and HMOs involve hospital care, availability of such care at a reasonable price is necessary to their survival. If a hospital-sponsored HMO squeezed all of its competitors out of the market, it would thereby somewhat increase the sum of its power, thereafter being able to earn monopoly profits on physicians', laboratory, x-ray, and other outpatient services previously rendered competitively.

The situation can also be recast as a "tying" problem by visualizing the hospital's refusal to accept patients except by referral from its own HMO, which refusal would be little different from charging a prohibitive price to patients of the HMO's competitors. Although the usual analysis again recognizes few occasions in which it is possible to increase monopoly power by tying, monopolization of the business of rendering primary care through such a tie-in could expand the hospital's monopoly power. See Bowman, Tying Arrangements and the Leverage Problem, 67 YALE L.J. 19, 25-27 (1957).

${ }^{127}$ On the remedies available and the problems with their administration, see KAYSEN \& TURNER, supra note 122, at 125-27; EDWARDS, supra note 122, at I7I-75.

${ }^{128}$ N.Y. PUB. HeAlth LAW $\$ \$ 2803,2807$ (McKinney Supp. 1970).

${ }^{120}$ Sce Priest, Possible Adaptation of Public Utility Concepts in the Health Care Field, in this symposium, p. 839 .

${ }_{130}$ Posner, Natural Monopoly and Its Regulation, 21 STAN. L. Rev. 548 (1969). See also relatcd articles by Comanor, Swidler, Shepherd, and Posner, in 22 STaN. L. Rev. 510 et seq. (1970).
} 
against the future, quality of service. This chronic deficiency in regulatory performance is a particularly ill omen in the health field, ${ }^{131}$ and it is certainly doubtful that outside accrediting agencies and other supervisory mechanisms would be able to sustain the quality of care in a hospital that is deprived of adequate funds. ${ }^{132}$

Another problem generated by rate regulation is the reduction in the incentive to achieve efficiency. ${ }^{133}$ If regulation were able to achieve its theoretical objective and could effectively limit the regulated firm's profits to a predetermined rate of return on invested capital, there would be practically no incentive for the firm to reduce costs. But fortunately, and perhaps ironically, regulation's own inefficiency makes it possible for regulated concerns to enjoy at least temporarily the fruits of improved efficiency. Thus, because of so-called "regulatory lag," reflecting inertia and the time necessary for discovery and negotiation or litigation of a rate reduction, a firm that outperforms predictions of its profitability is not immediately subject to a cutback in rates. 'This factor, combined with some regulators' willingness to recognize a "zone of reasonableness" in rate of return-that is, to allow some increases in profit rates above the original target rate without intervention-, ${ }^{134}$ suggests that efficiency incentives have not been altogether eliminated although they have been reduced. Given the vast inefficiencies known to exist in hospital management, it is fair to ask whether any weakening of the incentives to seek and achieve efficiencies would be wise. $^{135}$

Of course, because hospitals are largely nonprofit institutions, many of the normal economic assumptions do not hold. Perhaps my main reason for speaking as if they do is that the natural-monopoly argument for hospital regulation seems likewise to proceed from such assumptions. But monopoly profits earned by a nonprofit institution at consumers' expense are not plainly objectionable from a social

${ }^{131}$ One possible answer to the argument that effective rate regulation could not guarantee, and indeed might undermine, the quality of hospital care is that the regulators should be liberal. But that course represents an invitation to "gold-plating" and overinvestment in capital goods, a danger which exists in the regulated sector even when liberality is not an express goal. See Averch \& Johnson, Behavior of the Firm Under Regulatory Constraint, 52 AM. EcoN. Rev. r052 (1962); Baumol \& Klevorick, Input Choices and Rate of Return Regulation: An Overview of the Discussion, I Bell J. Econ. \& MaNagement ScI. I62 (x970); Posner, supra note 130 , at 599-6or. There is already a widely deplored tendency to excessive and uncoordinated investment in hospitals, attributable in large part to excessive discretion residing in decision makers. See notes 98-roo supra and accompanying text. Rate-of-return regulation, which also allows excessive room for maximization of managers' welfare at the expense of efficiency, Posner, supra, at $60 \mathrm{I}-03$, would do little to correct these influences and might play into their hands. Conceivably avoidance of rate-of-return regulation and substitution of comprehensive planning and of rate regulation based on "financial requirements," as tentatively recommended by Professor Priest, supra note 129, at $845-47$, could avoid some of these particular traps.

${ }^{183}$ Cf. Worthington \& Silver, Regulation of Quality of Care in Hospitals: The Need for Change, 35 LAw \& Contensp. Prob. 305 (1970).

${ }^{133}$ See Posner, supra note 130, at 597-606.

134 The "zone of reasonableness" seems an eminently sensible notion until it is realized that a firm approaching its upper boundary has not merely no incentive to seek but a positive incentive to avoid further efficiencies that might push it over the top, prompting a return to the lowest reasonable rate. One can only hope that managers lack the means of exercising such subtle control over profits.

${ }^{185}$ Rate setting on the basis of "financial requirements," looking in large measure to costs, see Priest, stipra note 129 , at $845-47$, would appear to offer no stronger cost-cutting incentives. 
standpoint since they are not redistributed to wealthy investors but are retained in the service of the enterprise, whose purposes are presumptively of general public benefit. ${ }^{138}$ Indeed, such wealth-redistributive effects of hospital monopoly as can be identified favor the poor, since it is only the more affuent who are paying more than the cost of the service they receive. Moreover, the public has been dependent on hospital monopolies for a long time to generate the funds needed to provide care for the indigent. ${ }^{137}$

Since enrichment of the monopolist is not likely to be the concern that justifies hospital regulation, it must be that efficiency concerns, stemming from the notion that monopolists-particularly nonprofit ones-are inherently lazy and wasteful, are foremost. ${ }^{138}$ I have already expressed my doubts that familiar forms of rate regulation are likely to induce efficiency. Perhaps, however, a loose kind of regulation on the basis of classification of hospitals and comparison of rates within each class might be instituted, ${ }^{138}$ receivership of conspicuously inefficient hospitals might then be employed as a sanction against their managements, who, after all, are the people whose self-interest must ultimately be either threatened or appealed to.

Whatever one may think of the foregoing arguments against the regulation of hospital charges, it is easily demonstrable that no kind of regulation can deal adequately with the problem of the hospital-sponsored HMO. The problem is a fairly common one in regulated industries and can be illustrated by a recent rulemaking decision by the Federal Communications Commission. ${ }^{140}$ The issue was the right of communications common carriers to offer data processing services to the general public. The difficulty lay, first, in the fact that data processing requires the use of telephone or telegraph lines and, second, in the fears of data firms that communications carriers entering the data processing industry would have an advantage because the regulated end of the business might subsidize the unregulated portion; such subsidization could be accomplished either by providing personnel, facilities, or services at less than cost or by purchasing data services at a favorable price. The danger, of course, was that the monopoly of communications services, even though regulated, could be used to create a monopoly in data processing. The FCC dealt with the problem by ordering "maximum separation," the creation of a rigid barrier between the carrier and its data processing activities. It required that a separate subsidiary be established, that it maintain separate books, offices, and

${ }^{133}$ Of course, although I know of no reason to think there have been serious abuses, high salaries and perquisites and payments to enterprises affiliated with trustees or administrators do offer opportunities for diverting profits from public use. Possibly an affiliated HMO would greatly cxpand opportunitics for diverting the nonprofit hospital's earnings into private hands through imaginative bookkeeping, salaries, profit-sharing, and strategic patient referrals.

${ }^{187}$ See note $\mathbf{5} 5$ infra.

${ }^{188}$ See Legislative Findings and Purpose, supra note 98.

${ }^{180}$ Cf. Lave \& Lave, The Extent of Role Differentiation Among Hospitals, 1970 (working paper, Graduate School of Industrial Administration, Carnegie-Mellon University).

${ }^{140}$ Regulatory and Policy Problems Presented by the Interdependence of Computer and Communication Services and Facilities (Final Decision and Order), No. I6979 (F.C.C., Mar. 18, 1971), in 21 P \& F Rablo REg. 2d 159I (I97I). 
personnel, and that the carrier not purchase any data services from the subsidiary or engage in any transactions with it other than the sale of communications services at published rates and on a nonpreferential basis. The decision amounted to a confession that no amount of regulatory supervision of bookkeeping $\mathrm{oi}^{-}$of the nature, purpose, or price of intracorporate transactions could assure that the regulated monopoly was not in some way subsidizing the unregulated portion of the enterprise.

Of course, the FCC might have barred the carriers entirely from entering the data processing business. Its decision not to do so was based on a sense that the data processing field might benefit from the entry of the carriers as a new competitive force with unusual technological capabilities, ${ }^{141}$ but the ruling prevents realization of some potential economies which the carriers would have been capable of achieving through integration of functions. ${ }^{142}$ The lesson for handling the problem of hospital-connected HMOs seems to be that regulation of one segment does not allay the apprehension that the regulated arm of the enterprise might subsidize the unregulated arm, by allowing customers of the former to bear some hidden expenses of the latter or by other means. Total separation, along the lines ordered by the FCC, seems in no way preferable to a complete prohibition of HMO formation by monopolistic hospitals, and the latter choice, even at the sacrifice of significant economies, would seem a possible solution. ${ }^{143}$ This remedy would of course be available whether or not the hospital was regulated, and it would be expedient only in communities where a powerful hospital monopoly existed and, because of the market's characteristics, could not be broken up. In no event could cost accounting be depended upon to protect the public from possible abuse since it could not supply the precision necessary to police transactions and joint-cost allocations between a hospital and its captive HMO.

One possible policy toward the possibility that a "natural" hospital monopoly could be extended into the market for primary health care would be to take no immediate action, on the ground that the problem's dimensions cannot be adequately anticipated at this time. Perhaps, with clarification of the interstate commerce point, the antitrust rule against predatory behavior could be relied upon to protect against serious abuses, and many monopolistic hospitals, being nonprofit enterprises, might abjure aggressive competition and allow other providers to coexist. Those tempted to achieve domination would be faced not only with antitrust risks but with the threat of regulation by their local communities if consumers came to feel that they were being exploited and denied the full benefits of HMO care. The relative ease

\footnotetext{
162 Id. para. Ix.

148 Id. paras. I3, I5.

${ }^{168}$ The following opinion on the appropriate antitrust remedy in specific cases is applicable as well to the formulation of a general policy where this class of problem is presented: "There will be at least some cases where horizontal dissolution is not feasible but where vertical dismemberment is, and the superiority of such relief to injunctive remedies-even for the victim-warrants that it be used." KAYSEN \&: TURNER, supra note 122, at I26.
} 
of entry into fee-for-service medicine would impose some restraint, although solo practitioners' higher costs, their reluctance to advertise and to compete on the basis of price, and the HMO's established contractual relationships with its enrollees would dilute this influence. Although somewhat inhibited by vulnerability to the squeeze, potential new entry by an HMO-perhaps stimulated by large employers or consumer groups-would prevent the hospital-affiliated HMO from exploiting its position very far. Finally, the competitive impact of other HMOs on the fringes of the market area would seldom be negligible.

Looked at in another way, however, the problem is somewhat different and substantially more serious than we have yet observed, and it therefore requires a better solution than any of those canvassed above. The source of the additional difficulty lies in the likely domination of community hospitals by the local medical society and physicians dedicated to the preservation of fee-for-service medicine. Traditionally, these hospitals, while nonprofit and often community-owned, are effectively controlled by local physicians and operated largely for their convenience and profit. An HMO established under such domination, far from being an overly aggressive competitor abusing competing HMOs and fee-for-service physicians alike, might instead be enlisted to protect the fee-for-service sector against the encroachment of HMO-type care. In pursuing this objective, it would preempt subscribers, making them unavailable as converts to other HMOs during the term of their contracts, and would serve generally as a "fighting ship," defending against HMO invasion threats by occasional price warfare ${ }^{144}$ but otherwise not aggressively developing the potentialities of HMO-type care as a substitute for fee-for-service medicine. The likely pattern would be that local physicians would recommend the hospital-sponsored HMO, would accept referrals only from it, and would use other sanctions of a more or less overt character against physicians and patients associating with new HMO entrants. The hospital-sponsored HMO would probably be designed primarily to serve a low-income clientele, relieving practitioners of their charity burden but leaving unimpaired their opportunities for practicing price-discriminating fee-for-service medicine among the middle and upper classes.

The thrust of our problem is thus abruptly changed. We are no longer worried primarily about HMOs' monopolistic potential but about the indestructibility of the fee-for-service monopoly and its ability to adapt to new environments by invoking

\footnotetext{
14t The "fighting ship" analogy, drawn from the history of ocean shipping conferences (cartels), can be seen in the following:

"The crudest form of predatory practice was the fighting ship. The conference would select a suitable steamer from among its lines to sail on the same days and between the same ports as the non-member vessel, reducing the regular rates low enough to capture the trade from the outsider. The expenses and losses from the lower rates were shared by the members of the conference. The competitor by this means was caused to exhaust its resources and withdraw from competition."

Federal Maritime Bd. v. Isbrandtsen Co., Inc., 356 U.S. 48I, 488 (r958). Shipping conferences, like medical societies, are combinations of competitors interested in the exclusion of noncooperating providers of the service. Monopolists of other kinds have on occasion used "fighting brands" to similar effect.
} 
the profession's control over many of the inputs needed for effective competition and its remarkable ability to police itself. In this new light, the issue becomes joined with that presented by those existing prepayment plans (mostly not hospitalconnected) which have been sponsored by medical societies in many communities as a means of reducing the threat of independent entry by prepaid group practice plans. These plans and their legal status are the next subject for discussion, and my final solution to the issue of hospital-sponsored HMOs will be offered as part of an attempt to resolve the larger problem of medical societies' power to inhibit new entry into local markets.

\section{B. The Risk of Subversion by Local Medical Societies}

The ability of the medical profession to enforce its preferences as to the organization of the medical care industry has been impressive. The welding of so large a number of economic units into a stable and effective organization to repress competitive tendencies has been accomplished by a variety of customs and devices that could not be easily uprooted or dismantled even if the will to do so could be found. ${ }^{145}$ Even assuming that pro-HMO legislation emerges intact from the legislative process without emasculating amendments-such as proscription of for-profit plans-, policy makers must be alert to the danger that realization of the HMO's potential by a fair test in a free market might be somehow prevented by doctors. It is my belief that the antitrust laws, if allowed to operate with accustomed force, could provide much of the needed protection.

The greater threat to realization of the hopes underlying the HMO proposals is presented not by the American Medical Association but instead by state and county medical societies or even by small groups of powerful doctors who occupy strategic positions on hospital boards and in the societies. In Group Health Cooperative v. King County Medical Society, ${ }^{146}$ decided by the Supreme Court of the State of Washington in I95r, the county medical society claimed to be enforcing "ethical" standards higher than those of the AMA against the Cooperative's prepaid group practice plan, and the court's discussion reflects credit, by comparison at least, on the AMA for its less restrictive policies. Since the AMA was somewhat earlier convicted of antitrust violations in its activities in opposition to Group Health Association, Inc., in Washington, D. $\mathrm{C}_{n}{ }^{147}$ the antitrust laws may have contributed something to its moderation of attitude. ${ }^{148}$

\footnotetext{
${ }^{165}$ See references cited in note 65 supra.

${ }^{160} 39$ Wash. 2d 586, 237 P.2d 737 (1951).

147 American Medical Ass'n v. United States, 3I7 U.S. 5 r9 (1943).

${ }^{148}$ I do not mean to express an opinion as to whether the AMA is complying with the antitrust laws at the present time. My point is rather that the local societies and local professionals often take the initiative in the skirmishing, are so deployed as to be tactically effective, but have lagged behind the AMA in falling back to positions that would be at least arguably defensible in an encounter with the antitrust laws. The AMA's public position on HMOs is a sort of unconvinced tolerance, acceptance of a need for a pluralistic system, and opposition only to government favoritism and subsidies for one delivery mode at the expense of others. See Division of Medical Practice, note 43 supra.
} 
Many of the tactics employed by local societies to disadvantage HMO-type care are clearly illegal by federal antitrust standards and would probably be held so if interstate commerce was found to be adequately affected. Some state courts have applied state antimonopoly legislation or other sanctions to restrain such activity. Thus, the practice of refusing medical society membership or hospital staff privileges to HMO-affiliated doctors has been disapproved, ${ }^{149}$ and other concerted activities of local professionals undertaken for the purpose of discouraging HMOs would probably be treated similarly by most courts. ${ }^{150} \mathrm{My}$ concern here is with less overt strategies that the societies might adopt in opposition to HMOs.

Each fee-for-service doctor has a substantial amount of monopoly power over his individual patients as a result of their medical ignorance and dependency and their willingness to pay. Medical societies can thus be viewed as coalitions of monopolists whose purposes in coming together include protection and strengthening of their individual market power. This view explains why the medical societies behave somewhat differently than do classical cartels, not bothering to fix prices or to make overt anticompetitive agreements; not facing intense competition to begin with, they have no need to collude to eliminate it and can be content merely to preserve the status quo. In a sense, of course, the societies engage in market division-a common cartel practice-by enforcement of ethical undertakings not to advertise their services or to criticize their competitors, in effect recognizing each doctor's "sphere of influence" over his particular patients. A further parallel to the activities of other cartels is reflected in the societies' commitment to preservation of a particular, highly discriminatory ${ }^{151}$ pricing system-fee-for-service. ${ }^{152}$

The power of a coalition of lawful monopolies may be greater than the sum of its

${ }^{140}$ Group Fealth Cooperative v. King County Medical Soc'y, 39 Wash. 2d 586, 237 P.2d 737 (195x). New York has by statute prohibited the denial of hospital privileges because of participation in a group practice plan. N.Y. PUB. Health LAW $\$ 206-2$ (McKinney Supp. 1970).

${ }^{150}$ Apart from the antitrust implications, courts may be willing to find a denial of equal protection on the basis of an arbitrary classification when the hospital denying privileges to HMO-affiliated physicians receives state funds. Cf. Sams v. Ohio Valley Gen. Hosp. Ass'n, 413 F.2d 826 (4th Cir. 1969).

151 Price discrimination in medicine involves charging different prices for the same service, usually on the basis of ability to pay. See generally Kessel, supra note 70. See also notes 84 supra \& 159 infra. The presence of such discrimination proves the absence of effective competition since competing providers would drive each other to price uniformly in accordance with cost or the physician's supply function. Health insurance and prepaid group practice reduce the discrimination possibilities and have thus been opposed by the profession except as a means of providing for low-income persons, whom they make better able to pay. See Kessel, supra. The popular justification for such price discrimination was that it permitted free care for the indigent and made care available irrespective of wealth. As health insurance covers more people and as government pays more and more of the cost of care for the elderly and the poor, this justification, whatever it was once worth, fades. But see note 84 stupra.

${ }^{152}$ Maintenance of a particular pricing system seems often to characterize the stabler form of cartcl. For helpful comparisons, see FTC v. Cement Institute, 333 U.S. 683 (r948) ("basing-point" pricing, which produced complete price uniformity, irrespective of freight differentials, from all sellers to each buyer, making shopping and bargaining unproductive); United States v. Paramount Pictures, Inc., 334 U.S. I3I (1948) (motion picture distributors' efforts to preserve a particular system of "runs and clearances"); Securities Exchange Act Release No. 8239 (I968) (describing the New York Stock Exchange's long battle to repress cost-justified quantity discounts and "give-ups" on brokerage services). 
parts. ${ }^{163}$ Thus a medical society can preserve and strengthen the market power of each physician-monopolist by enforcing mutual recognition of spheres of influence, by collective maintenance of the conditions giving rise to such power-such as consumer ignorance and inability to combine for bargaining effectiveness-, by influencing legislation, by collective opposition to forms of health care financing and delivery that would weaken individual monopolies, and perhaps even by controlling members' exploitation of their individual monopolies so as to reduce the likelihood of government intervention or new entry. Where certain of these purposes appear, ${ }^{154}$ the coalition may be open to attack either as monopolization under section 2 of the Sherman Act or as a "combination ... . in restraint of trade" under section $\mathrm{r}^{\mathbf{1 5 5}}$

An important defensive tactic employed by the medical profession has been the organization by state and local medical societies of their own prepayment plans. In the r930s and I940s, following the example of Blue Cross hospitalization plans, the profession established Blue Shield, a series of state and local physician-dominated service and indemnity plans covering physicians' services primarily. ${ }^{156}$ More recently a movement has begun toward creation of society-sponsored "medical care foundations," which are prepaid service organizations whose chief distinguishing characteristic is that they provide intensive peer review of fees and utilization as a means of controlling health insurance costs. ${ }^{157}$ Blue Shield reflected the profession's early recognition that avoidance of government intervention in the health care system required, first of all, an available insurance mechanism whereby consumers could obtain financial protection against the risk of illness. It was an attempt to meet that need in the manner least disruptive of the valued relationship between the physician-monopolist and his patients, since independent insurers, representing a vehicle of pro-consumer bargaining, were seen as excessively inclined to police fees

${ }^{163}$ In United States v. Grinnell Corp., 384 U.S. 563 (x966), it was held to be monopolization to join together firms controlling $87 \%$ of "accredited central station protective service," a business having distinct natural monopoly characteristics at the local level. The Supreme Court's analysis was not satisfying, but the result is easily defensible by observing that the local monopolies were greatly strengthened by eliminating competition along the margin of market areas and the threat of new entry in expanding markets.

${ }^{20}$ 'The societies' efforts to obtain protective legislation or administrative action cannot be made the subject of antitrust action. Cf. Eastern R.R. Presidents Conference v. Noerr Motor Freight, Inc., 365 U.S. I27 (I96I).

155 I5 U.S.C. $\$ \$ I, 2$ (I964).

${ }^{150}$ See, e.g., H. Somers \& A. Soners, Doctors, Patients \& Health Instrance 3i7-40 (ig6r).

${ }_{107}$ See Sasuly \& Hopkins, A Medical Society-sponsored Comprehensive Medical Care Plan, 5 Med. CARE 234 (I967); Note, supra note 7, at 919-21; Comment, supra note 65, at 992-94; Am. Med. News, Aug. ro, I970, at 8 . The foundations are in fact a species of HMO, but they resemble physiciansponsored health insurance somewhat more than provider prepayment. The society in effect accepts prepaid memberships which entitle enrollees to obtain care from any society member or other participating doctor, who in turn bills the society on a fee-for-service basis. The only departure from ordinary health insurance is the society's oversight of utilization, fees, and quality of care, which is typically more intensive than the review of claims by insurers. Some foundations are underwritten by insurance companies, and some in California have accepted capitation payments from the state for Medicaid beneficiaries. The plans offer no substantial opportunity for reorganizing the delivery system in more efficient ways, and indeed "they are intended to buttress and accommodate the traditional forms of medical practice in a time of change." Sasuly \& Hopkins, supra, at 234. 
and to second-guess the need for service. The medical care foundations represent, in part at least, a further response to the same fears and conditions, being prompted by the increasingly recognized need for some control-preferably administered in the collective interest of physicians rather than of patients-over those abuses of the insurance system that tend to inflate its cost. More immediately, the foundation plans have often been linked to specific fears about the encroachment of prepaid group practice plans in the medical society's territory. ${ }^{158}$

If society-sponsored prepayment plans could be viewed merely as an attempt to improve the service and performance of the insured-fee-for-service sector, ${ }^{160}$ they would present no antitrust problem. Even seen as an attempt to head off consumer coalitions for bargaining, the society plans might be deemed objectionable only if they actively prevented such coalitions from forming, and perhaps a distinction would be drawn between collective action merely removing the abuses inviting consumer coalitions and collective action to create obstacles to coalition formation. In any event, collective efforts preemptive of market opportunities for agencies likely to represent consumer interests, where undertaken with exclusionary intent, would seem promising candidates for a firm antitrust prohibition.

\footnotetext{
${ }^{188}$ A study of the Foundation for Medical Care of San Joaquin County, California, revealed that the impetus behind the formation of that foundation plan was physician concern over "the rapidly rising prices of health care services and the rise of new kinds of health care organization. Viewed as a par. ticularly troublesome problem was the growth in California of the Permanente medical group, providing service for the Kaiser Foundation Health Plan." Sasuly \& Hopkins, stipra note 157, at 235. See also Am. Med. News, Aug. Io, 1970, p. 8, 9, col. I: "At issue, the physicians thought, was the control of the private practice of medicine by physicians. The "threat' was the proposed establishment of 'closed panel' systems of medicine in hospital-based group practices. Physicians on salary would be a reality." For further evidence of the purpose behind formation of society-sponsored plans, see notes 159 \& 163 infra.

${ }^{150}$ Where they have been able to get away with it, society-sponsored plans have practiced price discrimination. See generally notes $84 \& 15 \mathrm{I}$ supra. This fact and the profession's interest in preserving its ability to price according to ability to pay are revealed in this 1952 statement by a former president of the New York County Medical Society:

"Too many physicians ... seem still to think that a medical society should be organized solely for scientific purposes and medical education and that it should not consider and act upon the economic and ethical problems that arise ... [W] [ith health insurance plans accepting persons with incomes of $\$ 6,500$ and over, private practice with free choice of physician is being destroyed ...

"Blue Shield and similar [doctor-controlled] plans should widen their coverage. The private practitioner must cooperate and be willing to accept lower fees. Medical coverage cost must be made more reasonable for the lower and middle income groups. That this can be done to full satisfaction of patient and physician alike is exemplified by the Windsor plan. The Windsor Medical Services, of Windsor, Ontario, Canada, a voluntary, nonprofit, prepaid medical care plan sponsored by the Essex County Medical Society ... is a comprehensive insurance plan in which more than 95\% of the physicians in [the] Society participate. The physicians are paid on a fixed schedule of fees. The monthly subscription rate varies, according to income, from a single subscriber earning $\$ 300$ or less to the family subscriber earning $\$ 6,500$ or less. . . The successful plan shows what prepaid fee for service could do. That is what Blue Shield should strive for. Compulsory health insurance will then be prevented."

Master, Impact of Medical Care Plans on the Medical Profession, 150 J.A.M.A. 766, 770 (1952) (footnotes omitted). See also Kessel, supra note 70, at 53, which notes that in California, "[i]n an effort to meet this competition [from the Kaiser plan], service-type plans have been offered by orthodox members of the medical profession that are non-discriminatory with respect to income."
} 
In United States v. Oregon State Medical Society, ${ }^{180}$ the Supreme Court affirmed the lower court's dismissal of the government's charge that a plan of the Blue Shield variety violated the Sherman Act. The plan, the Oregon Physicians' Service, was adopted by the medical society in response to the encroachment of health insurance and other prepayment plans in the state. After noting that before I94I the society had engaged in a "tooth-and-claw struggle" and "a crusade to stamp . . . out" the prepayment plans, the Court noted that an "abrupt about-face" occurred in that year and that the doctors, "instead of trying to discourage prepaid medical service, decided to render it on a nonprofit basis themselves" through a society-sponsored plan. ${ }^{101}$ Because the lower court had found as a fact that the medical society had undergone a change of heart, the Supreme Court had no basis for treating the plan as an exclusionary tactic. Moreover, the Court's description of the two kinds of "contract practice" against which the society-sponsored plan was directed indicated that they were not of the sort that could be successfully excluded from the market by the society's plan. ${ }^{162}$ 'They were merely simple insurance schemes and employers' plans providing care in kind to their employees. Since, unlike an HMO, neither type of plan is dependent on attracting some minimum number of subscribers in a community but can instead depend upon individual physicians devoting some part of their time to treating plan members, the Court did not view the case as one in which the society's plan had any exclusionary or monopolistic effect. ${ }^{163}$ If a preemptive or exclusionary purpose or effect of the society-sponsored plans vis-à-vis independent HMOs can be identified, the Oregon Medical Society case should not be a barrier to adoption of an antitrust rule condemning them.

I elect not to pursue the antitrust status of Blue Shield plans any further here. ${ }^{164}$

${ }^{100} 343$ U.S. 326 (1952).

101 Id. at $329-30$.

${ }^{102} I d$. at 328 . There were in fact, according to the trial court's findings, some HMO-type plans in existence in Oregon, including one of the Kaiser-Permanente groups. 95 F. Supp. I03, II4 (D. Ore. I950). Nevertheless, the government failed to indicate any particular effectiveness of the society-sponsored plan in excluding this variety of prepayment plan.

${ }^{108}$ The record clearly revealed that the society plans were conceived for the purpose of eliminating existing insurance plans. See Brief for the United States at 25-29, 36-41. Several plans were driven out of Oregon, but this result may have appeard to flow only from fair competition. The government did not strongly assert that Oregon Physicians' Service was itself illegal, but instead relied on exclusionary practices and an alleged boycott.

104 Under the federal McCarran-Ferguson Act, the business of insurance is subject to the antitrust laws only "to the extent that such business is not regulated by State law," except that the Sherman Act would apply to "boycott, coercion, or intimidation." I5 U.S.C. \$§ 1012(b), Iог3(b) (1964). If the society-sponsored prepayment plan were regulated as an insurer, as Blue Shield usually is, it might be entitled to claim this exemption. This is not perfectly clear, however, since the federal sather than the state definition of "the business of insurance" will govern, SEC v. National Securities, Inc., 393 U.S. $453,458-6$ I (I969), and group practice prepayment plans have been held by the federal courts not to be insurance for other purposes. Jordan v. Group Health Ass'n, I07 F.2d 239 (D.C. Cir. I939) (applying the D.C. Code). Moreover, in California, a society-sponsored prepayment plan of the Blue Shield variety was not deemed to be engaged in the insurance business so as to be subject to insurance regulation. California Physicians' Service v. Garrison, 28 Cal. 2d 790, I72 P.2d 4 (I946). Aside from their delegated plenary authority respecting "the business of insurance," the states cannot by regulation or statutory authorization insulate society-sponsored plans from the antitrust laws if federal policy can 
For one thing, the Oregon Medical Society case indicates that they do not in themselves have a serious exclusionary effect although the surrounding conduct deserves close scrutiny. Moreover, while they do preempt many employer-sponsored groups and thereby help to foreclose HMO entry, they are no worse in this respect than independent insurers, and they must compete for this business on a cost basis with such insurers as well as with HMOs. Introduction of an unrestricted HMO option for all members of employer-sponsored groups would eliminate all market foreclosure effects as to HMOs (a result that might also be accomplished by an antitrust decree if an occasion were presented). Although I do not wish to concede that the antitrust laws are inapplicable to Blue Shield, I am avoiding the issue because I doubt that Blue Shield alone poses a very substantial obstacle to emergence of a satisfactorily competitive health care marketplace.

My reasons for objecting to the medical care foundations more than I do to Blue Shield are the same reasons that one should fear an efficient and subtle monopolist more than a lazy and obvious one: the latter will soon lose its monopoly to new entrants-assuming they are not excluded by law or otherwise-, whereas the former may find sophisticated and highly effective means to ward off new competition. The foundations, properly viewed, are a mechanism for curbing the excesses of some cartel members for the purpose of preserving the cartelists' respective monopolies and profits against government attack and new competition. While they may in fact succeed in lowering health care costs, they will not duplicate the results of maintaining a competitive market. Instead, they will seek an entry-limiting price level which, though responsive in fact to potential HMO competition, will not be a competitive level. Of course, if there is to be no commitment to a market-oriented health care system, then the foundations may have a beneficial impact and should be tolerated or even encouraged, ${ }^{165}$ but, under my procompetitive premise, they should be recognized as part of a profit-maximizing strategy of a coalition of monopolists. As such, they may be open to antitrust attack. ${ }^{188}$

A difficult question is presented concerning whether establishment of a foundation might be treated as an "exclusionary practice" for purposes of applying section

fairly be said to preempt the field. Cf. Sears Roebuck \& Co. v. Stiffel Co., 376 U.S. 225 (1964). Butt see the line of cases commencing with Parker v. Brown, 3I7 U.S. 34I (1943).

${ }_{105}$ The foundations have attracted a good deal of attention and are generating some enthusiasm among reformers. The Nixon administration specifically amended its definition of "HMO" to clarify that foundations could qualify. Compare H.R. $r, \$ 239(\mathrm{a})$, proposed $\$ 1876(\mathrm{~b})(3)$, with S. I623, $\$$ Ior, proposed $\$ 604(\mathrm{a})(3)$; id. $\$ 201$, proposed $\S 628(\mathrm{~b})(3)$. The Kennedy-Griffiths bill, $\$ 48$, also cndorses the foundation concept.

${ }^{100}$ The foundations may be held exempt from federal antitrust law either because they are decmed to be engaged in the "business of insurance" and regulated by the state or because the state has authorized their activities. See note 164 supra. State laws authorizing only society-sponsored or society-approved plans might, for example, be given such an effect. E.g., GA. CODE ANN. tit. 56, $\$$ 56-1806 (1960); Iowa CODE ANN. \$ 514.4 (Supp. 1970); Kr. Rev. StaT. \$303.180 (1962); REV. Codes MONT. 1947, \$ 15-2304 (repl. vol. 2 (pt. x), 1967); Nev. Rev. Stat. $\$ 696.100$ (1963). By the same token federal legislation revealing a preference for a competitive health care marketplace would improve the chances that antitrust policy would be deemed paramount. But see note ${ }^{6} 65$ supra, which indicates the foundations may reccive an express Congressional blessing. 
2 of the Sherman Act, which requires only proof that a monopoly exists and that it has been obtained or protected by such an exclusionary practice. By this doctrine, a monopolist is denied the right to engage in certain kinds of conduct that would be wholly innocuous, or even indeed desirable, if undertaken by a competitive firm. Thus, in the two leading cases on the subject, Alcoa was held to have violated section 2 by the simple act of enlarging its productive capacity to keep ahead of the market's growth, ${ }^{167}$ and United Shoe Machinery Corporation was found to have defended its monopoly unlawfully by the nonpredatory tactic of leasing rather than selling its machines. ${ }^{108}$ Although it is an interesting question whether a monopolist who simply moderated his pricing policies to discourage new entry would be held to have engaged in an exclusionary practice for the purpose of applying section 2, it is reasonable to assume that he would not. Since a foundation plan does little more than control the abuses that some physicians might perpetrate against the insurance system with respect to utilization and fees, it can be said to be doing nothing more than moderating monopolistic behavior, and this conduct, while exclusionary in fact and restrictive of competition in the long run, may not be enough to make out a section 2 case. Perhaps the real objection lies in the collective nature of the effort being made, and this suggests that it may be more appropriate to pursue the matter as a combination in restraint of trade under section $\mathrm{r}$.

Taking the society-sponsored foundations briefly through the standard section I analysis, ${ }^{169}$ I find that a "per se" antitrust rule, requiring no specific showing by the plaintiff of anticompetitive purpose or effect and permitting no justification to be offered in defense, might well be appropriate to condemn them. Looking first to the possible benefits that foundation plans might yield, I expect that the highly desirable controls on fee-for-service physicians ${ }^{170}$ could probably be introduced in an equally effective but much less troubling way-namely by independent health insurers, acting ultimately on behalf of consumers but perhaps working in close cooperation with organizations of fee-for-service doctors interested in policing their colleagues for the purpose of reducing health insurance premiums. ${ }^{171}$ If this less

\footnotetext{
${ }^{107}$ United States v. Aluminum Co. of America, I48 F.2d 416 (1945).

${ }^{108}$ United States v. United Shoe Mach. Co., Iro F. Supp. 295 (D. Mass. 1953), aff'd per curiam, 347 U.S. 52I (I954).

${ }^{100}$ See P. AREedA, ANTITRUST ANALYsis 286-87 (1967).

${ }^{170}$ On the efficacy of these controls see F. Gartside, The Utilization and Costs of Services in the San Joaguin Prepayment Project (UCLA School of Public Health r97I).

${ }^{171}$ At a later point I discuss the need for fee-for-service doctors to police each other in order to make themselves competitive, i.e., to make health insurance premiums attractive as compared to HMO charges. See text accompanying note 232 infra. Although the foundation plans might seem a good vehicle for accomplishing this needed control over charges and utilization, it is preferable to retain health insurers as intermediaries. For one thing, I would fear the societies' attempts to assert jurisdiction over the charges of all providers, including HMOs, a goal already announced. Am. Med. News, Aug. Io, 1970, p. 8, 15. Furthermore, independent insurance companies would be more likely to dedicate themselves to stimulating some kind of price competition in the fee-for-service sector as a means of reducing premiums and thereby maximizing health insurance sales; a cartel of fee-for-service providers-such as Blue Cross or Blue Shield-would seek price reductions only to that level where monopoly profits would be maximized, resulting in a lower output of fee-for-service medicine. Of course, insurers might find safe and useful ways to enlist the medical societies in the reviewing process.
} 
restrictive alternative is indeed available, a court should not count the obvious benefits very heavily in weighing the plans' validity.

On the potential detriment side of the ledger, the threat to the public interest is considerable. The plans purport to regulate prices to a substantial degree, at least to the extent of setting limits on the fees that can be charged. Although the case law prohibiting the fixing of maximum prices is not terribly convincing on its face, ${ }^{172}$ it would almost certainly be binding in these circumstances. Indeed, a much stronger case can be made against the fixing of maximum prices here, not only because the maximum price would almost certainly also become the minimum-as physicians would have no incentive to charge less than the maximum permitted-, but also because the purpose is to set prices not at a competitive level but merely at a level that will reduce the likelihood of entry and therefore restrict competition in the long run. The entry barrier created by the foundation plans' contractual preemption of employersponsored groups and other prospective HMO subscribers provides another strong objection to the plan. ${ }^{173}$ Finally, although an occasional society plan might be helpful as a counterweight to a monopolistic HMO or as a means of checking the excesses of certain greedy fee-for-service doctors, these benefits would be hard for a court to identify in a given case or to weigh against specific identified harms, since it would seldom be possible to know what would have happened in the plan's absence. In such circumstances, a flat prohibition cutting off an activity with clear anticompetitive tendencies may be appropriate in spite of arguable benefits, and such a prohibition would serve the additional salutary purpose in this instance of not inviting societies to push right up to the line of whatever narrow exception might be carved out. The simplification of enforcement and discouragement of conduct that is at least highly questionable are substantial benefits that would flow from a per se rule.

A per se rule should probably not be adopted without a full judicial inquiry into the nature and functioning of foundation plans, ${ }^{174}$ and the outcome of such an inquiry is not easy to predict. Departures from the foregoing analysis are possible at several points. First, the utilization and fee review might be deemed a permissible "ancillary" restraint, a reasonable incident of running a prepayment plan the legitimacy of which might be deemed supported by the Oregon Medical Society case, state Blue Shield statutes, and general public policy. ${ }^{175}$ Second, the fee review

${ }^{172}$ See Albrecht v. Herald Co., 390 U.S. I45 (I968); Kiefer-Stewart Co. v. Joseph E. Scagram \& Sons, Inc., 340 U.S. 2 II (195r). Both cases involved so-called vertical restraints whereby a seller sought to limit the resale prices of his retailer-customers. The illegality of a horizontal restraint on maximum prices would seem to follow a fortiori. The elements of coercion, of assumed extragovernmental power, and restriction on "the freedom of traders," id. at 213, are the same in either case.

${ }^{173}$ I suspect that market preemption, rather than real concern with fees and utilization, is the chicf object in forming a foundation. In the San Joaquin situation, where a defensive purpose was uppermost, see note 558 supra, perception of the foundation's defensive effectiveness must have been based on the society's ability immediately to sign up employers who might otherwise welcome or even solicit Kaiscr's entry. Intent plays a major role in antitrust outcomes.

${ }_{174}$ Cf. White Motor Co. v. United States, 372 U.S. 253 (1963).

${ }^{175} \mathrm{Cf}$. Addyston Pipe \& Steel Co. v. United States, 85 Fed. $27 \mathrm{r}$ (6th Cir. 1898 ). I find this far 
program might be viewed as something other than price fixing, ${ }^{176}$ and the adoption of entry-limiting pricing and utilization policies might be somehow viewed as a legitimate collective endeavor, perhaps by analogy to the monopolization argument noted above. Third, the beneficial controls over fee-for-service medicine might be held not to be achievable by other means that did not produce dangers of "lay interference," and, finally, perhaps the plans would be found not to inhibit HMO development in fact. ${ }^{177}$ An antitrust court, hearing the enthusiasm of the many eminent physicians and other witnesses that could be produced on behalf of the foundation plans, would in any event have to possess remarkable clarity of vision to see their less appealing side. Perhaps few judges, or other observers for that matter, will be uncompromising enough to share my view that, on the basis of past history, doubts should be resolved against continued domination of health care delivery by organized medicine.

Upon a complete inquiry an antitrust court might reject the per se rule in favor of approaching each society-sponsored plan under what antitrust lawyers denominate the "rule of reason." Under this approach the facts of each case are considered in detail, the courts relying on the ability of enforcement agencies to detect, of evidence to reveal, and of judges to recognize the existence of abuses when they do in fact occur. Many trade association activities of a standard-setting variety have been evaluated and tolerated under such a rule-of-reason approach, ${ }^{178}$ and this case might be deemed to fall closest to these precedents. Still, courts have erred egregiously on some occasions, ${ }^{179}$ and have so far been inexplicably reluctant to impose the and away the best argument for upholding the foundations. Properly, it requires an assessment of whether public policy should or should not encourage medical societies' provision of prepayment plans. Since such collective endeavors are fundamentally at odds with a competitive marketplace, they should not be permitted unless an antitrust exemption can be found in federal or state law. See notes r6 4 \& r66 supra.

${ }^{270}$ Recently some efforts by Blue Cross and others to provide insurance coverage of prescription drugs have run into difficulties with state antitrust laws because of the price fixing involved in obtaining commitments from pharmacists on the amount of their professional service charge-on each prescription. E.g., Blue Cross v. Virginia ex rel. State Corp. Comm'n, 2 II Va. I8o, I76 S.E.2d 439 (I970) (held to violate Sherman Act as well); B \& I Pharmacy, Inc. v. Metropolitan Life Ins. Co., 46 Ill. $2 d$ I, 262 N.E.2d 462 (1970) (upheld on the basis of special statutory exemptions); Opinion of the Attorney General of Michigan, I969 Trade Cas. para. 72,80r. See Comment, 57 VA. L. Rev. 375 (197I); Comment, $65 \mathrm{Nw}$. U.L. REV. 940 (197I). Had the insurance plans been sponsored by an organization of the pharmacists themselves they would have resembled the medical care foundations more closely and been even stronger candidates for illegality. Possibly, however, the foundations could find a way of regulating fees-perhaps merely ascertaining whether they exceed the physician's usual and customary charges-that presents less of an antitrust problem.

177 Their exclusionary impact would indeed be greatly lessened if market opportunities for HMOs are successfully opened up in other ways-e.g., by requiring employers to make available the option of applying the cost of employer-purchased insurance coverage toward HMO enrollment. See text accompanying notes 28-30 infra. My estimate of the foundation plans' exclusionary impact is impressionistic, see notes $158,159,163,173$ stipra, and subject to correction if HMOs are found capable of entry.

${ }^{178}$ See Wachtel, Products Standards and Certification Programs, I3 ANTITRust Bull. I (I968); Legality of Standards-Recent Developments, 39 Magazine of Standards 18 (Ig68).

${ }^{170}$ A trade association's standard-setting scheme caused a firm which truly had a "better mousetrap," a new kind of plywood, to fail, and, in spite of this egregiously anticompetitive effect, the courts could find no antitrust violation. Structural Laminates, Inc. v. Douglas Fir Plywood Ass'n, 26I F. Supp. I54 (D. Ore. 1966), $a f^{\prime} d, 399$ F.2d I55 (9th Cir. I968), cert. denied, 393 U.S. I024 (1970). 
burden of establishing "reasonableness" on those competitors who would engage in collective activity presenting grave anticompetitive risks though some arguable benefits as well. ${ }^{180}$ My preference for a per se rule would be somewhat abated if, as an intermediate solution, the burden of establishing an innocent purpose and absence of an anticompetitive effect could be shifted to the plan's proponents. The treble-damage remedy might then adequately deter excesses.

The foregoing theorizing about society-sponsored prepayment plans can be usefully laid alongside the earlier discussion of the monopolistic potential of an HMO affliated with a hospital enjoying a high degree of "natural" monopoly power. The fear was there expressed that such hospitals, and thus their HMOs, would often be dominated by the local medical society and that the HMOs would in such circumstances be used primarily as a stalking horse for fee-for-service medicine. Thus it could preempt subscribers, and this foreclosure of market opportunities, together with additional competitive advantages and the "squeeze" potential derived from its hospital connection, would make entry by independent HMOs very difficult. Nevertheless, despite the apparent applicability in these circumstances of the rigid antitrust rule that I approved above, a more selective rule seems to me to be appropriate here. The difference in the two cases is simply that the hospital-based HMO is capable of achieving important efficiencies in the delivery of health care, whereas the society-sponsored prepayment plan is not. This difference could justify applying a more flexible antitrust rule to the former, allowing a private antitrust plaintiff or the Justice Department to succeed only if it could affirmatively establish the purpose or the effect of preempting market opportunties, excluding other HMOs, or protecting the fee-for-service sector of the market from outside competition.

A monopolization or conspiracy-to-monopolize theory under section 2 would seem the soundest doctrinal approach to the problem of the hospital-based HMO dominated by local fee-for-service doctors. ${ }^{181}$ The inquiry would be whether the HMO was

${ }^{180}$ Cf. United States v. Arnold, Schwinn \& Co., 388 U.S. 365,374 n.5 (I967): "The burden of proof in antitrust cases remains with the plaintiff, deriving such help as may be available in the circumstances from particularized rules articulated by law-such as the per se doctrine." Rational allocation of the burden of proof would have prevented the travesty described in note 179 supra.

${ }^{181}$ Use of $\S \mathrm{I}$ of the Sherman Act, outlawing contracts, combinations, and conspiracies in restraint of trade, would be appropriate for dealing with the foundation plans since they so clearly involve a combination of competing physicians. The hospital-based HMO, on the other hand, is not a creature of the medical society, and the requisite multiplicity of actors would be harder, though probably not impossible, to identify. The conspiracy-to-monopolize theory would seem to raise a similar problem, but in this context it seems less important that the conspirators be competitors.

There should be no doubt that fee-for-service physicians who by whatever means effectively exclude HMO competition are "monopolizing" (or attempting or conspiring to monopolize) the market for medical care. Their success in eliminating one form of competition strengthens their market powerthat is, their ability to discriminate in price, a distinctive feature of monopoly, and to increase returns by artificially creating demand and by repressing both price and quality competition through customary restraints. See references cired in note 65 stipra. One can anticipate some difficulty in persuading courts that a mere strengthening of earning power provides the basis for finding a violation of $\$ 2$, since monopolization has traditionally been defined in terms of an overwhelming market share possessed by a single producer. E.g., Aluminum Co. of America v. United States, I48 F.2d 416 (2d Cir. I945). But no such exacting definition has been insisted on in attempt and conspiracy cases where anticompetitive 
being used to perpetuate the local physicians' market power. While taxing the perspicacity of judges, the evidence in such a case should permit discriminating judgments to be made. The following would be relevant subjects for proof: $(a)$ the coexistence of other HMOs; $(b)$ the hospital's pricing policies, particularly any price squeeze attempts; (c) the hospital HMO's aggressiveness in attracting subscribers, with particular reference to whether recruitment efforts are pursued among middle-class patrons of fee-for-service doctors or are confined to low-income groups; (d) the means of securing specialists' services, whether by spreading its business evenly among fee-for-service practitioners while avoiding creation of in-house capability or by practicing selectivity on the basis of skill and price; $(e)$ aggressiveness in exploiting available economies, particularly in the use of paramedical personnel; and $(f)$ the mechanism of control, particularly with respect to the possibility of domination by fee-for-service doctors. ${ }^{182}$

\section{Applicability of the Antitrust Laws}

The difficulty of introducing a competitive regime into health care delivery should not be underestimated. Traditions are opposed to it, and doctors can be expected to resist what strikes them as unhealthy "commercial" influences. The best means of overcoming this resistance is by vigorous enforcement of the antitrust laws against all concerted efforts to exclude HMOs from the marketplace. Some possible uses of antitrust law have been suggested already. ${ }^{183}$

The Sherman Act is the law most likely to be called into play against professional combinations in restraint of HMO development or collective monopolization of the medical care market by fee-for-service physicians. Two threshold problems that must be faced are raised by the question whether in a particular case the alleged restraint affects "trade or commerce among the several States" within the meaning of the statute. The first question is whether we are dealing with either "trade" or "commerce," and the second is whether, if so, there is sufficient interstate impact.

As to the first question, the Supreme Court held in 1943 in the $A M A$ case that Group Health, Inc., of Washington, D.C., a nonprofit prepaid group practice plan whose activities were restrained by organized medicine, was engaged in "trade" and that the Sherman Act applied to the restraints imposed. ${ }^{184}$ Any HMO that might be formed would seem to be equally involved in "trade." Even if the case presented should involve a restraint practiced against a single doctor connected with an HMO,

intent was clear. See Turner, Antitrust Policy and the Cellophone Case, 70 Harv. L. REv. 28r, 303-08 (1956). To inquire whether the hospital-based HMO has monopolized merely HMO-type care in the community-perhaps a separate economic market despite the availability of fee-for-service care as a substitute-would not sufficiently open up the question of domination by fee-for-service doctors, though it would be appropriate where extension of the hospital monopoly was the only issue.

${ }^{182}$ Active participation by consumer groups in the policy-making function would go far toward dispelling concern.

${ }^{188}$ See also notes $185,220,221$, \& 229 infra.

186 American Medical Ass'n v. United States, 3I7 U.S. 5I9, 528-29 (I943). 
he should have no trouble if he can relate the restraint to a purpose to exclude HMOs from the market or to weaken their competitive position. ${ }^{185}$

The interstate commerce question is harder, in part because the $A M A$ case arose under section 3 of the Sherman Act, which is specifically directed to restraints occurring in the District of Columbia. Even though the Supreme Court in that case was not called upon to make a finding of the presence or absence of interstate commerce, some implication of its absence seems to have attached by reason of the Justice Department's selection of the case and its invocation of the more limited jurisdictional nexus. Likewise, in the Oregon Medical Society case, the Court did not have to consider whether the restraint alleged in the formation of the Society's own prepayment plan had any interstate impact. The trial court had assumed the existence of interstate commerce in dismissing the case, ${ }^{186}$ and the Supreme Court had no occasion to consider the point since the government had failed to establish any violation. ${ }^{187}$ Thus, the case law respecting HMO-type providers is indefinite. However, other cases suggest that medical practice generally involves no interstate aspect, ${ }^{188}$ reflecting the circumstance that its primary ingredient is personal services rather than goods moving across state lines and that the market area in which consumers purchase these services is localized by factors of convenience and accessibility.

The most likely argument that interstate commerce is involved in HMO operation would be based on the HMO's effect on commerce in prescription drugs. It would probably not be sufficient merely to show that HMOs would engage in pre-

\footnotetext{
${ }^{185}$ Where specialty board membership or hospital staff privileges are to be denied to a physician affiliated with an HMO, stringent procedural requirements may attach because of the anticompetitive risk presented. In Silver v. New York Stock Exchange, 373 U.S. $34 \mathrm{I}$ ( $\mathrm{r}_{9} 6_{3}$ ), the Exchange (a "combination" of its members) was held to have violated the Sherman Act by exercising its statutory powcrs to cut off wirc services to the plaintiff without first according him notice of the grounds for the action and an opportunity to rebut the charges. The Court reasoned that the danger of anticompetitive use of the Exchange's self-regulatory powers required that they be exercised in the least restrictive manner compatible with fulfillment of the Exchange's statutory functions. Assuming the requisite impact on interstate commerce, the denial of privileges to an HMO-connected physician is closely analogous: Hospitals and specialty boards have been entrusted by the public with responsibility for quality control in medicine, a power that is subject to grave anticompetitive abuse; procedural protections are therefore appropriate, and failure to provide them, as well as revealed abuses, will be penalized by treble damage awards under the antitrust laws. It is noteworthy that the Joint Commission on Accreditation of Hospitals (JCAH), which includes representatives of several trade groups, including the AMA and the AHA, provides significant procedural protections. See JCAF, STANDARds for Accreditation op Hospitals Iog-II (I969). Procedural protections may be required for other reasons as well. See Ludlam, Hospitalphysician Relations: The Role of Staff Privileges, in this symposium, p. 879 .

Another antitrust theory useful to physicians excluded from hospital staff privileges or society membership would be that applied in Associated Press v. United States, 326 U.S. x (1945). In that case, an open membership policy was compelled where deprivation carried with it a distinct competitive disadvantage. Presumably the staff's quality-control responsibilities could be reconciled with this principle.

${ }^{188} 95$ F. Supp. at ro5.

187 The Court did discuss the interstate commerce point with respect to another issue in the case. 343 U.S. at 337-39.

${ }^{188}$ See, e.g., Riggall v. Washington County Medical Soc'y, 249 F.2d 266 (8th Cir. 1957); Spears Free Clinic \& Hospital for Poor Children v. Cleere, 197 F.2d 125 (Ioth Cir. 1952); Polhemus v. American Medical Ass'n, I45 F.2d 357 (Ioth Cir. 1944).
} 
scribing and occasionally dispensing drugs. Rather the restraint would have to have some likely direct and substantial impact on interstate drug sales. ${ }^{189}$ Prescription drugs are a substantial item in the nation's health bill. Out-of-hospital prescriptions cost the public \$3.2 billion in 1966 , which was 7.6 per cent of national expenditures for health services and supplies in that year. ${ }^{190}$ If specific activities of a medical society that are repressive of HMO development could be said to affect this commerce materially, that effect would certainly be substantial enough to warrant application of the antitrust laws. Moreover, this result shoud not appear strained or unreasonable, since the drug industry is already the subject of extensive federal regulatory concern exerted under the commerce power.

If HMOs were required to cover and pay all or a portion of their enrollees' drug bills, there would be an extremely persuasive argument that any restriction on HMOs' ability to penetrate a market area would have substantial effects on interstate commerce and would warrant antitrust action. It is well recognized that fee-for-service physicians are not ideally situated to prescribe drugs in a manner assuring the public the highest value from the drugs they consume. Solo practitioners are thought not to be as well informed about drug therapy as they should be, and the method of merchandizing drugs by brand name and intensive promotion has often been criticized for failing to provide adequate information in a usable form. ${ }^{191}$ Physicians are apt to make prescribing decisions without reference to the price that the patient must pay the pharmacist. The result is that the prescription drug market is though to be excessively profitable for the drug companies and generally unresponsive to price competition. ${ }^{192}$ Although discussions of provider prepayment plans do not always recognize it, drug prescribing would appear to be an area in which HMO-type care could provide substantial and highly desirable efficiencies.

HMOs providing coverage of their enrollees' drugs would be in a position either to dispense them themselves or to prescribe them. In either case the HMO would be motivated to evaluate efficacy, safety, and price more carefully than do fee-for-service physicians. Judicious prescribing by generic rather than brand name and careful price and quality comparisons among pharmacists would contribute substantially to better performance in the prescription drug market. Furthermore, HMOs would be generally larger-scale providers and would therefore be in a better position to retain a staff pharmacologist or to seek out pharmacological literature and advice

\footnotetext{
${ }^{180}$ See Elizabeth Hospital, Inc. v. Richardson, 269 F.2d r67 (8th Cir. I959).

100 Task Force on Prescription Drugs, Final Report I (1969) [hereinafter cited as Task Force REPORT].

${ }^{101}$ See, e.g., H. Dowling, MEdicines for MAN ch. 7 (I970); Ruge, Regulation of Prescription Drug Advertising: Medical Progress and Private Enterprise, 32 LAW \& CONTEMP. ProB. 650 (I967); TAsK Force Report, 7-ri, 2I-24, 36-37.

${ }^{102}$ See generally Hearings on Competitive Problems in the Drug Industry Before the Monopoly Subcomm. of the Senate Select Comm. on Small Business, goth Cong., Ist Sess. (1967); TASK Force Report II-I5; Dowling, stpra note I9I, chs. 5 \& 6; Baehr, Drug Costs and the Constumer, in Drugs IN OUR SocIETY I79 (H. Talalay ed. I964).
} 
so as to improve the results of drug therapy. Under these circumstances there would be good reason to think that HMOs would improve the working of market forces in interstate commerce in prescription drugs and could substantially reduce the nation's drug bill while increasing the benefits of drugs to patients. ${ }^{108}$ These beneficial results would occur even where a coinsurance or deductible provision was incorporated. ${ }^{194}$

Although the arguments for including coverage of drug costs in HMO coverage are persuasive, the administration's proposals pending in Congress at the present time would not require coverage of out-of-hospital drug costs. ${ }^{105}$ This can be explained as an effort to reduce the cost of the insurance provided and to concentrate on those areas where rising costs are the greatest problem. ${ }^{196}$ The argument that interstate commerce in drugs would be adversely affected by restraints of trade directed against HMOs would be somewhat weaker if HMO coverage does not typically include drugs. Nevertheless, drugs prescribed while the patient is hospitalized will probably be covered, ${ }^{197}$ and HMOs would have the option of making drug insurance available to its enrollees. ${ }^{198}$ Furthermore, the larger-scale organization of HMOs would provide opportunities for improved prescribing, and normal competitive urges should lead HMOs to attempt to please consumers by helping them obtain the best drug for the money. One can visualize, for example, an HMO advertising that its prescriptions include generic drugs where appropriate and are written in consultation with a qualified pharmacologist. I would think that the government could procure a sufficient number of medical and economic experts to testify convincingly to the substantiality and desirability of these effects that an antitrust court could be persuaded that interstate commerce was in fact substantially and adversely affected by exclusionary tactics directed against HMOs.

The chances of persuading courts that antitrust enforcement is appropriate in these areas would be increased by a declaration by Congress as part of the legislative history of health care legislation that the antitrust laws are to be relied upon to

\footnotetext{
${ }^{103}$ See McCaffree \& Newman, Prepayment of Drug Costs Under a Group Practice Prepayment Plan, 58 AM. J. Pub. HeaIth I2I2 (I968), which finds a net cost saving to plan subscribers of $28 \%$ even after provision for profits earned and taxes payable on drugs purchased outside the cooperative. The substantiality of the potential impact of HMO coverage of prescription drugs is indicated as follows: "If costs similar to the Group Health level could be achieved for most of the population, the nation's drug bill would decline by over $\$ 800,000,000$ or just about 2 per cent of the nation's total health care expenditures." Id. at $\times 2 \times 8$.

${ }^{104}$ The HMO would seek to minimize drug costs in order to prevent the using up of the deductible or to reduce its coinsurance liability.

${ }^{208}$ Medicare does not cover outpatient drug costs either. See TAsK Force REPORT 49.69. Under Medicaid most states have exercised the option to cover drugs. See CCH Medicare \& Medicaid Guids para. 15,504 (I97I). Section 25 (b) of the Kennedy-Griffiths bill provides for coverage of the costs of approved drugs furnished to CHSO enrollees.

${ }^{198}$ Drug costs have remained remarkably stable, particularly as compared to other health costs. See Bureau of the Census, Statistical Abstract of the Untred States 62 (1970).

${ }^{107}$ Since these are covered under Medicare, they are likely to be covered in any new scheme. I have not been able to determine how substantial an item this is, but it is not likely to be insignificant.

${ }^{198}$ Several plans, most notably Group Health Cooperative of Puget Sound, have provided drugs with considerable success. See Baehr, supra note 192, at r83-86; McCaffree \& Newman, supra note x93.
} 
maintain HMOs' market opportunities. Further, express recognition of the importance of $\mathrm{HMO}$ formation in improving the performance of the drug industry would serve as a helpful guide to a judge faced with appraising the interstate commerce impact. If the Congressional committees should differ with my conclusions on this matter, one can visualize enactment of a "little Sherman Act" specifically applicable to the health care field. If interstate commerce were not thought a sufficient constitutional nexus, the legislation could be seen as being in aid of a legitimate federal purpose under the taxing and spending power as utilized in the Medicare, Medicaid, and proposed FHIP legislation. ${ }^{109}$

Although some of these matters are not as clear as one might wish, it would seem desirable for the Antitrust Division of the Department of Justice to commence some actions to determine the antitrust laws' capacity to recreate a competitive market in health care delivery. If the Nixon administration is sincere in its expressed desire to foster HMO development, it should quickly authorize such litigation, perhaps directed at some of the medical-society-sponsored prepayment plans. ${ }^{200}$ There seems to be no reason to await Congressional action on the various health proposals before moving in this constructive way to create opportunities for HMO formation. The Federal Trade Commission might also take an interest in these matters, dealing with exclusionary tactics as "unfair methods of competition."201

\section{Federal Preemption as a Means of Overcoming Restrictive State Legislation}

Many states have statutes, enacted largely at the behest of organized medicine, that in some way inhibit the formation of HMOs. ${ }^{202}$ In varying degrees, these laws will have the effect of deterring the formation of HMOs altogether or will tend toward the creation of plans of the kinds supported by medical societies, which, as we have seen, may be nothing but a defensive gambit by fee-for-service medicine. The administration and the national health insurance proponents agree that the presence of these laws would obstruct implementation of any federal policy for dealing with the health care crisis. ${ }^{203}$

\footnotetext{
${ }^{109}$ See notes 2 II-13 infra and accompanying text.

${ }^{300}$ In recent years the Antitrust Division has performed much useful service in reminding regulators and policy makers of the role that competition can play. It would be appropriate to add health care to the long list of fields, including banking, securities exchanges, transportation, and broadcasting, in which competition had been de-emphasized by policy makers and the Division's influence was exerted to restore it to a higher place. See Report of THE TAsk Force on Productivity aNd Competition (1969), urging that the Antitrust Division serve "as the effective agent of the Administration in behalf of a policy of competition."

201 I5 U.S.C. $\$ 45(1964)$.

${ }^{202}$ See Note, supra note 7 , at $960-75$, which concludes that the law is not as restrictive in practice as it appears to be on paper at least as regards nonprofit HMOs; AsPEN SYSTEM: CoRP., supra note no5. 208 See President's Heatth Message 6; S. I623, $\$ 40 \mathrm{I}$ (a); Kennedy-Griffiths bill $\$ 56(\mathrm{~b})$. Both S. I623, $\$ 4$ or (b), and the Kennedy-Griffiths bill $\$ 56(\mathrm{a})$ would also deal with restrictive state policies toward manpower licensure and utilization.
} 
The following language from the text of the Kennedy-Griffiths proposal suggests both the nature of the laws creating the problem and the remedy proposed:

If the Board finds that a proposed corporation will meet the requirements ... for participation as a comprehensive health service organization ...., but that it cannot be incorporated in the State in which it proposes to furnish services because the State law requires that a medical society approve the incorporation of such an organization, or requires that physicians constitute all or a majority of its governing board, or requires that all physicians in the locality be permitted to participate in the services of the organization, or makes any other requirement which the Board finds incompatible with the purposes of this title, the Board may issue a certificate of incorporation to the organization, and it shall thereupon become a body corporate. ${ }^{204}$

The Kennedy-Griffiths proposal also would permit a nonprofit hospital or CHSO to render care directly through employees without regard to whether state law would regard its activities as prohibited "corporate practice of a profession"; the provision would not, however, permit any employment or arrangement that was "likely to cause lay interference with professional acts or professional judgments."205

The Kennedy-Griffiths bill would leave intact any state law requiring the CHSO to be a nonprofit enterprise. ${ }^{206}$ Since I consider this an extremely unwise policy, one that is embodied in the Kennedy-Griffths proposal itself, I would like to see federal law expressly override it. While I recognize that the issue is not free from doubt and that states might have an interest in protecting their citizens in this regard, I am concerned that it will be difficult to get an open-minded re-examination of the question. Moreover, state policy makers may too readily accept the medical societies' version of the issue.

State laws also may purport to regulate HMOs under insurance laws. ${ }^{207}$ Federal law regulating HMOs, as under the Kennedy-Griffiths bill, would probably be construed to preempt these efforts.

The Nixon administration's FHIP proposal would deal with laws restrictive of HMO formation by declaring that agreements entered into by the Secretary of HEW with HMOs, under which services would be rendered to FHIP beneficiaries, would make state law inapplicable "to the provision of such services under such an agreement to the extent that such law or regulation is inconsistent with the obligations of the health maintenance organization under the agreement."208 While effective in dealing with the corporate-practice and insurance regulation problems

\footnotetext{
${ }^{204}$ Kennedy-Griffiths bill $\S 56(b)$.

${ }^{205} I d$. $\$ 56(\mathrm{a})(4)$.

208 Such a requirement usually flows from interpretation of the rule against corporate practice of a profession. See Note, supra note 7, at 960-62 and references there cited. A for-profit HMO, Omnicare, is currently trying, without success, to obtain a favorable ruling from the Attorney General of California. See letter from R. Stromberg to V. Stein, Nov. 26, rg69 (legal opinion and brief to the effect that Omnicare would not violate the corporate-practice rule).

207 See Note, supra note 7, at 969-74.

${ }^{208}$ S. I623, $\$ 401(a)$.
} 
insofar as implementation of FHIP is concerned, there may be a question whether this provision would have any effect on state laws as applied to the care of persons not covered by FHIP. ${ }^{209}$ If not, the result might be to create federal instrumentalities that are permitted to serve the poor and perhaps the elderly but are prevented by state law from serving other elements of the population. However, in view of the requirement in the FHIP proposal that HMOs must have non-FHIP enrollees to the extent of at least half their enrollment, ${ }^{210}$ a state law purporting to limit its right to accept non-FHIP enrollees would be "inconsistent" with the federal scheme."10a

The constitutional power of the federal government to override state legislation is of course not plenary. It seems clear, however, that a law like the Kennedy-Griffiths bill, which would be enacted under the same taxing and spending powers of Congress that permitted creation of the Social Security system in furtherance of the "general welfare,"211 would allow Congress to preempt the field against state laws in aid of achieving its legitimate constitutional purpose. ${ }^{212}$ It would be anomalous if a less far-reaching measure, such as the administration's proposals, could not be implemented by a similar express overriding of state authority, but, since the administration plan leaves much of the financing of health care in the private sector, it might be argued that the constitutional basis for preemption-federal spendingdoes not exist. ${ }^{213}$ Nevertheless, federal involvement through Medicare, Medicaid, and FHIP would seem a sufficient basis for specific and total invalidation as to all providers caring for beneficiaries of federal programs. If this were done, a physician with Medicare patients could not be interfered with by state authorities even as to his ability to treat other patients since the federal government could reasonably demand that its clients not be segregated from the general population in obtaining health care. If the taxing and spending power were deemed insufficient, the federal government could act in aid of its power over interstate commerce in prescription

\footnotetext{
209 The narrowness of the preemption attempted is attributable to the administration's attempt to use the government's contracting power as its basis for moving against state laws. See Paul v. United States, $37 \mathrm{I}$ U.S. $245\left(\mathrm{Ig}_{3}\right)$. Subsequent discussion indicates that this is perhaps too narrow an approach to the problem.

${ }^{210}$ S. $1623, \S 20 r$, proposed $\S 628(b)(5)$.

${ }^{2102}$ The AMA fails to recognize this wider preemptive effect. See Division of Medical Practice, supra note 43 , at 12 .

H.R. I as amended, $\S 226(a)$, proposed $\S I 876(j)$, provides, "The [contracting] function vested in the Secretary . . . may be performed without regard to such provisions of law or of other regulations relating to the making, performance, amendment, or modification of contracts of the United States as the Secretary may determine to be inconsistent with the furtherance of the purposes of this title." This language is obscure, but presumably state laws inhibiting performance of HMO contracts, including satisfaction of the membership requirements, would be superseded.

${ }^{211}$ Steward Machine Co. v. Davis, 30I U.S. 548 (1937); Helvering v. Davis, 30I U.S. 6I9 (1937). See also Chapman \& Talmadge, Historical and Political Background of Federal Health Care Legislation, 35 Law \& Contemp. Prob. 334, 342-46 (1970).

${ }^{312}$ Although the regulation of medical practice has traditionally been within the province of the states under their police power to legislate for the protection of the health, safety, and morals of their citizens, Congress may affix conditions to the expenditure of federal tax funds. See Oklahoma v. United States Civil Service Comm'n, 330 U.S. 127 (1947).

${ }^{213}$ See note 209 supra.
} 
drugs and over the interstate health insurance industry. It is hoped that Congress will see the need for clearing away all state legislation likely to inhibit the operation of market forces.

\section{E. Supplementary Measures to Strengthen Market Forces}

Numerous factors contribute to the strength or weakness of market forces in any marketplace, and many of these factors are susceptible to legislative and administrative influence to improve the market's over-all performance. A survey of the market for health services suggests some ways of making doubly sure that the market will deliver the things for which we count on it.

\section{Lowering Barriers to Entry}

HMO formation will occur more quickly and more often if the obstacles to their creation are fewer or less difficult to surmount, and it is therefore important that governmental policies be directed to reducing both the number and the negotiability of such obstacles. Only for compelling reasons should policy makers render entry materially more difficult than it has to be. The inquiry here is what entry barriers exist for would-be HMO organizers and what, if anything, can be done about them.

The administration has proposed federal financial aid for HMO formation as a means of reducing entry barriers. ${ }^{213 a}$ However, subsidies for start-up costs are usually inconsistent with market functioning and can distort competitive outcomes by permanently lowering the costs of the subsidized enterprise (by eliminating the need to earn a return on the full original investment). Nevertheless, the President's aid program may perhaps be justified, at least as to the concept if not as to the precise amount, as a means of compensating for allegedly unnatural and unwarranted barriers to acceptance created in consumers' and physicians' minds by the past activities of government and organized medicine; the proposed planning grants, temporary absorption of operating losses, and loan guarantees are all consistent with a purpose to lower barriers reflecting ignorance and risk attributable in part to these historical factors. More important perhaps, HMO subsidies seem quite appropriate in an industry where charitable and governmental subsidies are already so much a part of the landscape; however, this rationale provides little justification for subsidizing HMOs' provision of primary care, since fee-for-service doctors, their chief competitors in this business, do not enjoy such support.

Government should see that, to the extent possible, HMOs face no requirements for large capital investments. It is therefore significant that in the House-passed Medicare amendments HMOs are not required to render hospital care or to provide all specialists' services but may instead purchase these as needed in the fee-for-service sector. Some financial responsibility requirements will no doubt be imposed, but care should be taken not to be too demanding in this regard, perhaps accepting

\footnotetext{
${ }^{218 a}$ See text accompanying note 27 supra.
} 
bonds from the organizers as a way of protecting plan subscribers. Reinsurance has an important role to play in making small-scale HMOs viable and should be encouraged by policy makers.

Any legal provision mandating large size in an HMO seems inappropriate. It may prove to be the case that certain scale economies will compel many HMOs to be quite large, and indeed these economies are reportedly not exhausted in a hospitalbased HMO until it has 25,000 to 30,000 enrollees. ${ }^{214}$ Nevertheless, the ability of smaller HMOs to survive, perhaps by dint of characteristics other than rigorous efficiency and low cost, should be tested in the marketplace and not in legislative halls. The Senate Finance Committee, in its version of the proposed I970 Medicare amendments, would have required an HMO to have at least I0,000 subscribers, ${ }^{215}$ and, regrettably, the administration's proposed National Health Insurance Partnership Act of I97I incorporates this requirement. ${ }^{216}$ This would be a most unfortunate and unnecessary blow to the functioning of a health care marketplace.

I wish that it were needless to say that entry by HMOs should not be restricted by government on any grounds but minimal requirements of character, fitness, and financial responsibility. Congress should provide expressly that, even in the currently popular name of "comprehensive health planning" no for-profit HMO should be excluded from the marketplace on the ground that a "need" for it has not been demonstrated or that existing institutions require protection against its competition. Comprehensive health planning, admittedly needed, should not be turned into a system of licensing by "certificate of public convenience and necessity." Instead, it should be seen as a technique for coordinating the health investments of various levels of government and of the voluntary-nonprofit sector and for eliminating all factors besides the public interest in decision making regarding these expenditures. ${ }^{217}$ Monopolistic elements created by such governmental intervention

\footnotetext{
324 Note, supra note 7 , at 904-05.

215 S. REP. No. 9I-I 43I, at I36.

${ }^{2 x 0}$ See S. I623, $\$$ IOI, proposed $\S 604(a)(5) ; i d$. $\$ 201$, proposed $\S 628(b)(5)$.

${ }^{217}$ Unfortunately, Congress is on the brink of adopting legislation that would effectively create a system of rigid entry restrictions in the states and would, perhaps inadvertently, remove any realistic hope of recreating a dynamic and workable market for health services. A section of the House-passed version of H.R. I as amended, $§ 22 I$, which seems to this moment to have generated little controversy, would reduce federal Medicare payments to health facilities and HMOs to the extent that they represent recovery of depreciation and other costs connected with capital investments in facilities costing more than \$roo,000 that are constructed without approval (subject to federal review) of state planning agencies. Thus, the health planners would be ceded the power effectively to control all major new public and private investment in health facilities, including HMOs, and to prevent all new construction for which they are not satisfied that a "need," as they define it, exists. Experience in other regulated industries tells us that "need" is almost always defined with an eye to possible adverse effects on other providers of the service, indicating that legislation of this kind invariably protects existing providers from competition and explaining why it is regularly sponsored by them. This kind of law is depressingly similar to, among other things, the law restricting bank chartering and branching on the basis of "convenience and needs," which developed in the I93os as an expedient to protect against bank failures but which is now recognized as unnecessarily restrictive of needed and healthy competition. See, e.g., Kreps, Modernizing Banking Regulation, $3 \mathrm{I}$ LAw \& Contemp. Prob. 648 (Ig66).
}

As discussed carlier (see notes 98-100 supra and accompanying text), health planning agencies should 
have too often redounded to the public detriment and private profit and should be prevented from doing so again.

Ease of entry not only enlarges opportunities for entrepreneurs interested in HMO formation but supplies a beneficial restraining influence on sellers already operating in the market. Thus, a market populated by only a few sellers may yet behave competitively, in part because sellers recognize not only their existing rivals but also the risk that other sellers will appear if prices rise to a level making entry appear attractive. Preservation of such "potential competition"-which might come from HMOs operating in adjoining areas, employers interested in cheaper care for their employees, or indigenous fee-for-service physicians-should be an important policy consideration.

"Entry barriers" and "potential competition" have become largely talismans in antitrust law, used more for conjuring than as analytical tools. ${ }^{218}$ Nevertheless, careful antitrust enforcement could perform a useful service wherever certain practices appeared to have an entry-limiting effect. For example, the duration of HMO contracts with subscribers would be subject to control through antitrust rules on exclusive dealing, ${ }^{219}$ and tying arrangements, if identifiable, would be subject to antitrust action. ${ }^{220}$ Further, the disadvantages of non-hospital-based HMOs in purchasing hospital services might be deemed to flow from entry-limiting devices having conspiratorial aspects. ${ }^{221}$ Still, although the antitrust laws might serve, issues of these

be scrupulously limited to dealing with the investments of the governmental and nonprofit sectors and should be given no authority over private investment. The expediency arguments advanced for absolute control over entry are that public investments must be protected in order to improve their borrowing prospects and their capacity to serve the poor. But the losses from precluding competition for inefficient, price-discriminating monopolists would surely outweigh any saving in the cost of borrowing, and Congress is likely to improve the ability of the poor to pay for their own care, obviating the need for price discrimination. See note I5I supra. In any event, the arguments for protectionist regulation on behalf of hospitals, weak as they are, are far stronger than the case for restricting HMO entry. The Ways and Means Committee was responsible for extending the coverage of this provision to HMOs. Compare original H.R. I, $\$ 221$. Its work should be undone in the Senate so that at least non-hospitalbased HMOs will not become public utilities.

${ }^{218}$ See, e.g., FTC v. Procter \& Gamble Co., 386 U.S. 568, 585 (1967) (Harlan, J., concurring); General Foods Corp., [1965-67 Transfer Binder] TrADE Reg. Rep. 22,743, at 22,746 (1966) (Commissioner Elman dissenting).

${ }_{210}$ See, e.g., FTC v. Motion Picture Advertising Service Co., 344 U.S. 392 (1953).

${ }^{220}$ Consider, for example, whether a hospital-based HMO, such as a Kaiser plan, should be allowed to exclude competing HMOs and fee-for-service physicians and their patients from access to its hospital services. The antitrust issue would seem to turn on whether prepaid health carc is a "single product" or whether hospital and outpatient services are deemed to be "tied" together by the HMO, thereby foreclosing competitors from a needed service. Cf. Fortner Enterprises, Inc. v. United States Stcel Corp., 394 U.S. 495 (1969). A holding that this was an illegal tying arrangement would be surprising, but it would perhaps be defensible on the theory, often stated with respect to tying, exclusive dealing, and vertical integration, that entry barriers are objectionably raised if, because customers or suppliers are foreclosed, the potential entrant must come in on two levels with commensurately greater capital and know-how, supplying in this case not merely primary care but perhaps hospital services as well.

221 The difficulties faced by non-hospital-based HMOs are recognized in Note, supra note 7, at 907, 9ro-18. They take the form, in part at least, of preferential rates given to Blue Cross. Although I choose not to get into the problems of dealing with Blue Cross and Blue Shield under antitrust principlesprimarily they are problems of state versus federal power (see note 164 supra) -, it may be that an antitust attack on Blue Cross-Blue Shield will have to be mounted if HIMO entry on equal terms is 
kinds seem to me more appropriately committed to administrative oversight when presented in a specific industry context. Congress might wish to adopt this mechanism, specifying that maximization of HMO entry opportunities is to be a primary object.

\section{Facilitating Consumer Choice}

Whatever the precise nature of the insurance scheme adopted, consumers should be in a position to exercise free and informed choice in selecting a mode of coverage and the appropriate provider. The administration's plan would allow employees covered by their employer's health insurance program to elect to apply the cost of that coverage toward the purchase of an HMO membership, but this option should be exercisable with respect to any available HMO, not simply to HMO-type coverage provided by a subsidiary of the health insurer or by the local medical society. HMO subscribers and beneficiaries of health insurance should be entitled to withdraw from either type of plan at fairly short notice in order to transfer their business elsewhere. Administrative requirements should be introduced to define benefit packages on a uniform basis in order to facilitate price comparisons. Thus, some minimum package would be defined by law, and additional benefits could be classed and priced separately.

The medical profession has studiously maintained ethical rules against advertising by physicians. ${ }^{22}$ Under these rules the only information which can be conveyed to the public by physicians or groups thereof relates to the type of practice, office location and hours, and similar matters which are not likely to influence greatly the selection of a particular physician. Similarly, the means of communicating even this limited data are restricted. These "ethical" rules cannot be allowed to interfere with HMO developments, and advertising, at least to the extent of permitting consumer education and informed comparisons, seems necessary to facilitate choice between the traditional and innovational systems and among the innovational plans themselves. Administrative attention should be given to some regulatory prescription of disclosure in advertising messages. ${ }^{223}$ In addition to standardizing coverage and

to be facilitated. If it could be obtained, a legislative or administrative solution would be preferable since it would be both swifter and surer. Probably any attempt to deal with this issue can await a clearer demonstration that there is a problem.

${ }^{322}$ An early version of AMA, Principles of Medical Etrics $\$ 4$ (1953), contained the traditional proscription of advertising by members of the medical profession:

"Solicitation of patients, directly or indirectly by a physician, by groups of physicians or by institutions or organizations is unethical. This principle protects the public from the advertiser and salesman of medical care by establishing an casily discernible and generally recognized distinction between him and the ethical physician ...."

Section 5 further elaborated on the proscription. In 1957 a simplified revision of the Principles was promulgated in which advertising was prohibited in the following brief sentence: "He should not solicit patients." AMA, Principles of Medical Etrics $\$ 5$ (1957). It was emphasized that the semantic streamlining in this revision did not alter the traditional meaning. See also AMA, OpINIONS AND REPORTS OF THE Judiciar Council 25 (1969).

${ }_{223}$ California's Knox-Mills Health Plan Act, CaL. Gov't Code $\$ \S$ I2530-39 (West Supp. I969), provides regulation of this kind. See Note, supra note 7, at 977-78. 
terminology to facilitate price and quality comparisons, regulators might require disclosure of nonaccreditation or official quality control ratings or demerits. The medical profession's preference for noninformational advertising should be recognized as one more cartel tactic. ${ }^{24}$ Although there are of course some legitimate ethical considerations in advertising medical services, they do not extend to advertising of alternative modes of care. Apparently Kaiser-Permanente and other prepaid group practice plans have succeeded in advertising their services. ${ }^{225}$

\section{Preventing Competition in Risk Selection}

One danger in insurance schemes is that competition will take the form of competing for the better risks while excluding those most in need of insurance protection. Any legislative solution to the health care crisis must provide against this development. The pending proposals all appear to introduce the requirement that HMO-type providers adopt a first-come, first-served policy, and this would appear to be a reasonable approach to the problem. A similar requirement should also be imposed on health insurance companies.

Conceivably, an HMO or health insurer that found its enrolled population to be excessively risk-prone, due to age distribution or a high incidence of chronic ailments, could be allowed to apply for exemption from the first-come, first-served requirement. Such a provision for waiver would seem to be necessary to enable insurers to remain competitive. There are probably other difficulties of this kind that I cannot visualize at this point, but it is perhaps sufficient to call attention to this category of problems and to urge that administrative attention be directed to solving them in the manner most conducive to market competition. It seems almost essential to the achievement of this goal that "community rating" be required, since "experience rating" is probably workable only with a captive population, which would be antithetical to the operation of a competitive market. On the other hand, administratively granted exemptions from the first-come, first-served requirement would allow a plan to re-establish its ability to compete on a community-rating basis.

\section{The Role of Private Health Insurers}

The Nixon health proposals have been criticized, most notably by Senator Kennedy, as providing a "windfall" to the health insurance industry. ${ }^{223}$ Of course, if HMOs become a major provider of primary health care, the role of health insurers would be reduced, though they might find a new function in reinsuring smaller HMOs. Whether the long-term net effect of the administration's plan would be to increase the size or profits of the health insurance industry may not be predictable at this time.

\footnotetext{
224 The trade association in FTC v. Cement Institute, 333 U.S. 683, 715 (1948), "in the interest of eliminating competition, suppressed information as to the variations in quality that sometimes exist in different cement."

${ }^{225} \mathrm{Kessel}$, supra note 70, at 44 .

${ }^{228}$ N.Y. Times, Feb. 19, I97I, p. I, col. 8, at p. 16, col. I.
} 
Of course, health insurers might move directly into HMO formation and might profit handsomely in so doing. I see substantial merit, however, in prohibiting health insurers from entering the HMO sector. The obvious reason is to avoid domination of the market by Blue Cross-Blue Shield, which might in some communities come to sell the bulk of the health insurance while also controlling the major HMO and reinsuring the competing HMOs against excessive risks. ${ }^{227}$ Since Blue Cross is widely accused of being operated in the interest of the medical establishment, ${ }^{228}$ the arguments against Blue Cross's extension into the HMO sector parallel the arguments against medical society sponsorship of prepayment plans: there is good reason to suspect that Blue Cross HMOs would hang back rather than develop the full potential of the HMO concept and that avoidance of the establishment's discomfiture would be their primary raison d'être. ${ }^{229}$

A more subtle reason also supports excluding health insurers from HMO sponsorship. Health insurers must have a powerful financial stake in the survival of fee-forservice medicine if their efforts are to be directed, in a way they have never been before, to reducing costs and increasing efficiency in that sector of the market. As long as health insurers have enjoyed a protected position, they have been willing to confine themselves to paying the bills submitted, seldom disputing the amount of fees or the patient's need for the therapy or surgical procedure performed or the hospitalization ordered. The rise in medical costs has not hurt health insurers enough to enlist them in policing the providers, and the easier course has been to seek rate increases from regulatory agencies or experience-based rate adjustments from insured groups. The public has thus lost practically the entire benefit of health insurers' potential economizing influence over providers. ${ }^{230}$

Faced in a free market with vigorous competition from a cheaper and more efficient delivery system, the fee-for-service sector might not survive as more than a vestige if health insurance premiums-which consumers will compare to HMO membership charges-continued to reflect the inefficiencies of the solo practitioner and his overutilization of hospitals and other resources. While some might not mourn the passing of this delivery mode, it seems desirable to maintain fee-for-service medicine as an available alternative for the benefit of those who value highly the

${ }^{227}$ Blue Cross has already commenced its move into HMO formation. See Am. Med. News, Apr. 5, 197I, p. I2.

${ }_{328}$ E.g., HeALTH-PAC, supra note II5, at 158-63; Kotelchuck, Trying to Shake the Blues, HEALTHPAC BulI., Mar. I97x, p. I.

${ }^{320}$ Whether the antitrust laws could be used to accomplish the exclusion of Blue Cross and Blue Shield from HMO formation is not clear. As long as Blue Cross or Blue Shield performs solely as an indemnitor, it would normally be regulated under state insurance laws and therefore exempt from the antitrust laws under the McCarran-Ferguson Act, I5 U.S.C. $\$$ ror2(b) (I964). See note I64 supra. If, however, it should engage in the provision of services in the manner of an HMO, it would seem no longer to be engaged in "the business of insurance" under the most accepted definition. See Jordan v. Group Health Ass'n, xoy F.2d 239 (D.C. Cir. 1939). This would cause the loss of the McCarranFerguson Aet exemption and might open up remedial possibilities similar to those canvassed with respect to HMOs affiliated with monopolistic hospitals.

${ }^{380}$ See generally SOMERS \& SOMERs, supra note 156, ch. 20. 
personalized care and the right of physician selection that it affords. Moreover, HMO enrollees are known to purchase some fee-for-service care, and this alternative source of care should be kept available. ${ }^{231}$

The market alone cannot adequately weed out the inefficiencies of fee-for-service medicine. The reasons are familiar: patients cannot easily recognize excessive treatment and often welcome it for psychological reasons. On the other hand, an insurance company barred from HMO formation would be intensely motivated to keep costs down in order that its premiums not become prohibitive in comparison with HMO charges. While there are substantial limits to what they can achieve without undesirable interference with actual treatment, they are capable of more than they have achieved up to now and could be expected to maximize their efforts only if they are not indifferent whether patients choose health insurance or HMO care. The medical profession should see the benefit to themselves in stimulating insurers' assistance in preserving the best and eliminating the worst aspects of fee-for-service medicine. They should also see the need to strengthen peer review and other utilization controls in the fee-for-service sector. ${ }^{232}$ If the great power of the organized profession over its membership is not redirected to this task, fee-for-service medicine may not survive even to the extent to which, on merit, it is entitled.

The health insurance industry will also find an important role in reinsuring HMOs against those risks that the HMOs themselves cannot safely assume. Again, barring unnecessary restrictions, many of the services covered by such reinsurance will be specialist and hospital services purchased in the fee-for-service sector, and insurers will be motivated to control these costs in order that their reinsured HMOs will be better able to compete with larger HMOs which provide these services inhouse and require less reinsurance. In this process they will be assisted by the insured HMOs themselves, which will face experience-rated premiums and will therefore seek the best available value in specialist and hospital services. Because insurers and HMOs are more medically aware than other consumers buying care in the fee-for-service sector, their influence will be salutary. With all of these factors operating, it would be reasonable to expect in the future a much better performance from the fee-forservice sector, including its insurance component, than it has delivered in the past.

\section{Implications for Financing Schemes}

The functioning of the market for health care could be destroyed by a financing scheme that failed to preserve the cost-consciousness of at least the greater number of consumers. Medicare and Medicaid have already destroyed the cost-consciousness of many consumers, and these models cannot be extended very much farther. The administration's proposed FHIP would expand the number of federally subsidized consumers, but, since many participants in that plan would be paying their own

\footnotetext{
${ }^{231}$ See notes I9 \& 23 supra.

${ }^{232}$ See notes 157-59, 169-80 supra and accompanying text on the form that such efforts should not be permitted to take.
} 
way in part, it has been possible to design the plan to preserve cost-consciousness. The critical feature in making the market-oriented system work even with substantial numbers of federally subsidized consumers is the "proxy-shopping" device explained earlier. Under this system the government in effect accepts a private subscriber's judgment on the value and price of the care rendered by a particular HMO in paying for such care on behalf of one of its clients. Whatever financing system is ultimately adopted-and it will not pay to evaluate specific proposals here-, every detail of it must be evaluated in the light of its effect on consumer costconsciousness.

The handling of coverage, coinsurance, and deductibles will also require care if the market's ability to function is to be maximized. Complete exclusion from coverage throws consumers back on their own resources, which may be inappropriate from the standpoint of equity to the poor, protection against catastrophe, and loss of the potentiality for improved incentives through HMO development. Outpatient prescription drugs, for example, might be profitably included in coverage, though possibly subjected to a deductible or coinsurance requirement that would reduce program costs while retaining the correct incentives. ${ }^{233}$

While perhaps useful in reducing costs of the program to the government, coinsurance may also serve an important function in discouraging overutilization. A small per-visit charge is commonly recommended for this purpose, and outpatient psychiatric care is sometimes subjected to a large copayment requirement, presumably on the ground that it is largely elective and can be quite costly. Coinsurance does not deter equally in all economic classes, however, and may cause low-income consumers to forgo needed care. Graduated deductibles and coinsurance of the kind provided for in the FHIP proposal could be used to prevent unfairness in this regard. ${ }^{234}$

Another significant set of considerations relates to the benefits of any insurance scheme covering the poor. If coverage is significantly reduced by limits, deductibles, and coinsurance, plans may hesitate to enroll the poor because of the losses to be anticipated from defaults on bills for the services not covered. ${ }^{235}$ If enacted in its present form, the administration's proposed FHIP, which imposes more substantial limits on benefits for the poor than for the nonpoor, might disappoint many of the hopes expressed earlier. ${ }^{236}$ Because price competition among the plans would substantially eliminate the opportunity for making those overcharges to the affluent which have previously subsidized the poor, inability to pay will be even more significant than it previously was, and the disadvantage to the poor may in this respect be increased. But, since the affuent may ultimately benefit from a lowering of

\footnotetext{
${ }^{203}$ See notes $189-98$ supra and accompanying text.

234 S. $1623, \S 20 \mathrm{r}$, proposed $\S 626(\mathrm{~b})$.

285 See notes 76 \& 84 stipra.

${ }^{230}$ Much would depend on whether, as an accounting matter, collection losses could be counted as an expense of caring for the FHIP group in determining "retentions." See text accompanying notes 49-50
} supra. 
charges over-all, Congress should be less hesitant to employ the income tax system to provide the resources needed to care adequately for the poor and to protect them against discrimination by profit-conscious providers. Parsimony at this stage, by retarding realization of a functioning market-oriented system, would be a false economy.

\section{ConcLusion}

Enactment of the Nixon administration's health care proposals, even without the changes which I think are needed to create a truly dynamic market and the conditions for optimum HMO development, ${ }^{237}$ would somewhat strengthen the basis for relying on the market to improve the health care system's performance. A broadened health insurance plan for the poor, universal health insurance with an HMO option for everyone, and general encouragement of HMO development should expand consumer choice, restore some vigor to price and service competition in health care, and increase cost consciousness. Congress, attracted by the combination of a reasonable likelihood of meaningful change and the essential conservatism of a market-oriented approach, may well find the administration's program to its liking.

The danger that I most apprehend is that Congress, in enacting a program dependent on the market as the primary means of social control, would fail to close

${ }^{287}$ Specifically, I would propose the following changes and amendments:

(I) If it is not already so, FHIP coverage should be made adequate to prevent discrimination against program beneficiaries. See text accompanying notes $235-36$ stupa. Federal payment of less than $100 \%$ of the cost of caring for the poor (after reasonable deductibles and copayments) would be merely a further subsidy to charitable providers but would exclude profit-conscious providers from participating in such care and would bar the poor totally from "mainstream" medical care.

(2) Consideration should be given to whether price controls may be needed to cushion the impact of a truly adequate FHIP. See text accompanying notes 58-63 stpra. The intermediate approach of limiting payments under Medicare and FHIP, while protecting the public treasury, results in the discrimination against the poor objected to in (I) above.

(3) Provisions to put teeth into health planning legislation should exempt HMOs or at least nonhospital-based FMOs. See note 217 supra and accompanying text. While recognizing the complexity of the question, I also have reservations about enacting protection for existing hospitals.

(4) The legislative history should specify the market as one of the chosen mechanisms of social control and should note the appropriateness of antitrust enforcement to maintain it even in the face of inconsistent state law. See text accompanying notes I99-20I supra.

(5) To perfect the "proxy-shopping" device, the HMO definition should require that at least $50 \%$ of plan subscribers be self-supporting. See text accompanying notes $46-47$ supra.

(6) Employers should be required to give employees a choice of enrolling with any available HMO, not just a selected one. See text accompanying notes 28-30 supra.

(7) Requirements as to the minimum size of HMOs should be eliminated. See text accompanying notes 39 \& 214-r 6 supra.

(8) Medical societies and monopolistic hospitals should be barred, by antitrust action if not by statute, from HMO formation if they have the effect of preventing competitive HMO development. See text accompanying notes $\mathrm{rr} 9-82$ supra.

(9) Health insurers should be barred from HMO formation. See text accompanying notes 226-32 supra.

(Io) Attention should be given to reducing the incentive to engage in favorable risk selection. See p. 788 supra.

(II) The provisions preempting the field against the states should be clarified to confirm my understanding of their intended breadth. See text accompanying notes 208-13 supra. 
all of the loopholes that might allow some group-the medical societies, the emerging new elite in university medical centers, or the health planners ${ }^{238}$ - to dominate developments and the resulting market to an excessive degree. I have been at pains to show the vulnerability of the health care marketplace to trade restraints and monopoly, often imposed in the euphemistic name of quality assurance, ethics, and, lately, planning, and I have attempted to focus on the precise measures needed to combat monopolistic tendencies wherever they appear. Unfortunately, I see little room for compromise on the need to maximize HMO entry possibilities throughout the system and to foreclose collective action preempting or otherwise restraining independent HMO development. Congress must therefore scrupulously avoid enacting, and indeed must expressly prohibit-or anticipate antitrust action with respect to-, exclusionary measures of all but the most minimal kinds, such as character, fitness, and financial responsibility requirements. It must also prevent the provision of HMO-type care from being dominated, directly or indirectly, by persons-whether in the medical societies or the medical schools-who lack a total commitment to its maximum development, not as a stop-gap to forestall competition or government control or as a social welfare agency but as a competitive alternative attractive to all consumers. Where the need for added quality assurance or for compromise with the health care establishment appears, Congress should offer only strengthened oversight of the care rendered and stricter policing of objectionable practices, not exclusionary measures or exclusive privileges.

The chief obstacle to complete acceptance of the market model for health care delivery is probably an impression that increased reliance on the market and competition will exalt self-interest and commercialism, will dispel what altruism remains in health care, and will further devalue the human element in the relation between provider and patient. The probabilities seem otherwise to me, precisely to the extent that consumers value and, given the opportunity, will shop for attentive and sympathetic care and will express aversion for both the commercialized and the insensitive provider. Furthermore, the HMO's comprehensiveness and direct financial interest in its subscribers' health should make it responsive to the consumer's desire for health security, and salaried doctors in an HMO setting would seem freer to practice medicine altruistically-albeit with regard for economic efficiency-than are fee-for-service doctors. Moreover, the important object of pre-

${ }^{\text {as8 }}$ Michaelson, The Coming Medical War, N.Y. REv. of Books, July x, I97I, p. 32, observes how a three-way split in the ranks of the medical profession is occurring, with the medical societies losing power to "the new medical elite," which resides in the "urban university medical center," id. at 34 , denigrates the ordinary practitioner and his trade associations, and claims itself fit to be entrusted with all the decisions that must be made. The third group is a new radical fringe, which is about as critical of the new elite as of the old. A book originating with this third group, HEALTH-PAC, supra note II5, convincingly demonstrates that too often the values maximized by the decisions of the new elite, which controls vast sums dedicated by government and charity to health needs, are not consistent with the welfare of consumers. See notes 98-100 supra and accompanying text. The lesson may be that, because of this unresponsiveness to the public's concerns and the opportunities for abuse of power, nonprofit monopolies are no more to be trusted than the other kind. 
serving or increasing the physician's respect for his patients, particularly the disadvantaged ones, is more likely to be achieved by giving the latter meaningful alternatives-and assuring that they have the financial means of selecting among them-than by any other scheme that government might foster; only a vigorously competitive marketplace can overcome the monopolist's tendency to take its customers for granted. Unfortunately, the tendency these days is toward fostering monopoly in various forms, often under the protection of exclusionary regulation by comprehensive health planning agencies. ${ }^{239}$ This movement seems to pose a much greater threat than does the market to the consumer's freedom to select a provider on the basis of affinity and its responsiveness to his personal needs. The pluralism to which lip service is often paid by health planners and the contrivers of comprehensive "solutions" to the health care crisis is usually a pale substitute for the dynamic diversity that competition could inspire.

If the market model cannot be embraced wholeheartedly, it will probably have to be rejected altogether in the long run. Halfway measures are what we have now, and, lacking a clear perception of the problem, we are already moving clumsily to greater restrictionism. The addition of a monopolistic HMO to each market, which may be all the administration's plan in its present form would be able to achieve, seems to promise only an improvement, not a solution. While consumer choice would be increased slightly, consumers would hardly feel that their sovereignty had been restored, and the doctors' ability to run the health care system in large part for their own rather than consumers' advantage would not be greatly undercut, although power might be subtly shifted away from the medical societies toward what has been called "the new medical elite" in university centers. ${ }^{240}$ In these circumstances, the movement for a greater consumer role in decision making would prosper as a continuing exercise in "countervailing power," which is the last resort of a public confronting a powerful and unresponsive monopoly. I personally find such politicization an unsatisfying alternative when compared with what I regard as the market's ability to re-enfranchise consumers by offering them attractive alternatives and, with universal health insurance, meaningful freedom of choice. Even if one pretends, against the evidence, that nonprofit monopolies involve no opportunity for undue private gain, their demonstrated capacity for staggering inefficiency and for ignoring consumer wants should argue for a strong antimonopoly policy and a reinvigorated health care marketplace.

My expectation that independent HMOs can substantially improve the performance of the entire health care system rests, first of all, on their ability to impose, almost for the first time, a needed cost constraint on physicians in caring for their patients. Price and benefit-package competition from aggressive and cost-conscious HMOs

\footnotetext{
${ }^{230}$ See note 217 stupra, describing a federal effort to put teeth in state planning efforts. Parallel legislation in the states poses the same threat. North Carolina, for example, has just passed a bill denying anyone the right to construct health facilities until the "need" for them is certified by a state agency.

${ }^{240}$ See note 238 supra.
} 
would then introduce unprecedented but essential pressure to control costs in the insured-fee-for-service sector, and health insurers would be driven to institute at least a mild form of peer review calculated to reach the most substantial abuses. The extent of HMOs' actual penetration of the market will therefore not directly measure HMOs' over-all value to consumers, and indeed consumers may continue in large numbers to prefer fee-for-service care even at a higher price. Nevertheless, an available lower-cost substitute, even if it is perceived to be somewhat inferior, can impose an effective check on the exercise of monopoly power, resulting in lower prices and greater efficiency than would otherwise prevail. Thus, even if HMO-type care should appear inferior in some respect to fee-for-service medicine, it still has a vitally important market function to perform. No evidence suggests that any loss in essential quality can be anticipated that would outweigh or even approach the substantial benefits that can be expected to flow from infusing HMOs into the health care system. 